FRANCIELE CRISTINA BERNARDES

\title{
CARACTERIZAÇÃO DOS PADRÕES DE DRENAGEM LINFÁTICA NAS LINFOCINTILOGRAFIAS DE PACIENTES COM CÂNCER DE MAMA
}

Dissertação de mestrado apresentada ao Programa de Pós-Graduação Interunidades Bioengenharia - Escola de Engenharia de São Carlos / Faculdade de Medicina de Ribeirão Preto / Instituto de Química de São Carlos da Universidade de São Paulo como parte dos requisitos para a obtenção do título de mestre em Ciências.

Área de Concentração: Bioengenharia

Orientador: Prof. Dr. Lauro Wichert Ana 
AUTORIZO A REPRODUÇÃO E DIVULGAÇÃO TOTAL OU PARCIAL DESTE TRABALHO, POR QUALQUER MEIO CONVENCIONAL OU ELETRONICO, PARA FINS DE ESTUDO E PESQUISA, DESDE QUE CITADA A FONTE.

Ficha catalográfica preparada pela Seção de Tratamento da Informaçăo do Serviço de Biblioteca - EESC/USP

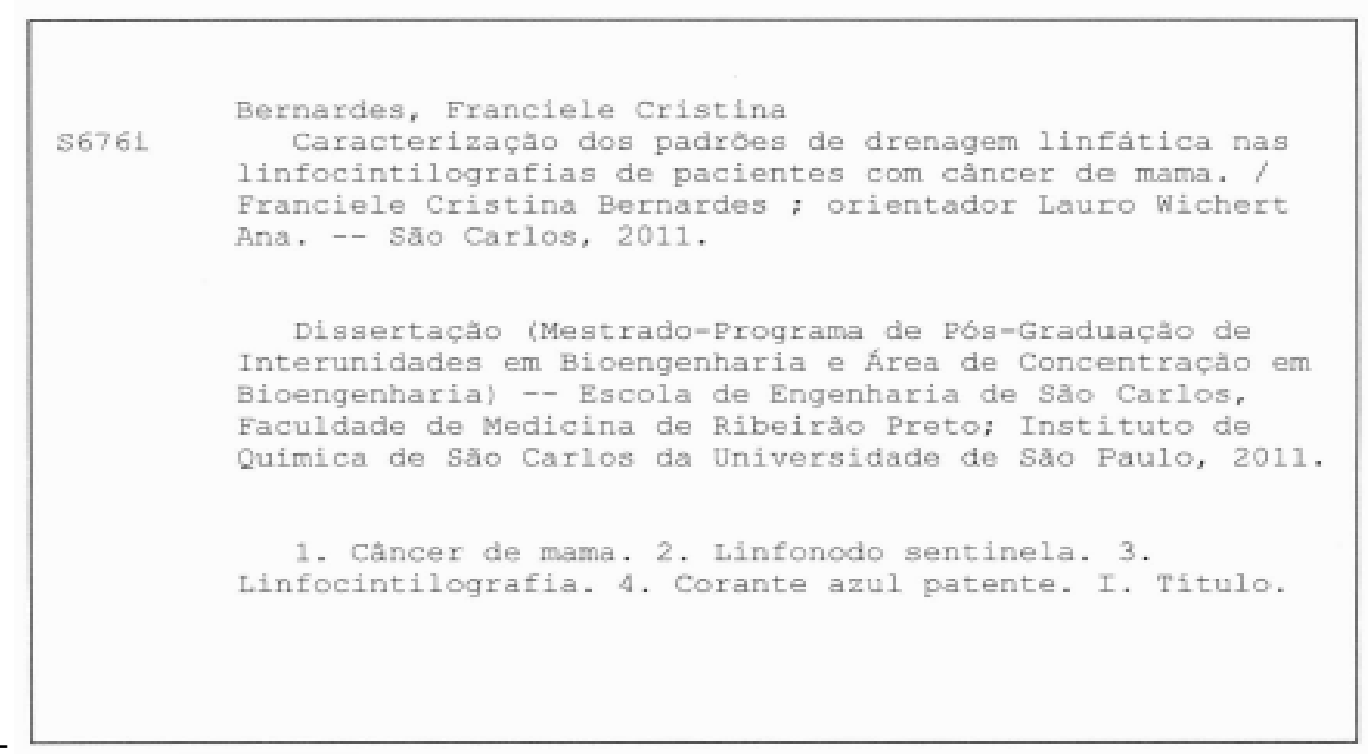


FRANCIELE CRISTINA BERNARDES

Título: "Caracterização dos padrões de drenagem linfática nas linfocintilografias de pacientes com câncer de mama"

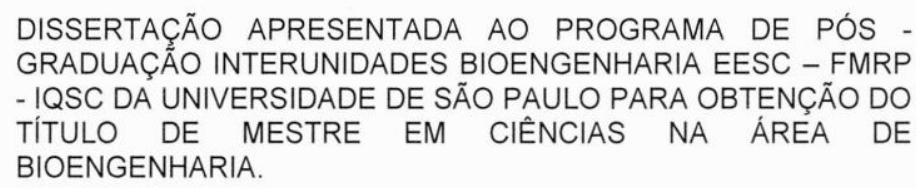

Aprovado em: $1,01,2012$

PROF. DR. LAURO WICHERT ANA (ORIENTADOR)

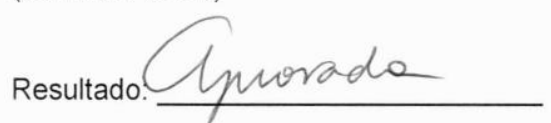

PROF. DR. HÉLIO HUMBERTO ANGOTTI CARRARA

Resultado: ATROVADA

PROF. DR. VALDAIR FRANCISCO MUGLIA

Resultado: (Whas) provads
Faculdade de Medicina de Ribeirão Preto USP

Assinatura:

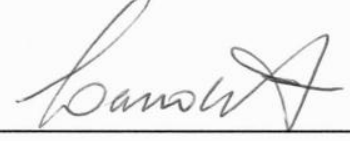

Faculdade de Medicina de Ribeirão Preto USP

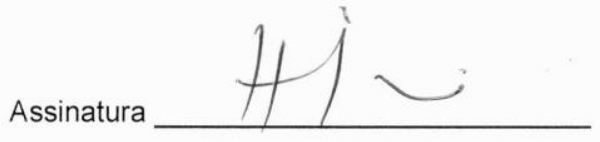

Faculdade de Medicina de Ribeirão PretoUSP

Assinatura

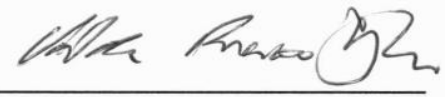




\section{DEDICATÓRIA}

Dedico este trabalho aos meus pais Antônio Vandair e

Luiza que sempre estiveram do meu lado me incentivando e me encorajando a seguir em frente e nunca desistir dos meus sonhos. A eles minha eterna gratidão. 


\section{AGRADECIMENTOS}

À Deus por me dar saúde e força para realização deste trabalho;

Aos meus pais Antônio Vandair e Luiza por sempre acreditarem em mim, por me proporcionarem toda educação, pela força de nunca me deixarem desistir, pela presença em todos os momentos da minha vida;

Ao meu orientador Prof. Dr. Lauro Wichert Ana, por todo ensinamento, conselhos, paciência e acima de tudo confiança que depositou em mim;

À Capes, pela bolsa concedida por 2 anos;

Aos meus amigos de iniciação científica Emerson, Sandro, por toda ajuda e dedicação desde o início do desenvolvimento deste trabalho;

Aos alunos de mestrado Talitha e Ricardo pela ajuda, contribuições e empenho;

Aos médicos nucleares Dra. Mery, Dra. Rafaela e Dr. Valésio pela realização dos exames de linfocintilografia;

A todos os funcionários da Seção de Medicina Nuclear pelo eficiente trabalho;

À toda equipe médica e funcionários do Centro Cirúrgico do Hospital das Clínicas pela realização das cirurgias.

Ao Hospital das Clínicas, por proporcionar a realização da pesquisa;

Ao Programa de Pós-Graduação Interunidades em Bioengenharia, pelo apoio e dedicação aos serviços prestados;

À todos que, mesmo a distância, acreditaram em mim. 


\section{Epígrafe}

"Mudam-se os tempos, mudam-se as vontades, Muda-se o ser, muda-se a confiança;

Todo o mundo é composto de mudança, Tomando sempre novas qualidades."

Luis de Camões 


\section{RESUMO}

BERNARDES, F. C. Caracterização dos padrões de drenagem linfática nas linfocintilografias de pacientes com câncer de mama. 2011. 87 f Dissertação (Mestrado) Programa de Pós-graduação Interunidades em Bioengenharia - Escola de Engenharia de São Carlos - Faculdade de Medicina de Ribeirão Preto - Instituto de Química de São Carlos da Universidade de São Paulo, 2011.

O câncer de mama (CA de mama), com exceção do câncer de pele do tipo não melanoma, é o tumor de maior incidência dentre as mulheres, sendo que no Brasil são encontrados principalmente nas regiões Sul e Sudeste. Seu principal tratamento é o cirúrgico. A disseminação do tumor pode ocorrer por via linfática, acometendo linfonodos regionais. A biópsia do linfonodo sentinela (BLNS) é um procedimento altamente relevante, é altamente sensível na identificação de metástases. A técnica de linfocintilografia (LINCT) préoperatória é essencial, pois permite avaliar a cadeia linfática acometida e possibilita a visualização do linfonodo sentinela (LNS) durante a cirurgia. O objetivo é descrever os padrões de drenagem linfática e avaliar a contribuição da LCINT na localização dos LNS em pacientes com CA de mama. No período de março de 2009 a agosto de 2011 foram estudados 70 casos sequenciais da rotina clínica, submetidos ao tratamento cirúrgico do CA de mama com estudo do LNS através da técnica de LCINT. Na LCINT foram aplicadas 4 injeções intradérmicas contendo $37 \mathrm{MBq}(1,0 \mathrm{mCi})$ do FITATO-Tecnécio99m, ao redor da aréola mamária. Após a localização do LNS foi realizado marcações na pele, nas incidências anterior, oblíqua e lateral, para auxiliar o cirurgião na abordagem cirúrgica ulterior, juntamente com a sonda gama intra-operatória e corante azul patente. Dos 70 casos submetidos ao estudo, todos são do sexo feminino (100\%) com faixa etária entre 28 e 77 anos, média de 54 anos. O tamanho médio do tumor encontrado nos pacientes foi de $1,4 \mathrm{~cm}$. Os tipos histológicos mais incidentes foram o carcinoma ductal invasivo com $45(64,4 \%)$ pacientes, seguido de carcinoma ductal in situ com 16 (22,8\%). No exame de LCINT, todos os pacientes apresentaram drenagem linfática do radiofármaco a partir do local da injeção. Em $43(61.5 \%)$ pacientes, observamos drenagem para 1 LNS, em $21(30 \%)$ para 2 LNS/LNNS (linfonodo não sentinela), em $5(7 \%)$ para 3 LNS/LNNS e em $1(1.5 \%)$ para 4LNS/LNNS. Dos 70 pacientes, 68 (97\%) apresentaram drenagem linfática ipsilateral e 2 (3\%) apresentaram drenagem linfática bilateral. Em relação aos territórios de drenagem linfática dos LNS/LNNS, em 68 (97\%) pacientes apresentaram drenagem para a região axilar, 1 $(1,5 \%)$ para a região mamária interna e $1(1,5 \%)$ para as regiões axilar e mamária interna. Os LNS/LNNS presentes na cadeia mamária interna não foram retirados. No intra-operatório, os cirurgiões utilizaram o corante azul patente em 35 (50\%) pacientes, destes o corante identificou os LNS/LNNS em 79\% dos casos. A técnica de LCINT possibilitou a visualização de todos os LNS e em alguns casos não foi possível a visualização do LNNS, o qual foi localizado e retirado com a sonda gama. Com isso, a técnica de LCINT foi eficaz em 88,5\% dos casos. Dos 69 pacientes submetidos à BLNS apenas 13 (18,8\%) pacientes apresentaram LNS/LNNS metastáticos, sendo estes submetidos à linfadenectomia axilar. Conclui-se que o exame pré-operatório de LCINT foi muito eficiente para o estudo da drenagem linfática, visualizando os canais linfáticos, linfonodos funcionalmente ativos e seus respectivos territórios de drenagem. Por tanto, esta técnica auxiliou o cirurgião na abordagem cirúrgica juntamente com a sonda gama intra-operatória e corante azul patente para a realização da BLNS.

Palavras-chave: Câncer de Mama, Linfonodo Sentinela, Linfocintilografia, Corante Azul Patente. 


\begin{abstract}
BERNARDES, F. C. Characterization of the lymphatic drainage of patients with breast cancer. 2011. 87 f Dissertação (Mestrado) - Programa de Pós-graduação Interunidades em Bioengenharia - Escola de Engenharia de São Carlos - Faculdade de Medicina de Ribeirão Preto - Instituto de Química de São Carlos da Universidade de São Paulo, 2011.

With the exception of non-melanoma skin cancer, the Breast cancer (breast CA) is the most incident cancer in women. In Brazil, the breast CA is more often found in South and Southeast regions. The main treatment of breast CA is the surgery. The main pathway for the tumor spreading is the lymphatic system, which may affect the regional lymph nodes. The sentinel node biopsy (SLNB) is of considerable importance, once it has a high sensitivity in identifying metastases. The technique of preoperative lymphoscintigraphy (LINCT) is essential because it allows evaluating the lymphatic drainage chain and enables the visualization of sentinel lymph node (SLN) during surgery. We aim here to describe the lymphatic drainage patterns and to evaluate the contribution of LCINT to the location of SLN in patients with breast CA. We evaluated 70 patients sequentially selected from the clinical routine, between march 2009 and august 2011, and that underwent the surgical treatment for breast CA, including the usage of the technique of LCINT for the SLN location. The LCINT were performed by the injection of four periareolar intradermal injections containing $37 \mathrm{MBq}$ $(1.0 \mathrm{mCi})$ of the radiopharmaceutical PHYTATE-99m-Technetium. Based on the LCINT images, we performed skin marks in the dermal projections of the SLN in all anterior/posterior, oblique and lateral views. Additionally, the gamma probe and blue dye were used to help surgeons in the surgical location of the SLN. All of the 70 patients of our study were female, ranging from 28 to 77 years, mean 54 years. The average tumor size was $1.4 \mathrm{~cm}$. The most commonly found histological types were invasive ductal carcinoma (45 patients, $64.4 \%$ ), followed by the in situ ductal carcinoma (16 patients, 22.8\%). All LCINT procedures were well succeeded in demonstrating at least one SLN in our sample of patients. We observed lymphatic drainage for only one SLN in 43 patients $(61.5 \%)$, for 2 SLN/SLNN in $21(30 \%)$ (non sentinel lymph node), for 3 SLN/SLNN in $5(7 \%)$ and for 4 SLN/SLNN in one patient (1.5\%). From the 70 patients, $68(97 \%)$ exhibited ipsilateral and $2(3 \%)$ exhibited bilateral lymphatic drainage. Concerning the lymphatic territories, 68 patients $(97 \%)$ exhibited drainage to SLN/SLNN in the axillary region, 1 patient $(1.5 \%)$ in the internal mammary region and another patient $(1.5 \%)$ in both axillary and internal mammary regions. The two SLN/SLNN found in the internal mammary chain were not removed. Complimentary to the LCINT, the surgeons used blue dye in 35 patients $(50 \%)$, which enabled them to identify the SLN/SLNN in 79\% of cases. On the other hand, LCINT allowed the visualization of all SLN (100\%). In some cases, in which was not possible to visualize the SLNN, these ones were found by the use of the gamma probe. Thus, the LCINT technique was effective to localize the SLN in $88.5 \%$ of cases. From the 69 patients who underwent SLN biopsy, only 13 patients (18.8\%) exhibited metastatic infiltration of the SLN/ SLNN. All these patients were submitted to the axillary dissection. We conclude that the preoperative LCINT was very effective for the study of lymphatic drainage, enabling the visualization of the lymphatic channels, functionally active nodes and their drainage areas. Therefore, this technique helped surgeons in the surgical approach with intraoperative gamma probe and patent blue dye for SLNB.
\end{abstract}

Keywords: Breast Cancer, Sentinel Lymph Node, Lymphoscintigraphy, Patent Blue Dye. 


\section{LISTA DE FIGURAS}

Figura 1 - Localização da mama.................................................................................14

Figura 2 - Estrutura da mama e das glândulas mamárias................................................... 15

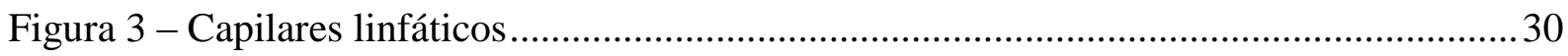

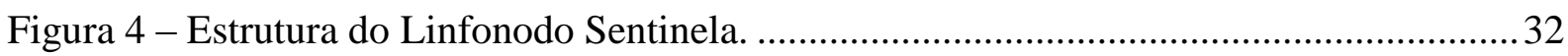

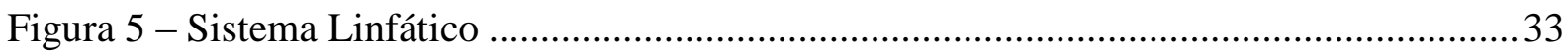

Figura 6 - Tipos Histológicos de CA de Mama encontrados nos pacientes submetidas ao

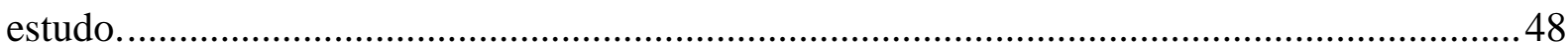

Figura 7 - Grau Histológico do CA de Mama encontrado nos pacientes submetidas ao estudo.

Figura 8 - Procedimentos Cirúrgicos realizados nos pacientes com CA de mama.

Figura 9 - Localização do Tumor de CA de Mama nos pacientes submetidos ao estudo. .......50

Figura 10 - Número de LNS/LNNS Drenado pelo radiofármaco Fitato- ${ }^{99 \mathrm{~m}}$ Tc em cada

paciente com CA de Mama.

Figura 11 - Imagens de linfocintilografia na projeção anterior, mostrando a drenagem

linfática do radiofármaco para os LNS/LNNS axilares.

Figura 12 - Imagens de Linfocintilografia nas projeções anteriores mostrando a drenagem

linfática do radiofármaco para LNS/LNNS axilares bilaterais.

Figura 13 - Imagens de Linfocintilografia nas projeções anteriores mostrando a drenagem do radiofármaco para LNS axilares e na cadeia mamária interna...............................................56

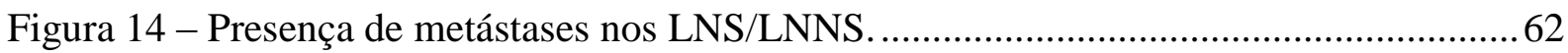

Figura 15 - Estado Axilar em relação aos LN dissecados na linfadenectomia axilar..............64 


\section{LISTA DE TABELAS}

Tabela 1 - Tumores TNM proposta pela União Internacional Contra o Câncer (UICC) de 2004.

Tabela 2 - Linfonodos TNM proposta pela União Internacional Contra o Câncer (UICC) de 2004.

Tabela 3 - Estadiamento TNM proposta pela União Internacional Contra o Câncer (UICC) de

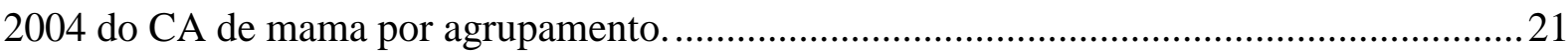

Tabela 4 - Classificação dos tipos histológicos segundo a OMS (2002)................................23

Tabela 5 - Classificação de Scarff-Bloom-Richardson modificado por Elston-Ellis..............25

Tabela 6 - Características Demográficas e Clínicas. ...............................................................50

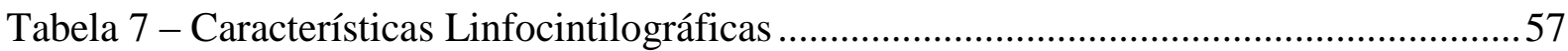

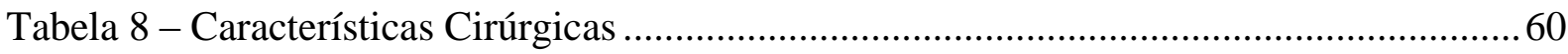

Tabela 9 - Resumo das Características Demográficas, Clínicas e Cirúrgicas das Pacientes com

CA de Mama submetidas ao Estudo. 65 


\section{LISTA DE SIGLAS}

\begin{tabular}{|c|c|}
\hline AJCC & The American Joint Committee on Cancer \\
\hline BLNS & Biópsia do Linfonodo Sentinela \\
\hline BIREME & Biblioteca Regional de Medicina \\
\hline BVS & Biblioteca Virtual da saúde \\
\hline CA & Câncer de Mama \\
\hline CEP & Comitê de Ética em Pesquisa \\
\hline DeCS & Descritores em Ciências da Saúde \\
\hline FMRP & Faculdade de Medicina de Ribeirão Preto \\
\hline $\mathrm{HC}$ & Hospital das Clínicas \\
\hline IARC & International Agency for Reserch on Cancer \\
\hline INCA & Instituto Nacional do Câncer \\
\hline LCINT & Linfocintilografia \\
\hline LNNS & Linfonodo não Sentinela ou parasentinela ou linfonodo satélite \\
\hline LNS & Linfonodo Sentinela \\
\hline $\mathrm{LN}$ & Linfonodo \\
\hline $\mathrm{MBq}$ & Megabequerel $(37 \mathrm{MBq}=1 \mathrm{mCi})$ \\
\hline $\mathrm{mCi}$ & Millicurie $(1 / 1000$ de curie $) ; 1$ curie $=3.7 \times 1.010$ desintegração por segundo. \\
\hline OMS & Organização Mundial da Saúde \\
\hline QC & Quadrante Central \\
\hline QIE & Quadrante Inferior Externo \\
\hline QII & Quadrante Inferior Interno \\
\hline QSE & Quadrante Superior Externo \\
\hline QSI & Quadrante Superior Interno \\
\hline SLN & Sentinel Lymph node \\
\hline SLNN & No sentinel lymph node \\
\hline SERPAT & Serviço de Patologia \\
\hline TCLE & Termo de Consentimento Livre e Esclarecido \\
\hline TNM & Classificação de Tumores Malignos \\
\hline UICC & União Internacional Contra o Câncer \\
\hline USP & Universidade de São Paulo \\
\hline${ }^{99 \mathrm{~m}} \mathrm{Tc}$ & Isômero Metaestável Nuclear do Elemento Radioativo Tecnécio \\
\hline
\end{tabular}




\section{SUMÁRIO}

1. INTRODUÇÃ

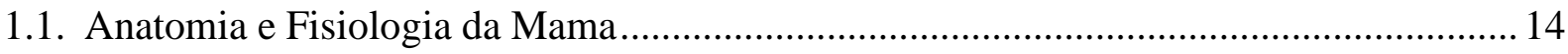

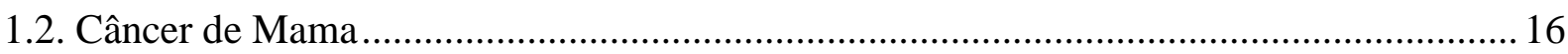

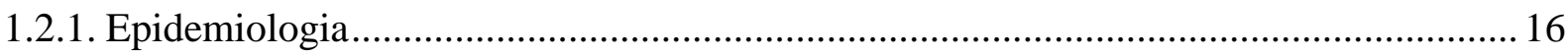

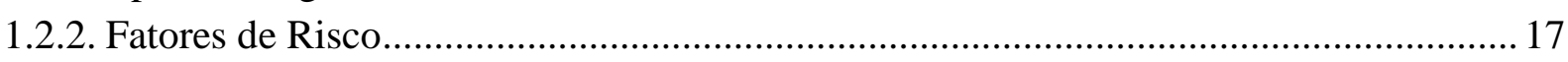

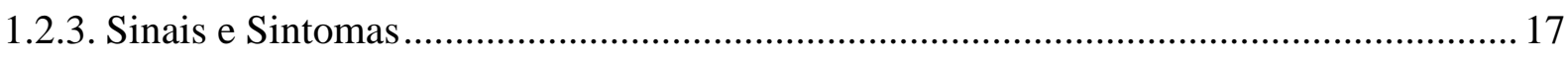

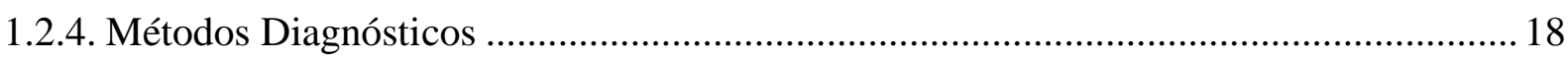

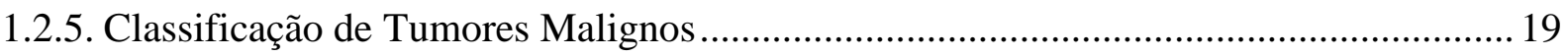

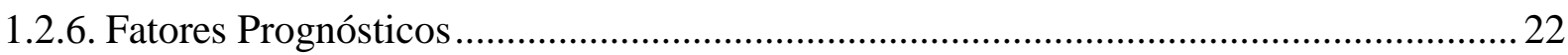

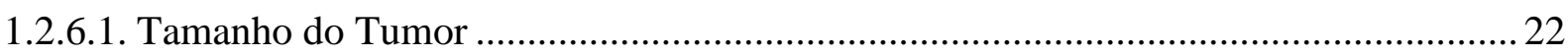

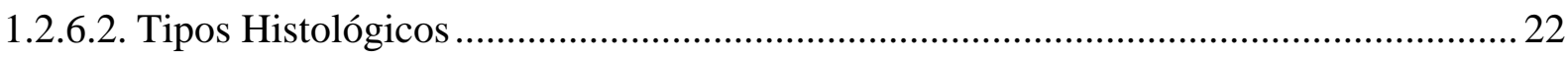

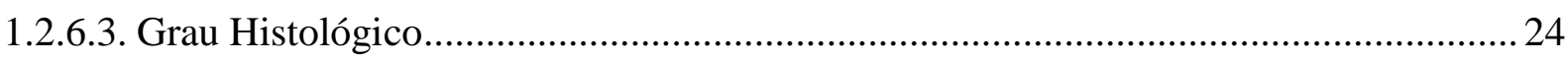

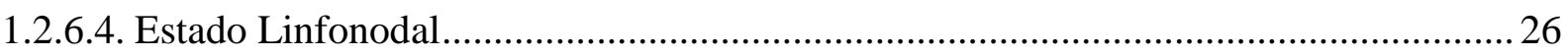

1.2.7. Modalidades Terapêuticas do CA de Mama.................................................................... 26

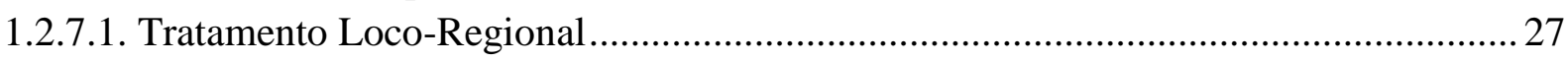

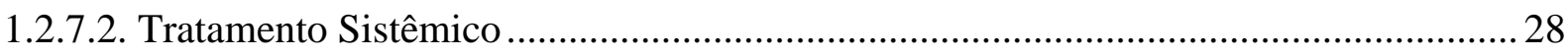

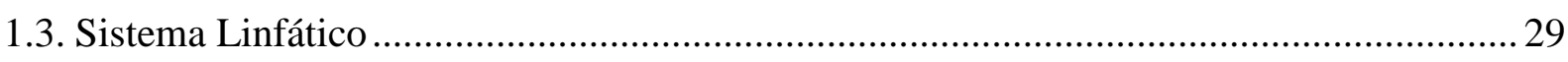

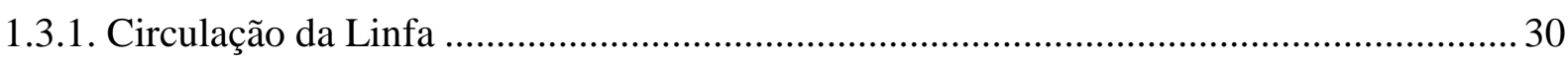

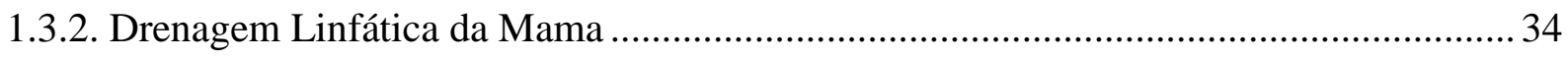

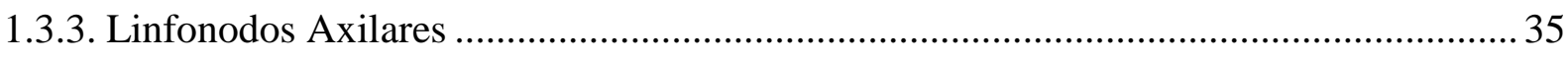

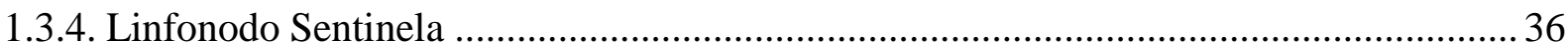

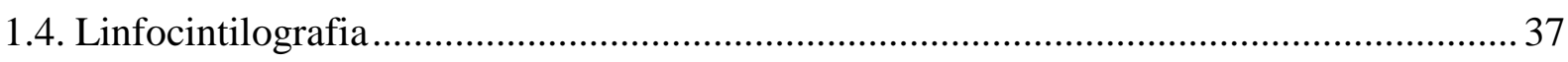

1.4.1. Radiofármacos Utilizados na Técnica de Linfocintilografia ......................................... 39

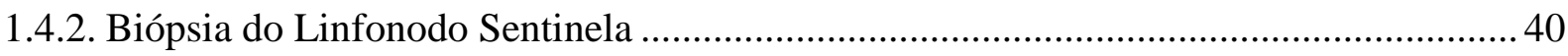

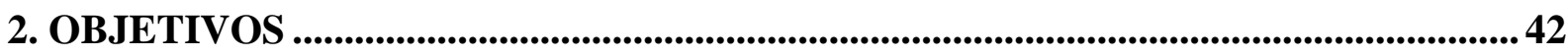

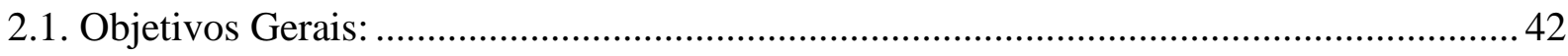

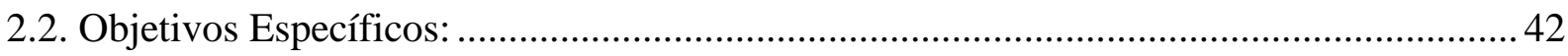

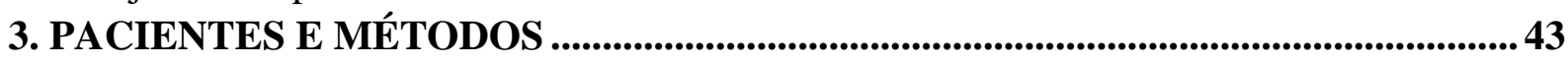

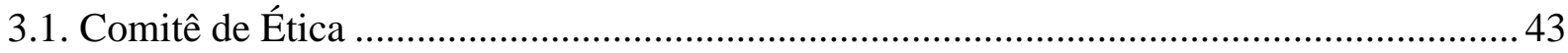

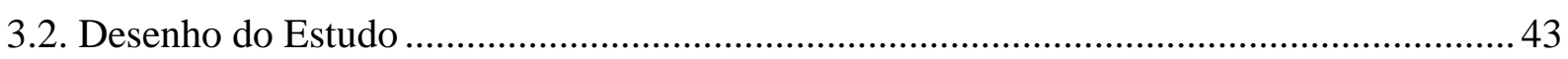

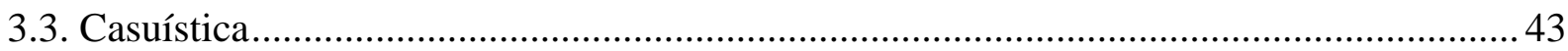

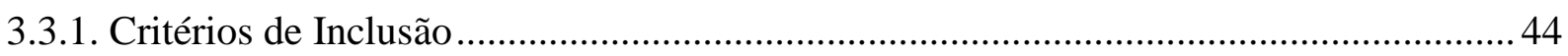

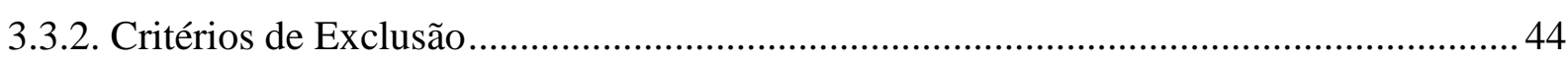

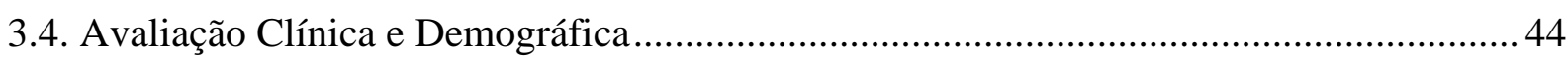

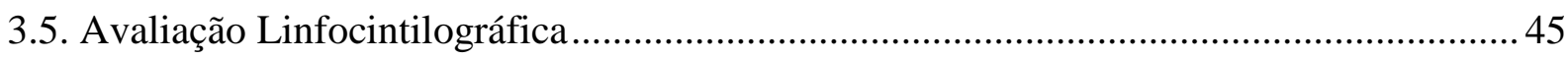

3.5.1. Método Pré-operatório: Linfocintilografia ............................................................ 45

3.5.2. Caracterização dos Padrões de Drenagem Linfática ..................................................... 46

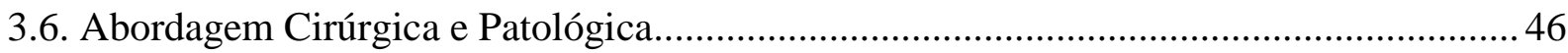

3.6.1. Cirurgia para Retirada do Linfonodo Sentinela......................................................... 46 


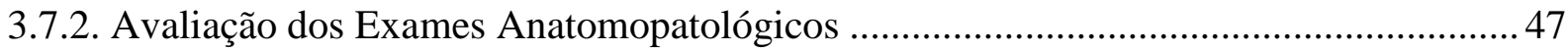

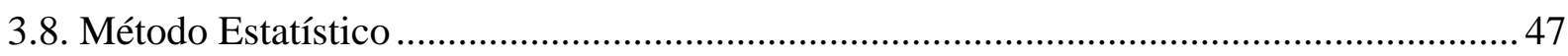

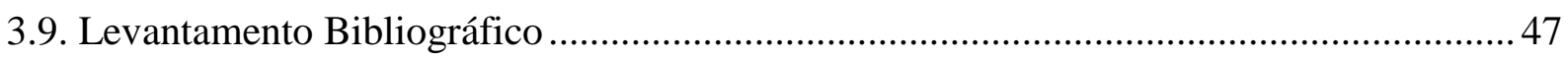

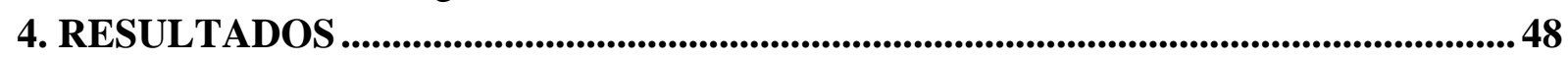

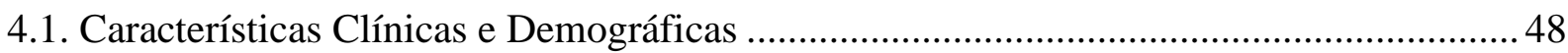

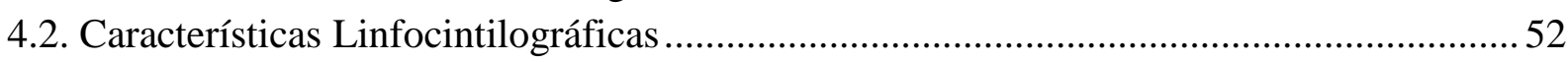

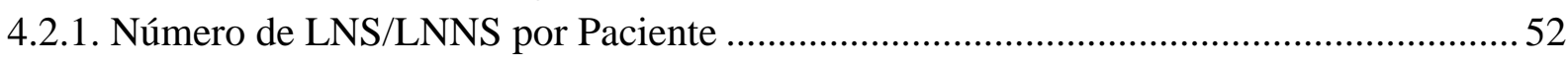

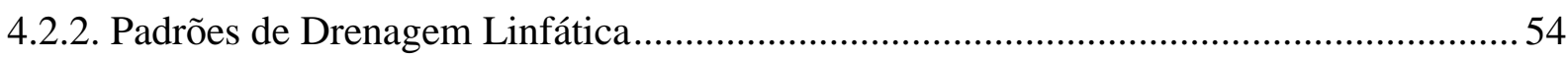

4.2.2.1. Descrição dos Padrões de Drenagem Linfática Axilares............................................ 56

4.2.2.2. Descrição dos Padrões de Drenagem Linfática da Região Mamária Interna .............. 57

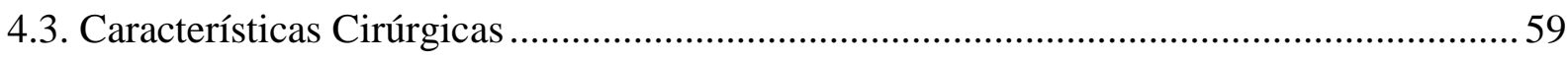

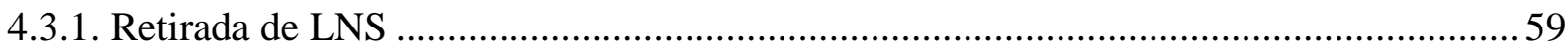

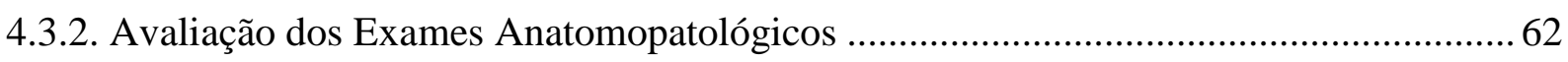

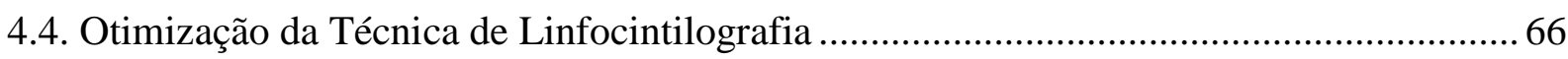

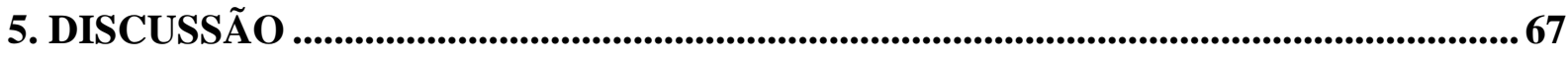

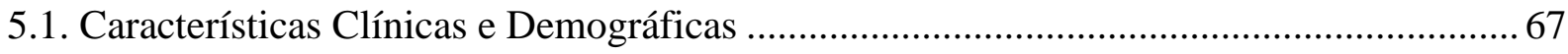

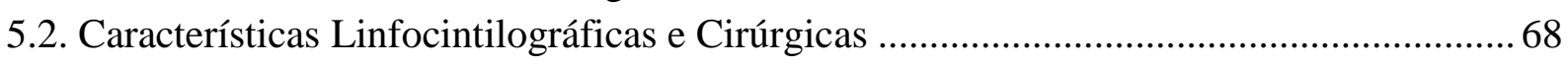

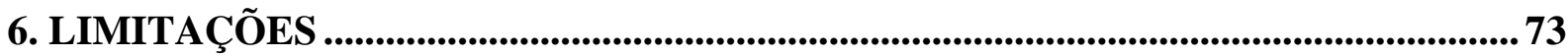

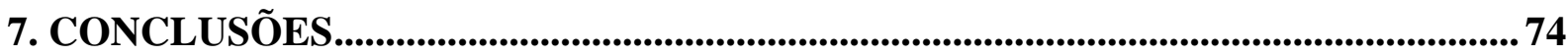

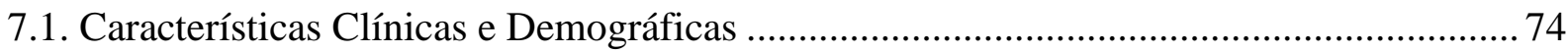

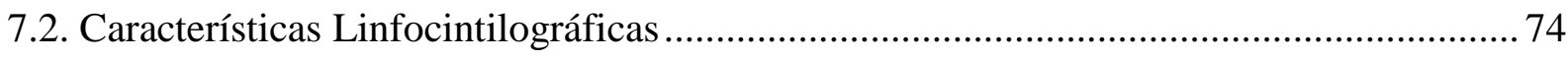

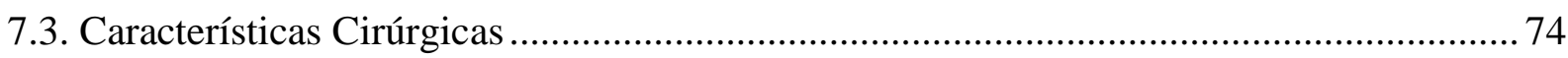

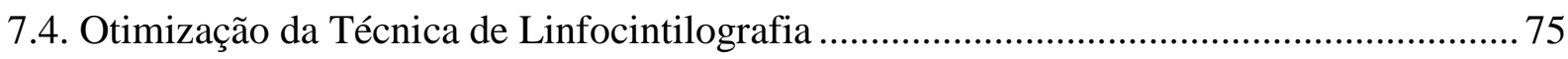

8. REFERÊNICAS BIBLIOGRÁFICAS .....................................................................76

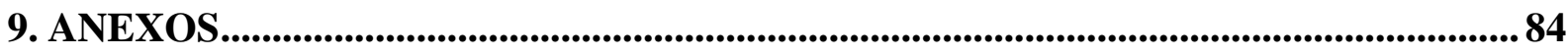

9.1. Anexo A - Termo de Consentimento Livre e Esclarecido (TCLE) ................................. 84

9.2. Anexo B - Formulário de Aquisição das Imagens de Linfocintilgrafia ........................... 87 


\section{INTRODUÇÃO}

Com os grandes avanços no tratamento cirúrgico de câncer de mama (CA de mama), torna-se necessário o conhecimento detalhado de todas as características anatômicas da mama e da região axilar. Essa região é o local habitual de intervenções cirúrgicas no tratamento do CA de mama. Dentro deste contexto, a anatomia e fisiologia da mama serão abordadas.

\subsection{Anatomia e Fisiologia da Mama}

As mamas estão localizadas sobre as costelas $2^{\mathrm{a}}$ a $6^{\mathrm{a}}$ encobrindo os músculos peitorais maior e menor, partes do músculo serrátil anterior e oblíquo externo do abdome, aos quais são ligadas por uma camada de tecido conjuntivo. O limite medial da mama pode chegar à margem lateral do externo e a margem lateral da mama segue a margem anterior da axila. $\mathrm{O}$ prolongamento axilar da mama se estende para cima e lateralmente em direção à axila, aproximando dos vasos axilares. Essa região, por sua vez, possui uma grande importância clínica devido à alta incidência de CA de mama e a drenagem linfática do processo axilar (Figura 1). (TORTORA e GRABOWSKI, 2006), (GRAAFF e MARSHALL, 2003)

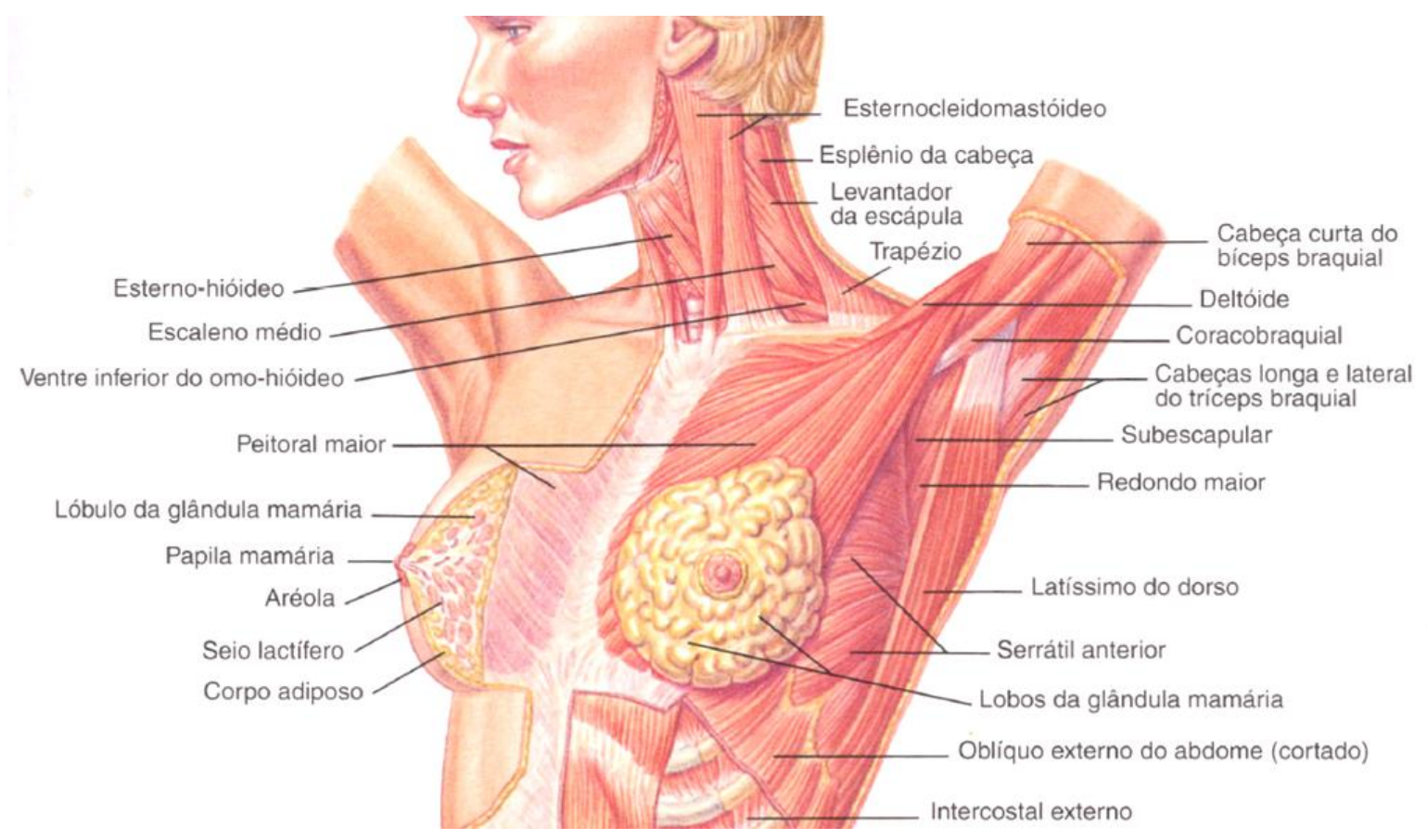

Figura 1 - Localização da mama. (GRAAFF e MARSHALL, 2003) 
Internamente, cada glândula mamária consiste em 15 a 20 lobos, cada um possui sua própria via de drenagem. Estes lobos são organizados radialmente e separados por tecido adiposo e faixas de tecido conjuntivo denominados de ligamentos suspensores da mama (ligamentos de Cooper), se estendem da pele à fáscia profunda que recobre o músculo peitoral maior, proporcionando sustentação às mamas. A quantidade de tecido adiposo determina apenas o tamanho e a forma da mama, não influenciando na amamentação. Em cada lobo da glândula mamária existem lóbulos menores em que são encontradas as glândulas secretoras de leite denominadas alvéolos (alveolus $=$ cavidade pequena). Agrupamentos de alvéolos mamários secretam leite no interior dos ductos mamários que convergem para formar os ductos lactíferos. O lume de cada ducto lactífero se expande próximo à papila mamária para formar um seio lactífero, neste ocorre o armazenamento do leito antes de escoar para a extremidade da papila mamária (Figura 2). (TORTORA e GRABOWSKI, 2006), (GRAAFF e MARSHALL, 2003)

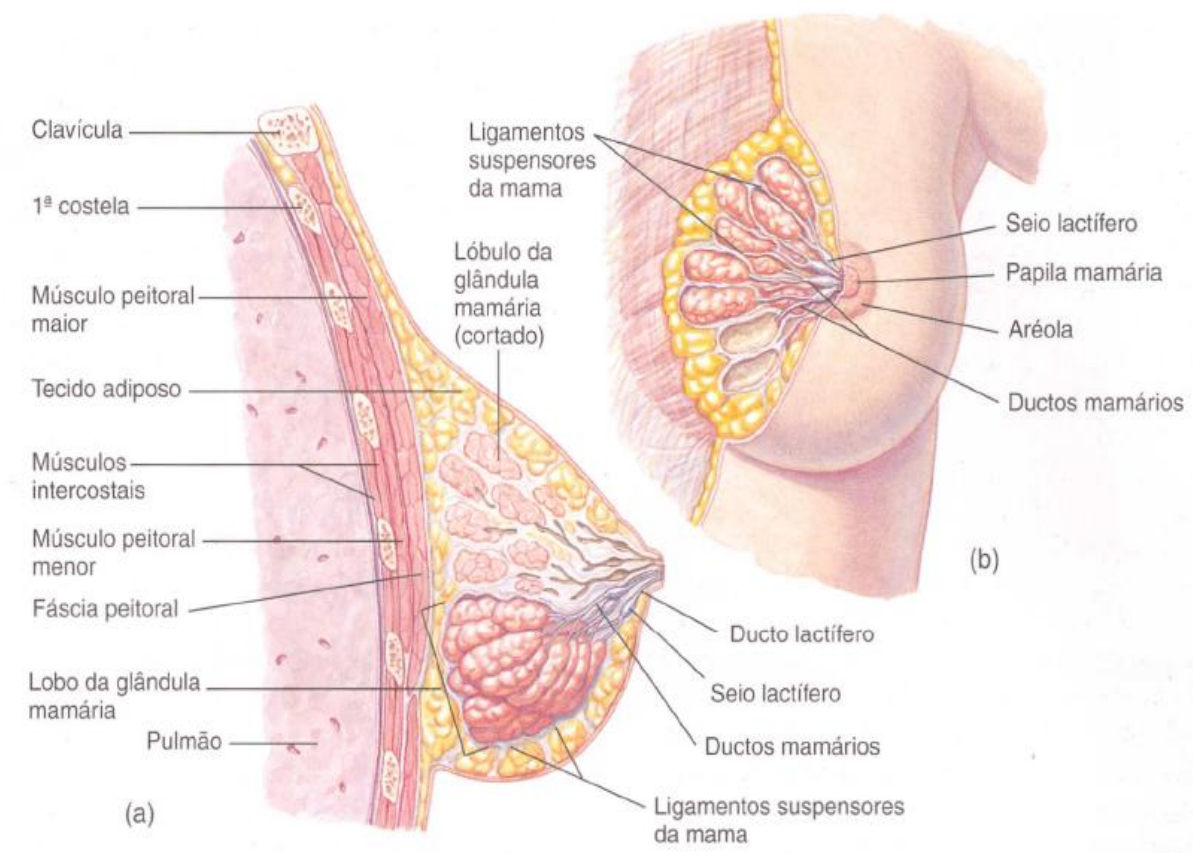

Figura 2 - Estrutura da mama e das glândulas mamárias. (GRAAFF e MARSHALL, 2003)

A papila mamária (mamilo) possui uma projeção pigmentada e circular da mama que possui musculatura lisa. A área circular de pele pigmentada que circunda a papila mamária é denominada de aréola mamária (aréola $=$ espaço pequeno). A superfície da aréola mamária pode apresentar saliências devido às glândulas areolares sebáceas próximas à superfície, as secreções dessas glândulas mantêm a flexibilidade das papilas mamárias. (GRAAFF e MARSHALL, 2003) 
Os ramos perfurantes da artéria torácica interna que entram na mama pelo segundo, terceiro e quarto espaços intercostais (próximo à lateral do esterno) e os ramos mamários laterais superficiais (ramos da artéria torácica lateral) realizam a irrigação sanguínea da glândula mamária. O retorno venoso é realizado pelas veias que acompanham as artérias correspondentes. (GRAAFF e MARSHALL, 2003)

\subsection{Câncer de Mama}

Acredita-se que o CA de mama é uma consequência da interação de fatores genéticos com estilo de vida, hábitos reprodutivos e meio ambiente. (JOHNSON-THOMPSON e GUTHRIE, 2000). Isto resulta no fato de que cerca de 90\%-95\% dos casos de CA de mama podem ser atribuídos a mutações somáticas ao longo da vida, nas quais as células se dividem e se multiplicam rapidamente, levando à transformação de células normais em células malignas. Os demais 5\%-10\% dos casos são interpretados com sendo de origem genética, devido à herança de uma mutação germinativa ao nascimento, tornando essas mulheres suscetíveis ao CA de mama. (BILMORIA, 1995)

\subsubsection{Epidemiologia}

Com as campanhas de prevenção do CA de mama, nas últimas décadas há um aumento significativo da taxa de diagnóstico da doença no mundo. A cada ano, aproximadamente $22 \%$ dos novos casos de câncer em mulheres são de mama. (INCA, 2009), (GIGLIO e IYEYASU, 2008)

Segundo dados do International Agency for Reserch on Cancer (IARC/OMS), em 2008 estimou-se que o CA de mama fosse o segundo câncer mais incidente com 1,29 milhões de casos novos, sendo o primeiro o CA de pulmão. Nos EUA e norte da Europa a incidência de CA de mama é considerada alta, no Oriente Médio e América do Sul intermediária e na Ásia é considerada baixa. (GIGLIO e IYEYASU, 2008)

As estimativas de 2010 e 2011 para CA de mama no Brasil, segundo o INCA, são de 49.240 com um risco estimado de 49 casos a cada 100 mil mulheres. Na Região Sudeste, o câncer de mama é o mais incidente entre as mulheres, com um risco estimado de 65 casos novos por 100 mil. Sem considerar os tumores de pele não melanoma, este tipo de câncer 
também é o mais frequente nas mulheres das regiões Sul (64/100.000), Centro-Oeste (38/100.000) e Nordeste (30/100.000). Na Região Norte é o segundo tumor mais incidente (17/100.000). (INCA, 2009)

Embora o CA de mama apresente um bom prognóstico quando diagnosticado e tratado precocemente, as taxas de mortalidade ainda continuam elevadas, possivelmente devido ao diagnóstico tardio da doença. Na população mundial, a sobrevida média após cinco anos é de $61 \%$. Nos países desenvolvidos essa taxa aumenta para $73 \%$, enquanto que nos países em desenvolvimento essa sobrevida diminui para 57\%. (INCA, 2009) Diante destes índices, há um grande problema de saúde pública responsável por um número significativo de óbitos entre as mulheres adultas. (MARIANI et al., 1998)

\subsubsection{Fatores de Risco}

A etiologia do CA de mama é considerada heterogênea assim como nos outros cânceres, havendo muitos os fatores de risco, (GIGLIO e IYEYASU, 2008) entre eles os mais importantes são:

a) Fatores Reprodutivos: gestação tardia, não amamentar, não ter filhos, menopausa tardia, menarca precoce e outros;

b) Fatores Hormonais: reposição hormonal por mais de 5 anos, uso de contraceptivos hormonais por mais de cinco anos e outros;

c) Fatores Nutricionais: obesidade pós-menopausa, consumo excessivo de álcool, gorduras saturadas e monoinsaturadas e baixa atividade física;

d) Fatores Familiares: antecedentes familiares que tiveram a doença;

e) Fatores Genéticos: BRCA1 e BRCA2 (genes supressores de tumor);

f) Outros Fatores: CA de mama prévio, idade acima dos 40 anos e outros, exposição a radiação ionizante, diagnóstico de doença benigna e outros.

\subsubsection{Sinais e Sintomas}

No início do desenvolvimento do CA de mama não apresenta sintomas específicos, por isso a necessidade da realização do exame clínico e mamografia, pois as lesões nessa fase não são palpáveis. (INCA, 2009) 
O sinal mais frequente de CA de mama é a presença de tumor ou nódulo palpável na mama, que em $20 \%$ dos casos associam-se a dor mamária, e em outros casos pode se manifestar como nódulos palpáveis na axila. (XAVIER et al., 2002)

\subsubsection{Métodos Diagnósticos}

Para a detecção do CA de mama é recomendado o "tríplice diagnóstico": realização do exame clínico, obtenção de exames de imagem e análise de amostra tissular. (GIGLIO e IYEYASU, 2008), (INCA, 2004)

O exame clínico da mama (ECM) é fundamental para o diagnóstico do câncer. Deve ser realizado como parte do exame físico e ginecológico, e constitui a base para a solicitação dos exames complementares. Para a sua adequada realização, ele deve seguir os seguintes passos: inspeção estática e dinâmica, palpação das axilas e palpação da mama com o paciente em decúbito dorsal. (INCA, 2004)

Quanto aos exames de imagem, o exame da mamografia continua sendo a mais importante técnica para a avaliação das mamas, sendo o método de escolha para o rastreamento populacional do CA de mama em mulheres assintomáticas e sendo, também, a primeira técnica de imagem indicada para avaliar a maioria das alterações clínicas mamárias. Assim, permite o diagnóstico precoce de lesões não palpáveis, resultando na diminuição da mortalidade por CA de mama. Isto favorece a escolha de opções terapêuticas, aumenta a probabilidade de sucesso do tratamento e as chances de sobrevida. (HUMPHREY et al., 2002), (FLETCHER e ELMORE, 2003). Além da mamografia, podem ser realizadas também a ultra-sonografia (US) e a ressonância magnética (RM). Todas estas são importantes para a detecção, o diagnóstico e a definição da conduta nas doenças mamárias. Outras técnicas menos utilizadas incluem a tomografia computadorizada (TC), a tomografia por emissão de pósitrons (PET), a espectroscopia por ressonância magnética e a ultra-sonografia com contraste. (CHALA e BARROS, 2007)

Finalmente, a análise da amostra tissular, esta é realizada quando o paciente apresenta nódulo mamário que foi visualizado, anteriormente, pelos exames de imagem e dependendo do tamanho do nódulo, detectado no exame clínico. Esta amostra pode ser obtida por biópsia de fragmento com agulha denominada de core biopsy. É um diagnóstico histológico préoperatório de câncer que aumenta a probabilidade de margens cirúrgicas livres na cirurgia 
definitiva, reduz o número de cirurgia e ainda melhora o resultado oncológico e cosmético. (TIEZZI, 2007)

O INCA não incentiva o auto-exame das mamas como estratégia isolada de detecção precoce do CA de mama. Este exame é observador-dependente, não consegue reduzir a mortalidade e ainda provoca insegurança quando é negativo, pois os nódulos menores que 1 cm não são palpáveis e, portanto, não detectáveis. (INCA, 2009)

\subsubsection{Classificação de Tumores Malignos}

O estadiamento do CA de mama é baseado na classificação clínica proposta pela União Internacional Contra o Câncer (UICC) de 2004, sendo referida como classificação TNM (Classificação de Tumores Malignos), em que $\mathrm{T}$ refere-se à dimensão do tumor primário, $\mathrm{N}$ a presença ou ausência de metástases para linfonodos regionais e $\mathrm{M}$ a presença ou ausência de metátateses à distância. E a classificação pós-cirúrgica é designada para pTNM em que a graduação histopatológica $(\mathrm{G})$ pode ser inserida, como pode ser visto na Tabela 1 e Tabela 2. (INCA, 2004)

A classificação tem como objetivo auxiliar o planejamento terapêutico, oferecer subsídios para o prognóstico, permitir avaliação dos resultados do tratamento, proporcionar intercâmbio de informações entre diferentes centros, e ainda fornecer elementos para a realização das pesquisas clínicas sobre CA de mama. (TELLES, CARMO e GONÇALVES, 1997)

A classificação clínica é composta pelas características do CA de mama que são determinadas para classificar o tumor. Essas características são: presença ou ausência de CA invasor e suas dimensões e presença ou ausência de invasão exterior da mama (como por exemplo, a pele da mama, ao músculo ou à caixa torácica). O estadiamento do $\mathrm{CA}$ de mama segundo a TNM pode ser visto na Tabela 3.

A classificação Patológica é determinada de acordo com o número, tamanho e localização dos depósitos de células de CA de mama nos linfonodos, incluindo os linfondos axilares, supraclaviculares e linfonodos intramamários. Essa classificação determina que o tamanho do tumor é a medida do componente invasivo. Também há a presença da gradação histopatológica sendo utilizado o estudo de Eston e Ellis (1991) que será abordado em fatores prognósticos. 


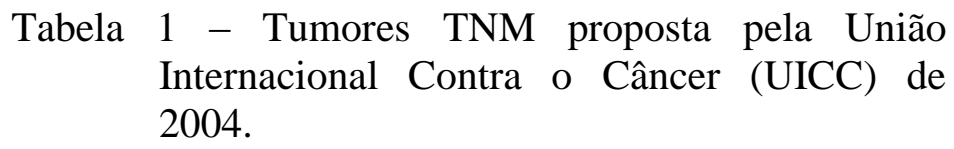

\begin{tabular}{cc}
\hline Tumor & Características \\
\hline Tis & Carcinoma in situ \\
T1 & $\leq 2 \mathrm{~cm}$ \\
T1 mic & $\leq 0,1 \mathrm{~cm}$ \\
T1a & $>0,1 \mathrm{~cm}$ até $0,5 \mathrm{~cm}$ \\
T1b & $>0,5 \mathrm{~cm}$ até $1 \mathrm{~cm}$ \\
T1c & $>1 \mathrm{~cm}$ até $2 \mathrm{~cm}$ \\
T2 & $>2 \mathrm{~cm}$ até $5 \mathrm{~cm}$ \\
T3 & $5 \mathrm{~cm}$ \\
T4 & Parede torácica/pele \\
T4a & Parede torácica \\
T4b & Edema/ulceração cutânea, \\
& nódulos cutâneos satélites \\
T4c & Ambos T4a e T4b \\
T4d & Carcinoma inflamatório \\
\hline Legenda: T - Tumor; mic - micrometástases; $(1,2,3,4)-$ \\
tipos de tumores; (a, b, c, d) - subtipos de tumores.
\end{tabular}

Tabela 2 - Linfonodos TNM proposta pela União Internacional Contra o Câncer (UICC) de 2004.

\begin{tabular}{|c|c|c|c|}
\hline & Classificação & & Características \\
\hline \multirow[t]{5}{*}{ N1 } & Linfonodos axilares & pN1mic & $\begin{array}{l}\text { Micrometástases, }>0,2 \mathrm{~mm} \leq 2 \\
\mathrm{~mm}\end{array}$ \\
\hline & móveis & $\mathrm{pN} 1 \mathrm{a}$ & 1-3 linfonodos axilares \\
\hline & & $\mathrm{pN} 1 \mathrm{~b}$ & $\begin{array}{l}\text { Linfonodos mamários internos } \\
\text { com metástases microscópica por } \\
\text { BLNS, mas não clinicamente } \\
\text { aparente }\end{array}$ \\
\hline & & $\mathrm{pN} 1 \mathrm{c}$ & \\
\hline & & & $\begin{array}{l}\text { 1-3 linfonodos axilares e } \\
\text { mamários internos com metástases } \\
\text { microscópica por BLNS, mas não } \\
\text { clinicamente aparente }\end{array}$ \\
\hline $\mathrm{N} 2 \mathrm{a}$ & Linfonodos axilares fixos & $\mathrm{pN} 2 \mathrm{a}$ & 4-9 linfonodos axilares \\
\hline
\end{tabular}




\begin{tabular}{|c|c|c|c|}
\hline & \multicolumn{3}{|c|}{$\begin{array}{l}\text { Continuação da Tabela Linfonodos TNM proposta pela União } \\
\text { Internacional Contra o Câncer (UICC) de } 2004 \text {. }\end{array}$} \\
\hline $\mathrm{N} 2 \mathrm{~b}$ & $\begin{array}{l}\text { Linfonodos mamários } \\
\text { internos, clinicamente } \\
\text { aparentes }\end{array}$ & $\mathrm{pN} 2 \mathrm{~b}$ & $\begin{array}{l}\text { Linfonodos mamários internos, } \\
\text { clinicamente aparentes, sem } \\
\text { linfonodos axilares }\end{array}$ \\
\hline N3a & $\begin{array}{l}\text { Linfonodos infra- } \\
\text { claviculares }\end{array}$ & $\mathrm{pN} 3 \mathrm{a}$ & $\begin{array}{l}\geq 10 \text { linfonodos axilares ou infra- } \\
\text { claviculares }\end{array}$ \\
\hline $\mathrm{N} 3 \mathrm{~b}$ & $\begin{array}{l}\text { Linfonodos mamários } \\
\text { internos e axilares }\end{array}$ & $\mathrm{pN} 3 \mathrm{~b}$ & $\begin{array}{l}\text { Linfonodos mamários internos, } \\
\text { clinicamente aparentes, com } \\
\text { linfonodo(s) axilar(es) ou > } 3 \\
\text { linfonodos axilares e mamários } \\
\text { internos com metástases } \\
\text { microscópica por BLNS, mas não } \\
\text { clinicamente aparente }\end{array}$ \\
\hline $\mathrm{N} 3 \mathrm{c}$ & $\begin{array}{l}\text { Linfonodos supra- } \\
\text { claviculares }\end{array}$ & $\mathrm{pN} 3 \mathrm{c}$ & Linfonodos supra-claviculares \\
\hline
\end{tabular}

Legenda: $\mathrm{N}$ - Linfonodos; $\mathrm{p}$ - pós-cirúrgico; mic - micrometástases; $(1,2,3,4)$ - tipos de linfonodos; ( $\mathrm{a}, \mathrm{b}, \mathrm{c}, \mathrm{d})$ - subtipos de linfonodos; BLNS - Biópsia do linfonodo sentinela.

Tabela 3 - Estadiamento TNM proposta pela União Internacional Contra o Câncer (UICC) de 2004 do CA de mama por agrupamento.

\begin{tabular}{llll}
\hline Estádio & T & $\mathbf{N}$ & M \\
\hline E0 & Tis & N0 & M0 \\
EI & T1 & N0 & M0 \\
EIIA & T0 & N1 & M0 \\
& T1 & N1 & M0 \\
& T2 & N0 & M0 \\
EIIB & T2 & N1 & M0 \\
& T3 & N0 & M0 \\
EIIIA & T0 & N2 & M0 \\
& T1 & N2 & M0 \\
& T3 & N1, N2 & M0 \\
EIIIB & T4 & N0, N1, N2 & M0 \\
EIIIC & Qualquer T & N3 & M0 \\
EIV & Qualquer T & Qualquer N & M1 \\
\hline
\end{tabular}

Legenda: E (Estádio); T (Tumor); N (Linfonodos); M (presença ou ausência de metástases); ( 0 , I, II, III, IV) tipos de estádios; $(1,2,3,4)$ tipos de tumores ou linfonodos. 


\subsubsection{Fatores Prognósticos}

Fatores prognósticos são parâmetros que fornecem informações a respeito da evolução clínica da neoplasia no momento do diagnóstico e que servem como preditor da sobrevida do paciente. (ZUCCARI et al., 2008)

Os fatores prognósticos utilizados na avaliação do CA de mama são: tamanho do tumor, tipo e grau histológico, estado linfonodal, estado dos receptores hormonais (receptores de estrógeno, RE, e receptor de progesterona, RP), hiperexpressão de HER2 (receptor do fator de crescimento epidérmico humano 2), Ki-67 (proteína nuclear humana encontrada em todas as partes ativas do ciclo celular, sendo largamente empregada como marcador de proliferação), gene supressor de tumor localizado no cromossomo 17p (P53) e a presença de invasão angiolinfática. (ZUCCARI et al., 2008), (ISAACS, STEAMS e HAYES, 2001)

\subsubsection{Tamanho do Tumor}

O tamanho do tumor é considerado um dos fatores prognósticos mais importantes no câncer de mama, e quanto maior o tamanho do tumor, maior a probabilidade de comprometimento de linfonodo axilar, com redução no intervalo livre de doença e sobrevida. (ISAACS, STEAMS e HAYES, 2001)

Os pacientes que apresentam tumores menores que $1 \mathrm{~cm}$, aproximadamente de 10 $20 \%$ possuem metástases linfonodais e cerca de $90 \%$ dos pacientes com tumores menores que $1 \mathrm{~cm}$ e linfonodos negativos para envolvimento metastátco têm sobrevida de 10 anos livre de doença. (FITZGIBBONS et al., 2000)

\subsubsection{Tipos Histológicos}

O CA de mama é geralmente classificado em primeiro lugar pela suas características histológica de amostras de biópsia visualizadas em microscopia óptica.

A maioria dos CA de mama são derivados do epitélio de revestimento dos dutos ou lóbulos, sendo classificados como carcinoma ductal ou lobular. Estes ainda são denominados de carcinoma in situ quando ocorre o crescimento de baixo grau de células cancerosas ou précancerosas no compartimento de tecido especial, como o ducto mamário, sem invasão dos 
tecidos vizinhos. E carcinoma invasivo quando não se limita ao compartimento de tecido inicial e invade o tecido circundante, ocorrendo a disseminação para outras partes do corpo. (GINSBURG et al., 2010),

De acordo com a classificação dos tumores da mama da Organização Mundial da Saúde (2002), tem-se os seguintes tipos histológicos incluindo tumores benignos e malignos, podendo ser visualizados na Tabela 4. (BOCKER, 2002)

Tabela 4 - Classificação dos tipos histológicos segundo a OMS (2002).

\begin{tabular}{ll}
\hline Carcinoma Ductal Invasivo & Lesões Precursoras \\
\hline Subtipos: & Neoplasia Lobular: \\
1. Carcinoma Pleomófico & 1. Carcinoma Lobular in situ \\
2. Carcinoma Osteoclástico com Células Gigantes & Lesões Proliferativas Intraductais: \\
3. Carcinoma com características coriocarcinomatosas & 1. Hiperplasia Ductal Usual \\
4. Carcinoma com características melanóticas & 2. Hiperplasia Epitelial Plana \\
Carcinoma Lobular Invasivo & 3. Hiperplasia Ductal Atípica \\
Carcinoma Tubular & 4. Carcinoma Ductal in situ \\
Carcinoma Invasivo Crivoso & Carcinoma Microinvasor \\
Carcinoma Medular & Neoplasias Papilares Intraductais: \\
Carcinoma mucinoso e outros tumores com abundante & \\
mucina: & 1. Papiloma Central \\
1. Carcinoma mucinoso & 2. Papiloma Periférico \\
2. Cistadenocarcinoma e Carcinoma de Células Colunares & \\
Mucinosas & 3. Papiloma Atípico \\
3. Carcinoma de Células em anel de Signet & 4. Carcinoma Papilar Intraductal \\
Tumores Neuroendócrinos: & 5. Carcinoma papilar intracistico \\
1. Carcinoma Neuroendócrino Sólido (carcinóide da mama) & Lesóes Benignas do Epitélio: \\
2. Tumor Carcinóide Atípico & 1. Adenose, incluindo as variantes \\
3. Carcinoma de Células em aveia (pequenas células) & 2. Adenose Esclerosante \\
4. Carcinoma Neuroendócrino de células grandes & 3. Adenose Apócrina \\
Carcinoma Invasivo Papilar & 4. Adenose de Ducto Atenuado \\
Carcinoma Invasivo Micropapilar & 5. Adenose Microglandular \\
Carcinoma Apócrino & 6. Adenose Adenomioepitelial \\
Carcinomas Metaplásicos: & Cicatriz radial / Lesão Esclerosante \\
1. Carcinomas Epiteliais Metaplásicos Puro & Complexa \\
2. Carcinoma de Células Escamosas & Adenomas: \\
3. Adenocarcinoma com Metaplasia de Células Fusiformes & 1. Adenoma Tubular \\
& 2. Adenoma Lactação \\
\hline
\end{tabular}


Continuação da Tabela Classificação dos tipos histológicos segundo a OMS (2004).

\begin{tabular}{|c|c|}
\hline 4. Carcinoma Adenoescamoso & 3. Adenoma Apócrino \\
\hline 5. Carcinoma Mucoepidermóide & 4. Adenoma Pleomórfico \\
\hline Epitelial Misto/ Carcinoma Mesenquimal Metaplásico: & 5. Adenoma Ductal \\
\hline 1. Carcinoma Rico em Lipídios & Lesões Mioepiteliais \\
\hline 2. Carcinoma Secretório & 1. Mioepiteliais \\
\hline 3. Carcinoma Oncocíticos & 2. Adenose Adenomiepitelial \\
\hline 4. Carcinoma Adenóide Cístico & 3. Adenomioepitelioma \\
\hline 5. Carcinoma de Células Acinares & 4. Mioepitelioma Maligno \\
\hline 6. Carcinoma de Células Ricas em Glicogênio & Tumores Fibroepiteliais: \\
\hline 7. Carcinoma Sebáceo & Fibroadenoma \\
\hline 8. Carcinoma Inflamatório & Tumor Filodes \\
\hline 9. Carcinoma de Mama Bilateral & 1. Benigno \\
\hline Tumores Mesenquimais (incluindo Sarcomas): & 2. Borderline \\
\hline 1. Haemangioma & 3. Maligno \\
\hline 2. Angiomatose & $\begin{array}{l}\text { Sarcoma Periductal Estromal, de } \\
\text { baixo grau }\end{array}$ \\
\hline 3. Haemangiopericitoma & Hamartoma Mamário \\
\hline 4. Hiperplasia estromal pseudoangiomatosa & Tumores do mamilo \\
\hline 5. Miofibroblastoma & Adenoma no Mamilo \\
\hline 6. Fibromatose (agressivo) & Adenoma Siringomatoso \\
\hline 7. Tumor inflamatório miofibroblastico & Doença de Paget do Mamilo \\
\hline 8. Lipoma & Linfoma Maligno \\
\hline \multicolumn{2}{|l|}{ 8.1. Angiolipoma } \\
\hline 9. Tumor de células granulares & Tumores Metastáticos \\
\hline \multicolumn{2}{|l|}{ 10. Neurofibroma } \\
\hline 11. Schwannoma & Tumores da mama masculina: \\
\hline \multicolumn{2}{|l|}{ 12. Angiosarcoma } \\
\hline 13. Lipossarcoma & Ginecomastia \\
\hline 14. Rabdomiossarcoma & Carcinoma \\
\hline 15. Osteosarcoma & 1. in situ \\
\hline 16. Leiomioma & 2. Invasivo \\
\hline 17. Leiomiossarcoma & \\
\hline
\end{tabular}

\subsubsection{Grau Histológico}

O grau histológico é definido pelo sistema de classificação ou o sistema de pontuação da classificação de Scarff-Bloom-Richardson modificado por Elston-Ellis, sendo um sistema 
de estadiamento do CA de mama que examina as células e estrutura do tecido do câncer determinando o quão este tecido é agressivo e invasivo. (BLOOM e RICHARDSON, 1957), (SCARFF e TORLONI, 1968), (ELSTON e ELLIS, 1991) Para isso são avaliados três parâmetros que estão presentes na Tabela 5, sendo eles:

Percentual de diferenciação tubular: é classificado de acordo com a formação tubular, quando há a presença de mais de $75 \%$ do campo com formação tubular as células encontramse bem diferenciadas, de 10-75\% há uma tentativa moderada de diferenciação tubular e menos que $10 \%$ apresentam pouca diferenciação tubular.

Avaliação do pleomorfismo nuclear: é classificado de acordo com o tamanho, forma e coloração dos núcleos, sendo considerado pleomorfismo baixo quando os núcleos estão uniformes em tamanho, forma e coloração, pleomorfismo intermediário quando há variação em grau moderado e pleomorfismo alto quando há núcleos irregulares em forma, tamanho e coloração.

Índice Mitótico: é classificado de acordo com a quantidade de mitoses encontradas por campo, sendo baixo quando o número de mitoses é menor que 10 por campo, intermediário quando há de 10 a 20 mitoses e alto quando há mais que 20 mitoses por campo.

Tabela 5 - Classificação de Scarff-Bloom-Richardson modificado por Elston-Ellis.

\begin{tabular}{cccc}
\hline Escores & $\mathbf{1}$ & $\mathbf{2}$ & $\mathbf{3}$ \\
\hline Diferenciação Tubular & $75 \%$ & $10-75 \%$ & $<10 \%$ \\
Pleomorfismo Nuclear & Pleomorfismo & Pleomorfismo & Pleomorfismo Alto \\
& Baixo & Intermediário & \\
Índice Mitótico & Baixo $(<10)$ & Intermediário $(10-20)$ & Alto $(>20)$ \\
\hline
\end{tabular}

A cada uma destas características é atribuída uma pontuação que varia de 1 a 3 . Os escores são somados para uma classe que irá variar entre 3 a 9. Este valor é então usado para classificar o tumor como segue abaixo:

Grau I (3-5): Bem diferenciado, possui melhor prognóstico;

Grau II (6-7): Moderadamente diferenciado, possui prognóstico intermediário;

Grau III (8-9): Pouco diferenciado com pior prognóstico 
Tumores de grau inferior, com um bom prognóstico, podem ser tratados com cirurgia menos agressiva e medicação e têm melhor taxa de sobrevida.

\subsubsection{Estado Linfonodal}

É o fator prognóstico mais importante de sobrevida livre de doenças e sobrevida total no CA de mama. Este fator determina o número de linfonodos dissecados, número de linfonodos comprometidos, tamanho do maior foco metastático e invasão capsular e extensão a tecidos extranodais. (FITZGIBBONS et al., 2000)

O comprometimento do linfonodo axilar pode ser uma consequência da agressividade do tumor primário, com tendência à metástase para outros órgãos. Quanto maior o número de linfonodos acometidos, pior será o prognóstico dos pacientes. A presença de um a três linfonodos metastáticos de $\mathrm{CA}$ da mama tem sido considerado mais favorável a uma sobrevida livre de doença do que o encontro de quatro ou mais linfonodos positivos. (GIGLIO e IYEYASU, 2008), (FISHER et al., 1983)

Os pacientes com linfonodos livres de acometimento têm menor índice de recidiva local e sobrevida mais longa. Destes pacientes, aproximadamente 20-30\% irão desenvolver recorrência da doença em dez anos. (GIGLIO e IYEYASU, 2008)

A detecção de metástases em linfonodos axilares inferiores ou iguais a $2 \mathrm{~mm}$, em seu maior diâmetro, é associada a um prognóstico mais favorável com sobrevida livre de doença e sobrevida global que os pacientes com linfonodos axilares metastáticos maiores que $2 \mathrm{~mm}$. (HAINSWORTH et al., 1993)

\subsubsection{Modalidades Terapêuticas do CA de Mama}

As modalidades terapêuticas para o tratamento do CA de mama são: cirurgia e radioterapia para tratamento loco-regional; quimioterapia, hormonioterapia e terapia alvo para tratamento sistêmico. 


\subsubsection{Tratamento Loco-Regional}

Os tipos de cirurgia para o tratamento do CA de mama são: Cirurgias Conservadoras (Quadrantectomia e Tumorectomia) e Cirurgias Não Conservadoras (Mastectomia).

A quadrantectomia é definida como ressecção de todo o setor mamário correspondente ao tumor, incluindo a pele e a fáscia do músculo peitoral maior. (VERONESI et al., 1981) Já a tumorectomia consiste na remoção de todo o tumor com uma margem de tecido mamário livre de neoplasia ao seu redor. (FISHER et al., 1985) As duas técnicas são consideradas métodos seguros. Os estudos clínicos randomizados comparando a quadrantectomia e a tumorectomia com a cirurgia radical não demonstraram prejuízo de sobrevida global com a utilização das técnicas de preservação da mama, em seguimento em longo prazo. (FISHER et al., 2002), (VERONESI et al., 2002)

Para a realização de cirurgias conservadoras devem ser levados em consideração alguns parâmetros, são eles: pacientes com CA de mama em estádio I e II, relação do tamanho do tumor com o volume da mama, realização de mamografia prévia para o planejamento cirúrgico, ausência de comprometimento de pele, tumor único ou multifocais com distância máxima de $2 \mathrm{~cm}$ entre as lesões, avaliação das margens cirúrgicas e motivação do paciente para realização de radioterapia adjuvante. (SOLIN et al., 1996), (VERONESI et al., 1990)

E as contra-indicações para realização de cirurgia conservadora são: gestação, tumor multicêntrico, microcalcificações de aspecto malignos em diferentes áreas da mama e história de radioterapia previa na mama são consideradas como contra-indicações absolutas. E ainda há as contra-indicações relativas, sendo: localização do tumor (infiltração do complexo aréolo-mamilar), relação do tamanho do tumor com o volume da mama, mama de tamanho grande e história de doenças de colágeno. (FISHER et al., 1993), (VERONESI et al., 1993)

As cirurgias conservadoras devem ser sempre seguidas de radioterapia adjuvante e de biópsia do linfonodo sentinela (BLNS) e/ou linfadenectomia axilar. (SOLIN et al., 1996), (SCHWARTZ et al., 2000) A linfadenectomia é o fator indicador de prognóstico mais importante, pois realiza a excisão do linfonodo sentinela (LNS) fornecendo assim algumas vantagens terapêuticas. A informação prognóstica contribui para o planejamento do tratamento sistêmico e a excisão de doença linfonodal foi demonstrada como fator preventivo de recorrência local. Em pacientes com câncer de mama em estádio inicial, a BLNS demonstrou ser um método eficaz para predição de metástases em linfonodos axilares, sendo o procedimento atual realizado em pacientes com axila clinicamente negativa. (VERONESI et al., 2006) 
A mastectomia, cirurgia não conservadora, proposta por Halsted em 1884, consistia na remoção em bloco de toda a mama e ampla excisão de pele sobrejacente, na dissecção completa da axila e ressecção do músculo peitoral maior e menor. (HALSTED, 1894) Na década de 90, questionou-se a prática pela remoção do músculo peitoral maior, particularmente quando este não se encontrava envolvido pelo tumor. Com isso propôs um procedimento que preservava o músculo peitoral maior. (PATEY e DYSON, 1948) Hoje a mastectomia radical modificada foi substituída pela mastectomia total com o mapeamento do LNS em pacientes sem metástases axilares, através da BLNS. Também há a Mastectomia simples ou total que consiste na retirada da glândula mamária com a pele e complexo aréolopapilar e a mastectomia subcutânea que consiste na retirada de apenas a glândula mamária. (GERBER et al., 2003), (SACCHINI et al., 2003)

$\mathrm{Na}$ radioterapia é utilizada radiação de alta energia para destruir as células cancerosas e sua capacidade de multiplicação. Após a cirurgia conservadora é necessário realizar a radioterapia em toda a mama dos pacientes que foram submetidos a essa cirurgia, independente do tipo histológico, idade, uso de quimioterapia e/ou hormonioterapia e mesmo com margens cirúrgicas livres de comprometimento. O uso de radioterapia em pacientes pósmastectomia tem sido indicado com a presença de apenas um fator considerado consensual. (SOLIN et al., 1996), (SCHWARTZ et al., 2000), (FISHER et al., 1997)

Alguns estudos têm demonstrado que a adição de radioterapia ao tratamento local não somente reduz as taxas de recorrência loco-regional como também aumentam a sobrevida global, tanto para mulheres na pré como na pós-menopausa. (OVERGAARD et al., 1999), (RAGAZ et al., 2005).

\subsubsection{Tratamento Sistêmico}

O tratamento sistêmico é composto de dois tipos de terapia, são elas: hormonioterapia e quimioterapia. A hormonioterapia adjuvante é empregada em todos os pacientes que possuem receptores hormonais positivos, tais como receptores de estrógeno e receptores de progesterona. São administrados medicamentos antiestrogênicos para bloquear os efeitos hormonais que promovem o crescimento tumoral. (FISHER et al., 1997)

$\mathrm{Na}$ quimioterapia é realizado o uso de medicamentos para danificar ou matar as células cancerosas. Essa terapia é recomendada na presença e na ausência de doença metastática, nos pacientes com linfonodos positivos e nos com linfonodos negativos com 
tumores maiores de $1 \mathrm{~cm}$, e ainda, deve ser considerada em pacientes com menos de 40 anos. (BONADONNA et al., 1998)

A terapia-alvo utiliza medicamentos ou outras substâncias com alvo molecular específico, capazes de inibir ou ativar caminhos que resultam na morte celular (apoptose) e proporcionando, em ultima análise, um grande benefício terapêutico para o paciente com menor toxicidade. Em exemplo de terapia alvo é o trastuzumabe utilizado em paciente com CA de mama metastático com hiperexpressão de HER2 (receptor de fator de crescimento epideérmico humano 2). O trastuzumabe é um anticorpo monoclonal humanizado de administração venosa que se liga a porção justa-membrana do domínio extracelular do receptor HER2 impedindo a ativação da tirosina quinase (TK) intracelular. (BUZDAR, 2003), (PEGRAM et al., 2005), (SLAMON et al., 1989)

\subsection{Sistema Linfático}

O sistema linfático possui sua origem embrionária no mesoderma, em que se desenvolve juntamente com os vasos sanguíneos. Na vida intra-uterina, podem surgir algumas modificações no desenvolvimento embrionário. Estas modificações constituem características morfológicas pessoais, que variam entre os indivíduos. (GARRIDO, 2000)

O sistema linfático representa uma via acessória da circulação sanguínea, permitindo que os líquidos dos espaços intersticiais possam fluir para o sangue sob a forma de linfa. (SCHAUER et al., 2005) Possui três funções primárias, são elas: 1.Drenagem do excesso de líquido intersticial. A maioria dos componentes do plasma sanguíneo é filtrado pelas paredes dos vasos capilares sanguíneos para formar o líquido intersticial (liquido presente no espaço, interstício, entre as células dos tecidos corporais, derivado da filtração e da difusão pelos capilares). Depois de passar para os vasos linfáticos, o líquido intersticial é denominado de linfa (lympha = líquido claro). Tais fluídos são quimicamente similares ao plasma sanguíneo, a principal diferença é que o líquido intersticial e a linfa possuem menos proteínas que o plasma sanguíneo. Isso ocorre devido que a maioria das moléculas protéicas do plasma é muito grande para serem filtradas pela parede do vaso capilar. Com isso, os vasos linfáticos transportam para fora dos espaços teciduais às proteínas e grandes partículas que não podem ser removidas por absorção direta dos capilares sanguíneos. Este retorno da proteína para o sangue, dos espaços intersticiais, é essencial para manter o volume sanguíneo normal. 2. 
Transporte de lipídeos alimentares, em que os vasos linfáticos transportam os lipídeos e as vitaminas lipossolúveis (A, D, E, K) absorvidos pelo trato gastrointestinal ao sangue. 3 . Realização das respostas imunes, em que o tecido linfático inicia as respostas específicas contra células anormais. (TORTORA e GRABOWSKI, 2006) (GUYTON e HALL, 2006)

\subsubsection{Circulação da Linfa}

Os vasos linfáticos iniciam-se como capilares linfáticos (vasos minúsculos fechados em uma das extremidades) localizados nos espaços intercelulares (Figura 3). Os capilares linfáticos são maiores que os capilares sanguíneos e apresentam uma estrutura única que permite o fluxo do líquido intersticial para o seu interior, mas não o oposto. As células endoteliais que constituem a parede do capilar linfático se justapõem nas extremidades capilares. Nesta disposição, quando a pressão é maior no líquido intersticial do que na linfa, as células se separam através dos espaços entre as extremidades da parede do capilar linfático, fazendo com que o líquido intersticial entre no leito capilar. E quando ocorre o oposto, a pressão é maior no interior do capilar linfático, levando as células a se aderirem mais firmemente, impedindo que a linfa retorne para o espaço intersticial. (TORTORA e GRABOWSKI, 2006)

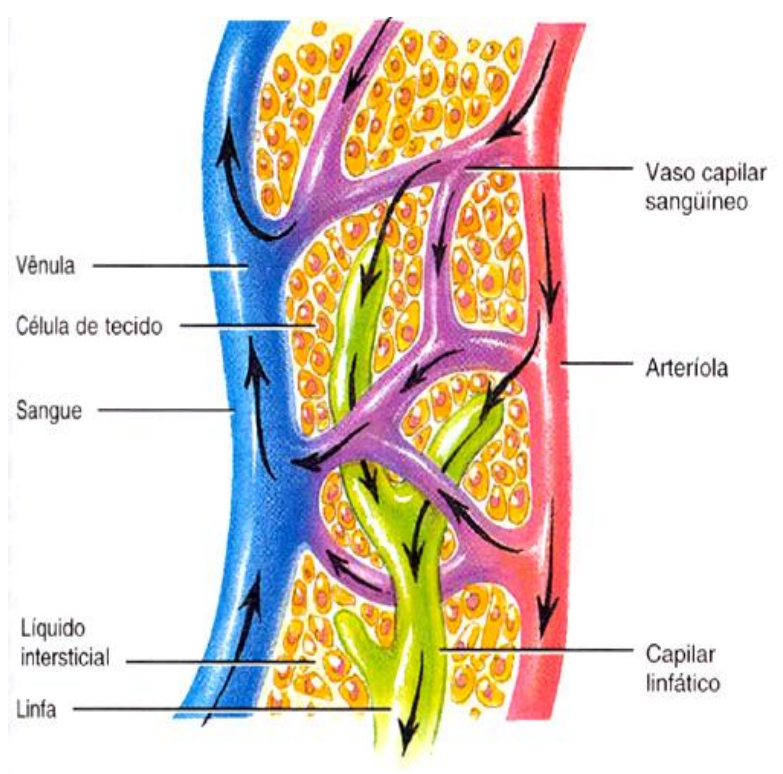

(a) Relação entre os capilares linfáticos e as células de tecidos e vasos capilares sangüineos

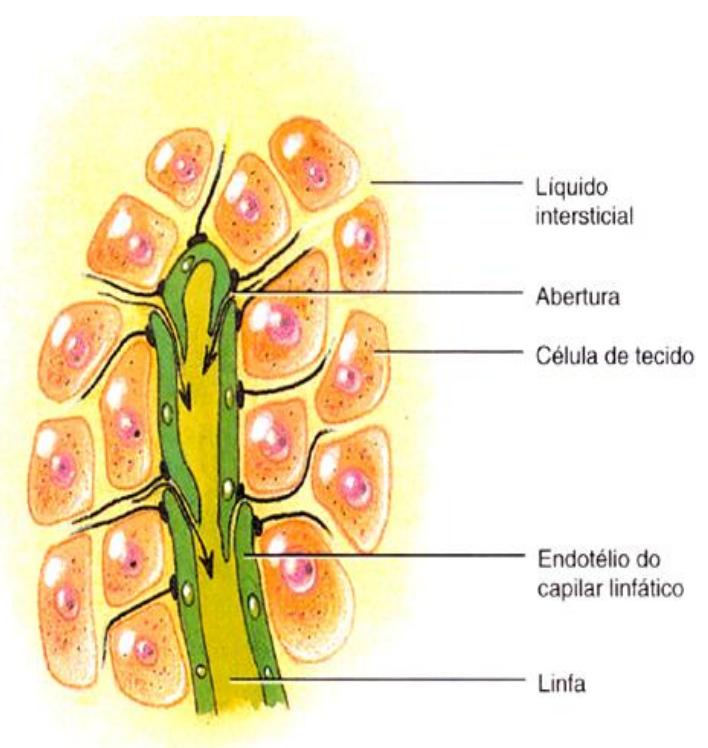

(b) Detalhes de um capilar linfático

Figura 3 - Capilares linfáticos. (TORTORA e GRABOWSKI, 2006) 
No momento em que os vasos capilares sanguíneos se ligam a dois vasos sanguíneos maiores, os capilares linfáticos iniciam-se nos tecidos e carregam a linfa que se forma em direção a um vaso linfático maior. Do mesmo modo que os capilares sanguíneos convergem para formar as vênulas e veias, os capilares linfáticos unem-se para formar os vasos linfáticos cada vez maiores. Estes por sua vez, assemelham-se estruturalmente às veias, possuem paredes mais finas e apresentam mais válvulas. (TORTORA e GRABOWSKI, 2006)

Ao longo dos vasos linfáticos encontram-se aproximadamente 600 linfonodos, estes por sua vez possuem forma de feijão. (Figura 4) Os linfonodos são distribuídos por todo corpo geralmente em grupos, encontram-se densamente concentrados junto às glândulas mamárias, nas axilas e nas virilhas. Cada linfonodo é coberto por uma cápsula de tecido conjuntivo denso. Em seu interior, as diferentes regiões do mesmo podem conter células B que se desenvolvem em células plasmáticas ou plasmócitos, bem como células $\mathrm{T}$, células dendríticas e macrófagos. A linfa é filtrada pelo linfonodo em que ela entra por um dos vasos linfáticos aferentes. À medida que a linfa flui através do linfonodo, as substâncias estranhas são capturadas por fibras reticulares situadas nos espaços intercelulares. Essas substâncias estranhas são destruídas pelos macrófagos por fagocitose e pelos linfócitos por respostas imunes, celular e humoral. A linfa filtrada deixa a outra extremidade do linfonodo por meio dos vasos linfáticos eferentes. Os plasmócitos e as células T que no interior do linfonodo se dividiram também podem deixar o linfonodo e circular para outras partes do corpo. As válvulas linfáticas direcionam o fluxo da linfa para dentro através dos vasos linfáticos aferentes, e para fora por meio dos vasos linfáticos eferentes. (TORTORA e GRABOWSKI, 2006) 


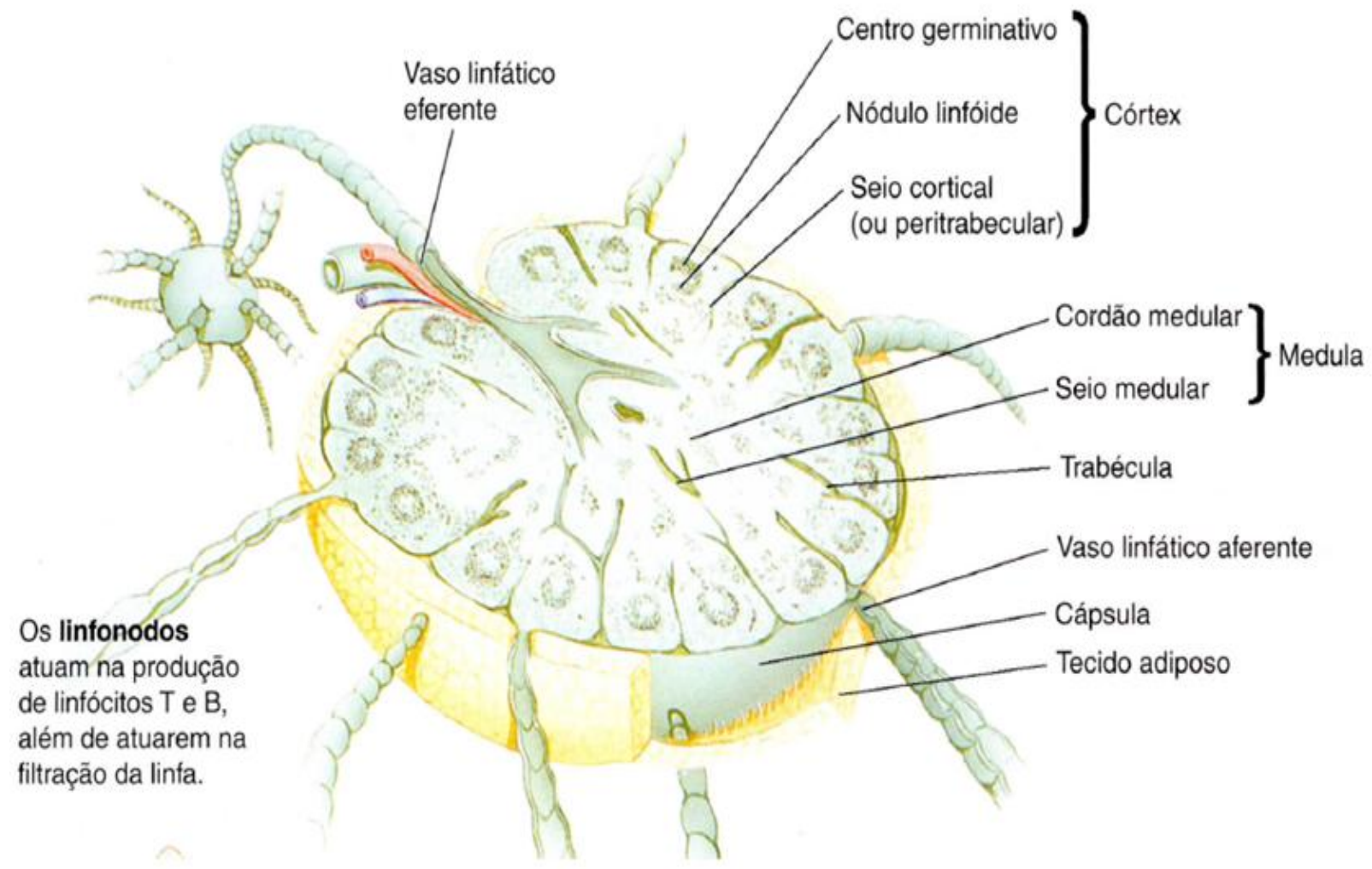

Figura 4 - Estrutura do Linfonodo Sentinela. (GARTNER e HIATT, 2007)

Dos vasos linfáticos, a linfa passa por um dos dois canais principais, são eles: o ducto torácico e o ducto linfático direito, podendo ser visualizada na Figura 5 toda a drenagem linfática da linfa. O ducto torácico é o principal ducto coletor de linfa, ele recebe a linfa do lado esquerdo da cabeça, pescoço, tórax, membro superior esquerdo e do campo inteiro abaixo das costelas. O ducto linfático direito drena a linfa do lado superior direito do corpo. Em fim, o ducto torácico esvazia-se de sua linfa na junção das veias jugular interna esquerda e subclávia esquerda, ao mesmo tempo o ducto linfático direito o faz na junção das veias jugular interna direita e subclávia direita. Assim a linfa drena de volta ao sangue. (TORTORA e GRABOWSKI, 2006) 


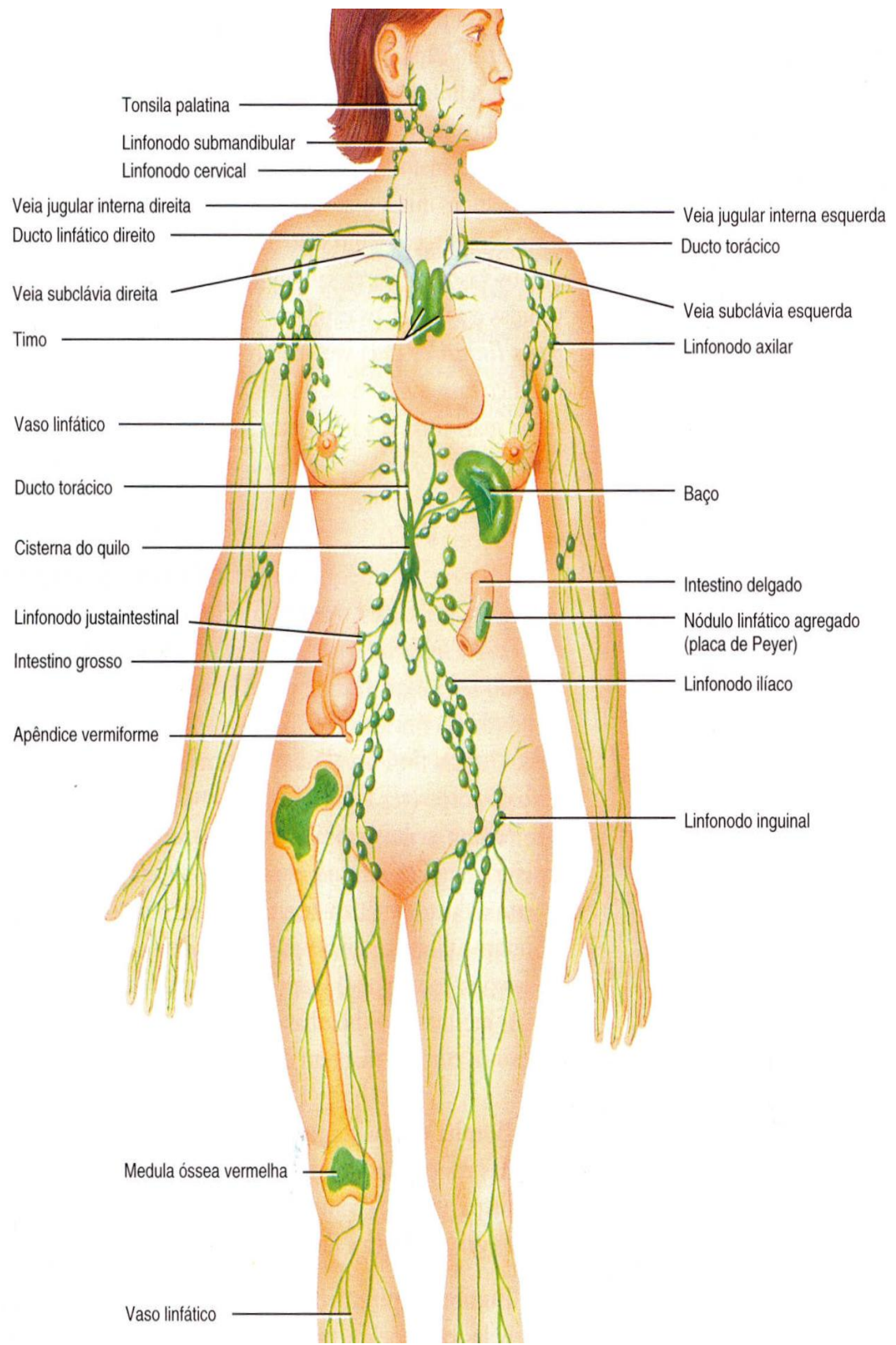

Figura 5 - Sistema Linfático. (TORTORA e GRABOWSKI, 2006) 


\subsubsection{Drenagem Linfática da Mama}

Os vasos linfáticos da mama são numerosos, tanto superficialmente, como no parênquima glandular. A mama é classificada com quatro plexos linfáticos, sendo: dois plexos linfáticos superficiais e dois plexos linfáticos profundos. Os plexos superficiais estão localizados no plexo cutâneo (derme) e no plexo subcutâneo (região subcutânea). Já os plexos profundos, um está localizado no plexo facial (fáscia do músculo peitoral maior) e o outro no plexo glandular (glândula mamária, incluindo os lóbulos e ductos mamários). O plexo glandular se comunica com a região do plexo subcutâneo por meio dos vasos linfáticos que acompanham os ductos lactíferos. O plexo subcutâneo, por sua vez, encontra-se abaixo da aréola mamária sendo denominado de plexo subareolar. O plexo facial se comunica com o plexo subcutâneo por meio dos vasos linfáticos ao longo dos fascículos fibrosos do estroma. (WILLIAMS et al., 1989), (ROMRELL e BLAND, 1998) Os vasos linfáticos da mama podem ainda se comunicar com o plexo linfático do fígado e o plexo subdiafragmático pelos vasos da parede abdominal. Há estudos que mostram que a densidade dos vasos linfáticos no plexo superficial é maior que a densidade do plexo profundo. (TANIS et al., 2001), (MACÉA e FREGNANI, 2006)

A drenagem do plexo superficial é realizada diretamente aos gânglios linfáticos axilares. O plexo profundo também realiza a drenagem para a axila, mas este pode inicialmente drenar os gânglios linfáticos intramamários e interpeitorais. A drenagem linfática da mama pode ocorrer nos gânglios linfáticos paraesternal, neste caso, tal drenagem é exclusiva para o plexo profundo. De modo casual, os vasos linfáticos podem acompanhar os feixes cutâneos dos vasos intercostais para a parte posterior dos linfonodos intercostais. Com isso a linfa continua para o ducto torácico. Os vasos linfáticos superficiais da mama continuam sua drenagem para os linfonodos cervicais (linfonodos supraclaviculares). (TANIS et al., 2001), (MACÉA e FREGNANI, 2006)

Há relatos que os linfonodos ao longo dos vasos torácicos internos recebem a linfa dos quadrantes mediais. Estudos antecedentes mostram que os gânglios linfáticos axilares e os gânglios linfáticos torácicos internos recebem a linfa de todos os quadrantes da mama devido à ampla rede linfática. Há predominância da drenagem para a axila, pois tal rota corresponde a mais de três quartos da drenagem linfática mamária. (ROMRELL e BLAND, 1998) 


\subsubsection{Linfonodos Axilares}

O principal local de metástases são os gânglios linfáticos axilares, sendo também o principal grupo de drenagem linfática da mama. Há cinco grupos de gânglios linfáticos axilares, são eles: 1. Linfonodos Anteriores (peitorais) - composto de três a cinco linfonodos localizados ao longo da parede medial da axila, em que recebem a linfa pela glândula mamária. 2. Linfonodos Posteriores (subscapular) - formado por seis a sete linfonodos localizados ao longo da margem da parede posterior axilar e região subscapular. Tais linfonodos recebem a linfa da parte posterior da parede torácica e região periscapular. 3 . Linfonodos Laterais - consiste de quatro a seis linfonodos localizados medialmente e posteriormente a veia axilar perto da parede lateral da axila. Estes linfonodos recebem parte da linfa proveniente do membro superior, exceto a linfa pelos vasos linfáticos que acompanham a veia cefálica. 4. Linfonodos Centrais - composto de três ou quatro linfonodos localizados profundamente em relação ao músculo peitoral menor perto da base axilar. Este grupo recebe a linfa dos linfonodos anteriores, posteriores e laterais drenando a linfa para os linfonodos apicais. 5. Linfonodos Apicais (subclavicular) - consiste em todos os gânglios linfáticos localizados no ápice axilar. Tais linfonodos recebem a linfa de todos os grupos axilares de gânglios linfáticos e também dos linfonodos que acompanham a parte distal da veia cefálica. (ROMRELL e BLAND, 1998), (MACÉA e FREGNANI, 2006)

Fisiologicamente, a linfa é drenada a partir dos gânglios linfáticos anteriores, passando pelos gânglios centrais e apicais, nos gânglios posteriores os fluídos linfáticos eferentes são drenados para os gânglios centrais e apicais. Os linfonodos laterais, como já mencionado, recebem grande quantidade de linfa proveniente do membro superior, apenas a linfa transportada pelos vasos linfáticos que acompanham a veia cefálica realiza sua drenagem diretamente para os gânglios centrais e depois para os gânglios linfáticos apicais. Neste ultimo, os vasos linfáticos eferentes provenientes dos gânglios apicais, se juntam formando o tronco subclávio que ao longo de seu percurso vão se unir ao tronco jugular (realiza a drenagem da linfa da cabeça e do pescoço) e ao tronco broncomediastinal (realiza a drenagem dos linfáticos da parede torácica e da víscera) para o término da realização do processo de drenagem da linfa no lado direito no ducto linfático direito e do lado esquerdo para o canal torácico. (ROMRELL e BLAND, 1998), (MACÉA e FREGNANI, 2006), (FREGNANI e MÁCEA, 2009)

Segundo a classificação TNM (UICC, 2009), os linfonodos axilares são classificados em três níveis, denominados de Níveis de Berg., são eles: Nível I - nível mais baixo ou 
exterior, gânglios linfáticos localizados lateralmente ou abaixo da margem inferior do músculo peitoral menor. Os linfonodos anteriores, posteriores e laterais estão inclusos neste nível. Nível II - linfonodos localizados profundamente em relação ao músculo peitoral menor. Neste nível estão presentes os linfonodos centrais e possivelmente, alguns gânglios linfáticos apicais. Nível III - linfonodos localizados medialmente ou superiormente a margem superior do músculo peitoral menor, sendo incluso os linfonodos apicais. (SOBIN, GOSPODAROWICZ e WITTEKIND, 2009), (BERG, 1955)

\subsubsection{Linfonodo Sentinela}

Linfonodo sentinela (LNS) é definido como qualquer linfonodo que recebe drenagem linfática diretamente do tumor primário. (COCHRAN et al., 2000)

Os primeiros relatos LNS foram mencionados em uma palestra realizada pelo patologista alemão Rudolf Virchow. E apenas na década de 20, Braithwaite, cirurgião inglês, foi o primeiro a mencionar o termo "sentinela" após estudar o sistema linfático, em que escreveu "glândulas sentinelas" para um conjunto de linfonodos que receberam drenagem de um determinado local. (THOMPSON e UREN, 2005) Muitos estudos posteriores foram conduzidos para validar a informação da drenagem para um LNS.

Em 1977, Cabanas descreveu o conceito fisiológico do LNS no estudo com câncer de pênis, concluindo que quando a BLNS fosse negativa para metástase, nenhuma complementação cirúrgica com o intuito de retirar os outros linfonodos seria necessária. (CABANAS, 1997)

O primeiro estudo que utilizou a linfocintolografia para identificar a cadeia linfonodal e o LNS intra-operatório extirpando-o e correlacionando-o com os restantes dos linfonodos foi de Morton et al. em 1992, em pacientes com melanoma cutâneo. Eles definiram o LNS como o primeiro a drenar diretamente um câncer específico, e por esta razão, o primeiro sítio a receber metástases se ocorrer disseminação linfática, tendo sido também apontado como fator prognóstico para os demais linfonodos da região. (MORTON et al., 1992), (FILHO e FILHO, 2002),(KRAG et al., 1993) Já no estudo de Nieweg et al. (2001), definem o LNS como o nódulo linfático mais próximo da lesão primária; entretanto, esta definição não leva em consideração a fisiologia e a variabilidade anatômica dos territórios de drenagem linfática. 
Em 1993, Krag et al. foram os primeiros a relatar a realização da BLNS usando um colóide radioativo em pacientes com CA de mama. E em 1994, Giuliano et al. descreveram a técnica com azul patente em 174 mulheres com CA de mama, demonstrando acurácia preditiva de $100 \%$ do LNS em relação ao estado linfonodal axilar. Desde então, muito estudos têm mostrado a viabilidade e precisão da BLNS em CA de mama, resultando sua prevalência como uma técnica para a determinação no estadiamento nodal para o CA de mama. (ALBERTINI et al., 1996), (GIULIANO et al., 1997), (GUENTHER, KRISHNAMOORTHY e TAN, 1997), (VERONESI et al., 1997)

\subsection{Linfocintilografia}

Com a possibilidade de disseminação de células tumorais através do sistema linfático para todo o organismo, acometendo os linfonodos regionais, é muito importante a localização dos linfonodos que realizam a drenagem de tais tumores, no caso, CA de mama. As pesquisas iniciais sobre o comprometimento linfonodal foram direcionadas para a identificação de linfonodos livres ou comprometidos.

$\mathrm{Na}$ década de 50, pela primeira vez, foi mostrado que a drenagem linfática era realizada da mama para a axila utilizando o corante azul vital. (TURNER-WARWICK, 1959)

A linfocintilografia (LCINT) foi descrita inicialmente por Sherman et al (1953). E em 1965, Graxon, et al. descobriram o primeiro colóide ligado ao nucleotídeo tecnécio $\left({ }^{99 \mathrm{~m}} \mathrm{Tc}\right)$, iniciando a possibilidade da realização do exame de linfocintolografia.(KESHTGAR et al., 2000) A técnica envolve injeção intradérmica de radiofármacos ao longo de 2 a 3 horas e em seguida observar sua drenagem pelos canais linfáticos até chegarem aos linfonodos. Radiopartículas com diâmetro entre 5 e 50nm são consideradas ideais para conseguirem penetrar ao longo das paredes dos capilares linfáticos, além da realização de massagem local e reforça essa penetração. A linfocintolografia era usada inicialmente apenas para estudar a fisiologia da drenagem linfática dos membros inferiores e diagnosticar a presença de linfedema. (KESHTGAR et al., 2000), (SHERMAN, TER-PROGOSSIAN e TOCUS, 1953)

Foi quando, na década de oitenta, o exame de linfocintolografia surgiu como um método para identificar a cadeia de nódulos linfáticos nos territórios de drenagem dos sítios de injeção de colóides marcados com o radioisótopo Tecnécio-99m $\left({ }^{99 \mathrm{~m}} \mathrm{Tc}\right.$ ). (XAVIER et al., 2002) 
Com o exame de LCINT foi possível realizar BLNS, aqueles supostamente contendo metástases em pacientes com melanoma, CA mama, câncer de pênis, câncer de tireóide, entre outros. (VALDOS OLMOS et al., 1999) E com essa técnica foi possível diminuir a morbidade relacionada às extensas linfadenectomias, uma vez que esvaziamentos desnecessários foram evitados ao se demonstrar a não infiltração dos LNS, principalmente em CA de mama e melanoma. (NIEWEG e ESTOURE, 2004a)

A técnica da LCINT é comumente realizada no período pré-operatório, sendo uma técnica simples e de fácil execução. Ela é realizada através de injeções intradérmicas na região da biópsia ou da aréola mamária, de pequenos volumes de uma solução contendo o Ácido Fítico (ou Fitato), marcado com o radioisótopo ${ }^{99 \mathrm{~m}}$ Tecnécio (Fitato- ${ }^{99 \mathrm{~m}} \mathrm{Tc}$ ). (MARIANI et al., 1998), (NIEWEG, TANIS e KROON, 2001), (NOGUCHI et al., 1999) Logo após a aplicação, o radiofármaco começa a ser transportado por via linfática, sendo captado pelos linfonodos. Em seguida, o LNS é identificado e demarcado na pele com canetas dermográficas, em 3 projeções (anterior, oblíqua e lateral), o que adicionalmente auxilia na abordagem cirúrgica subsequente. (KRYNYCKYI et al., 2004)

Os melhores resultados quanto à localização do LNS são obtidos ao se associar a LCINT com a utilização intra-operatória da Sonda Gama. Este equipamento foi originalmente criado para auxiliar cirurgiões na localização de tecidos tumorais no cérebro através da detecção de radioatividade captada pelo aparelho na região de neoplasia. (MARIANI et al., 1998) Esta técnica foi posteriormente nomeada por outros autores como cirurgias radioguiadas e introduzida na prática clínica já em 1985 para a detecção de tumores coloretais. (MARIANI et al., 1998)

Veronesi, et al. (1997) testaram o uso da LCINT e da cirurgia radioguiada com a Sonda Gama na BLNS em 163 pacientes com CA de mama. A taxa de identificação do LNS foi de $98 \%$, com 97,5\% de concordância entre o status do LNS e o status do restante da cadeia axilar. Em pacientes com tumores menores que 1,5 cm, o LNS foi capaz de predizer o status axilar com $100 \%$ de acurácia. Os autores deste estudo concluíram que BLNS, através do uso de radiocolóides e da Sonda Gama, é capaz de predizer o status axilar com alta acurácia, permitindo poupar mulheres com LNS negativo da linfadenectomia axilar e suas potenciais complicações, devendo ser prontamente aplicada em pacientes com tumores menores que 1,5 $\mathrm{cm}$. Concluíram também que o risco de falso negativo é baixo, podendo ser minimizado evitando-se utilizar a técnica em tumores multifocais.

No CA de mama, a utilização intra-operatória da Sonda Gama tem se mostrado eficiente em detectar todos LNS demonstrados na LCINT precedente. (KRYNYCKYI et al., 
2004) A eficácia da Sonda Gama, utilizada isoladamente no rastreamento intra-operatório do LNS, tem sido defendida por outros autores. (MARIANI et al., 1998) Portanto, a associação das duas técnicas, LCINT e Sonda Gama, têm evidenciado uma elevada acurácia na localização do LNS. A utilização conjunta das duas técnicas possui grande relevância clínicocirúrgica devido às evidências de disseminação de micrometástases linfáticas para os LNS, onde a sua remoção cirúrgica pode implicar em importante fator prognóstico para estes pacientes, por se tratar de um procedimento de fácil execução, requerendo menor remoção tecidual e permitindo o controle da atividade de base para mapeamento completo do CA de mama. (MARIANI et al., 1998)

Diante das contribuições do uso combinado das três técnicas localizatórias dos LNS no CA de mama e a sua contribuição dentro de um contexto cirúrgico e de prognóstico terapêutico em longo prazo tornam-se importante conhecer as contribuições destes métodos em um conjunto de pacientes com diferentes padrões de drenagem linfática. Ademais, pontuamos a necessidade de conhecermos as diferentes contribuições de cada uma destas técnicas, frente às topografias nas quais o CA de mama se localizam. No Hospital das Clínicas da Faculdade de Medicina de Ribeirão Preto da Universidade de São Paulo (HC-FMRP-USP), a linfocintolografia tem sido uma técnica diagnóstica crescentemente solicitada e inserida em um contexto de pesquisa clínica e tecnológica. Com isto, surge a necessidade premente de se realizar uma revisão da literatura científica e determinar no HC-FMRP-USP, a contribuição desta técnica diagnóstica na avaliação dos padrões de drenagem linfática em pacientes com CA de Mama.

\subsubsection{Radiofármacos Utilizados na Técnica de Linfocintilografia}

Para a realização da técnica de LCINT é necessário a utilização de um radiofármaco, este por sua vez, é determinado de acordo com a disponibilidade limitada de dificuldades técnicas no preparo. (ZIESSMAN, O’MALLEY e THRALL, 2006)

$\mathrm{Na}$ literatura, muitos protocolos têm sido utilizados com discretas diferenças quanto à atividade radioativa empregada, volume de injeção, número de injeções e tecido alvo injetado (subcutâneo, intratumoral e peritumoral). (HUNG et al., 2005), (SUN et al., 2010), (VIDALSCART et al., 2010)

A absorção do radiofármaco pelos linfonodos ocorre através do mecanismo de fagocitose. Segundo Uren e colaboradores (2003) considera-se ideal o uso de partículas com 
diâmetro entre 5 e $50 \mathrm{~nm}$. Partículas menores que $100 \mathrm{~nm}$ são ideais para ocorrer à dispersão do local da injeção para os canais linfáticos e linfonodos. (WILHELM, MIJNHOUT e FRANSSEN, 1999) Já as partículas de maior diâmetro apresentam uma dificuldade na movimentação através dos vasos linfáticos, enquanto que partículas de menor diâmetro não sofrem fagocitose e transitam rapidamente do LNS para linfonodos secundários. A maior parte da dose injetada permanece no local da injeção e apenas $0,5 \%$ da dose alcançam o LNS. (CZERNIECKI et al., 2001)

Em relação à dosagem do radiofármaco, é recomendado uma dose de 37 a 80 MBq para a visualização do LNS em CA de mama, quando administrado por via intradérmica, subcutânea, subareolar e periareolar. Já a visualização dos canais linfáticos é considerado a utilização de 60 a 80 MBq. Esta dosagem também é preferida quando a técnica de LCINT é realizada um dia antes da cirurgia. E para administração intratumoral é considerado uma dose de 60 a 100 MBq do radiofármaco. (BYRD et al., 2001)

A detecção do LNS ocorre devido ao radiofármaco, em que o colóide é ligado, este ultimo, possibilita que a radioatividade seja detectada pela câmara cintilográfica. (CZERNIECKI et al., 2001)

Entre os radiofármacos mais empregados estão os nanocolóides de albumina usados na Austrália e Europa e o enxofre coloidal modificado e filtrado nos Estados Unidos. No Brasil, em virtude da sua limitada disponibilidade e dificuldades técnicas no preparo do enxofre coloidal, os radiofármacos mais empregados são o Dextrano e o Fitato - ${ }^{99 m}$ Tc. (ZIESSMAN, O’MALLEY e THRALL, 2006)

O Fitato- ${ }^{99 \mathrm{~m}} \mathrm{Tc}$ tornou-se uma alternativa para detecção do LNS, devido à similaridade na distribuição do fitato e dos nanocolóides. (ZIESSMAN, O’MALLEY e THRALL, 2006)

\subsubsection{Biópsia do Linfonodo Sentinela}

A biópsia do LNS (BLNS) é importante como um método de amostragem seletiva, minimamente invasivo e altamente sensível na identificação de metástases, por isto, é um procedimento importante a ser realizado em pacientes com CA de Mama. (ROSS, 1997)

As indicações para a realização da BLNS são: axila clinicamente negativa, tumores primários e menores que $3 \mathrm{~cm}, \mathrm{CA}$ invasivo de mama e CA de mama operável. Se o exame revelar ausência de metástase no LNS considera-se que os demais linfonodos em sua base de 
drenagem são negativos para envolvimento metastático. Por outro lado a presença de metástase no LNS é indicação de esvaziamento axilar. (SHWARTZ et al., 2002), (URBAN et al., 2002)

Na tomada de decisão cirúrgica quanto ao CA de mama, a importância de se biopsiar os LNS deve-se ao fato de o estadiamento patológico da axila possuir valor prognóstico quanto à sobrevida, trazendo informações que influenciam nas decisões terapêuticas adjuvantes imediatas e aumentando a chance de cura clínica. (KRAG et al., 1993) 


\section{OBJETIVOS:}

\subsection{Objetivos Gerais:}

Descrever os padrões de drenagem linfática em pacientes operados por CA de Mama e avaliar a contribuição da LCINT na localização dos LNS nesta modalidade de cirurgia oncológica.

\subsection{Objetivos Específicos:}

2.2.1. Descrever as características clínicas e demográficas de pacientes com CA de mama.

2.2.2. Caracterizar e descrever os padrões de drenagem linfática habituais nessa casuística;

2.2.3. Descrever os achados cirúrgicos e anatomopatológicos, bem como as alterações encontradas nos LNS submetidos à BLNS, quanto à presença ou não de infiltração metastática em relação à axila negativa;

2.2.4. A depender dos territórios de drenagem linfática atingidos pela neoplasia, observar se há diferenças na contribuição localizatória dos LNS entre os métodos de LCINT e Azul Patente.

2.2.5. Protocolar, otimizar e aperfeiçoar a técnica de LCINT de pacientes com CA de mama, realizada na Seção de Medicina Nuclear do HC-FMRP- USP. 


\section{PACIENTES E MÉTODOS}

\subsection{Comitê de Ética}

Este projeto de pesquisa foi aprovado pelo Comitê de Ética em Pesquisa (CEP) do HC-FMRP-USP. PROCESSO HCRP: 10373/2010. Os pacientes foram convidados a assinar o Termo de Consentimento Livre e Esclarecido (TCLE) quanto ao uso das informações contidas nos seus prontuários médicos, e quanto à permissão para registro fotográfico apenas das áreas relacionadas às suas lesões mamárias, respeitando as suas privacidades através do anonimato. (ANEXO A)

\subsection{Desenho do Estudo}

Estudo prospectivo observacional, descritivo, não controlado, que avaliou os achados da LCINT em uma amostra de pacientes com CA de Mama.

\subsection{Casuística}

Foram incluídos 70 pacientes sequenciais da rotina clínica com CA de Mama, procedentes do Ambulatório de Mastologia do HC-FMRP-USP, onde os procedimentos cirúrgicos foram indicados e o acompanhamento pós-operatório realizado.

Por indicação clínica, os pacientes foram submetidos à realização do exame de LCINT na Seção de Medicina Nuclear. As imagens deste exame foram exibidas no Centro Cirúrgico e a sua contribuição foi contextualizada durante o ato cirúrgico, no sentido de documentar o auxílio do exame na localização do LNS.

Os pacientes foram encaminhados para a BLNS radioguiada, associada ou não a ampliação das margens cirúrgicas e esvaziamento da cadeia linfática. 


\subsubsection{Critérios de Inclusão}

Foram incluídos os pacientes com CA de Mama nos estádios I e II, com axila clinicamente negativa, com diagnóstico histopatológico de carcinoma e submetidos à biopsia do LNS. Estes pacientes procedentes do Ambulatório de Mastologia do HC-FMRP-USP, e por indicação clínica, submetidos ao exame de LCINT.

\subsubsection{Critérios de Exclusão}

Foram excluídos todos os pacientes com CA de mama que já houvessem sido submetidos à LCINT previamente e que já tenham realizado cirurgia de mama e linfadenectomia axilar. Isto é, excluímos pacientes cujo leito de avaliação de drenagem linfática já tenha sido abordado cirurgicamente e, portanto, poderia apresentar alterações anatômicas que afetariam a técnica da LCINT.

\subsection{Avaliação Clínica e Demográfica}

As variáveis levantadas foram:

- Sexo (feminino e masculino);

- Idade;

- Tamanho do tumor $(\mathrm{T} 1 \leq 2 \mathrm{~cm}, \mathrm{~T} 2>2$ até $5 \mathrm{~cm}$ e T3 $>5 \mathrm{~cm})$;

- Localização do tumor (QSE - Quadrante Superior Externo; QIE - Quadrante Inferior Externo; QSI - Quadrante Superior Interno; QII - Quadrante Inferior Interno; CENTRAL - Quadrante Central, 2Q - Dois Quadrantes);

- Tipo histológico (CDI, CDIS, CLI, outros);

- Grau histológico (grau I, grau II, grau III);

- Procedimento Cirúrgico (cirurgia conservadora ou radical) 


\subsection{Avaliação Linfocintilográfica}

\subsubsection{Método Pré-operatório: Linfocintilografia (LCINT)}

Todos os pacientes foram submetidos à LCINT pré-operatória na Seção de Medicina Nuclear do HC-FMRP-USP. O exame foi realizado aproximadamente de 3 horas antes do procedimento cirúrgico de remoção do(s) possível(is) LNS/LNNS evidenciado(s) pelas imagens. Utilizou-se uma câmara cintilográfica (gama-câmara) modelo Siemens Orbiter (Siemens Medical Systems, IL, EUA).

O exame de LCINT consistiu na aplicação de 4 injeções intradérmicas, contendo 1,0 $\mathrm{mCi}$ de atividade do radiofármaco FITATO- ${ }^{99 \mathrm{~m}} \mathrm{Tc}$ (fármaco: Fitato, produzido pelo IPEN/CNEN, marcado com aproximadamente 20mCi de atividade do radioisótopo Tecnécio$\left.99 \mathrm{~m}\left({ }^{99 \mathrm{~m}} \mathrm{Tc}\right)\right)$. Este radiofármaco foi administrado em quatro pontos cardeais distantes $1 \mathrm{~cm} \mathrm{da}$ borda da aréola mamária ou da cicatriz pós-operatória da mama quando o paciente já foi submetido a procedimentos cirúrgicos.

Aconselhou os pacientes à realização de massagem efetiva por aproximadamente 2 minutos sobre os pontos de injeção, para estimular a migração e o transporte linfático das partículas de radiocolóides.

A aquisição das imagens foi obtida aproximadamente 60 minutos após a aplicação das injeções intradérmicas na mama, em que o radiofármaco foi drenado por via linfática sendo captado pelos LNS e possivelmente por outros LN subseqüentes, LNNS.

Com a localização do LNS através do detector da Gama - Câmara, a projeção do mesmo foi demarcada na pele, nas incidências anterior $\left(0^{\circ}\right)$, oblíqua $\left(45^{\circ}\right)$ e lateral $\left(90^{\circ}\right)$. Cada projeção foi realizada com 600.000 contagens/projeção.

Pequenas máscaras de chumbo foram colocadas sobre os sítios de injeção do radiofármaco, para a vizualização de apenas os canais linfáticos e os respectivos LNS e LNNS fossem documentados nas imagens de LCINT.

A projeção cutânea dos linfonodos captados foi demarcada na pele ("X") com auxílio de uma caneta dermográfica, nas 3 incidências e usada como referência para posterior incisão cirúrgica.

Após a demarcação na pele, utilizou-se um Fantoma (Flood), trata-se de uma placa acrílica preenchida com ${ }^{99 \mathrm{~m}} \mathrm{Tc}$ para gerar imagens de fundo, posteriores aos pacientes, 
facilitando a visualização da silhueta dos pacientes e a localização dos linfonodos que captaram o radiofármaco.

O exame de LCINT foi acompanhado por um médico nuclear para identificação imediata e correta da primeira captação focal distinta da imagem injetada.

Todos os dados obtidos com a realização a LCINT foram documentados em formulários e arquivados no banco de dados da pesquisa.

As imagens linfocintilográficas foram exportadas como imagens DICOM 3.0 pela Workstation VISION 2 (General Eletric, EUA) para o Servidor Clínico MEDNUCLEAR da Seção de Medicina Nuclear do HC-FMRP-USP. A partir deste servidor, as LCINT foram exibidas ao médico nuclear e aos cirurgiões no centro cirúrgico via rede PACS (Picture Archiving and Communication System), utilizando-se um Software Livre denominado KPACS (http://www.k-pacs.net).

De posse das imagens localizatórias do LNS/LNNS feitas pela LCINT, dos dados clínicos do prontuário do paciente, do uso do corante azul patente injetado pelo cirurgião e do uso adicional da Sonda Gama, os cirurgiões foram informados com precisão sobre a provável localização do LNS, o qual deverá ser biopsiado.

\subsubsection{Caracterização dos Padrões de Drenagem Linfática}

Foram avaliadas as LCINT realizadas na Seção de Medicina Nuclear, descrevendo os respectivos padrões de drenagem linfática desenvolvidos, assim como a quantidade de LNS/LNNS envolvidos e ainda foi realizada uma comparação com a literatura destes dados. Os exames de LCINT e, ulteriormente, o rastreamento por Sonda Gama dentro do centro cirúrgico foram realizados rotineiramente por indicação clínico-cirúrgica.

\subsection{Abordagem Cirúrgica e Patológica}

\subsubsection{Cirurgia para Retirada do Linfonodo Sentinela}

As respectivas cirurgias para retirada dos LNS/LNNS acometidos foram realizadas no centro cirúrgico do HC-FMRP-USP, com a equipe de cirurgiões mastologistas. Todos os 
pacientes foram submetidos à anestesia geral. Os cirurgiões utilizaram em alguns pacientes o corante azul patente, injetado 20 minutos antes da excisão dos LNS. Utilizou-se a sonda gama durante o procedimento intra-operatório, para a localização e retirada dos LNS/LNNS. Entretanto, estes resultados sobre a eficácia da utilização da sonda gama não foram avaliados especificamente neste estudo, por tratar-se de projeto futuro de investigação. Os LNS/LNNS encontrados e retirados foram enviados para exame anatomopatológico.

\subsubsection{Avaliação dos Exames Anatomopatológicos}

Para avaliar a presença ou ausência de invasão metastática nos LNS retirados, foram consultados os prontuários dos pacientes através do Módulo ATHOS, pertencente ao Sistema HC-FMRP-USP, uma rede intranet que disponibiliza as informações, laudos e resultados de exames realizados nos pacientes. Os LNS/LNNS foram avaliados pelo Serviço de Patologia (SERPAT) do HC-FMRP-USP, segundo protocolo local.

\subsection{Método Estatístico}

Por se tratar de um estudo prospectivo observacional, o qual se constituirá como base para futuros estudos, não se realizou, para o propósito atual, testes de hipóteses.

A partir dos dados ora apresentados e discutidos, novos estudos deverão contemplar investigações específicas e apropriadamente delineadas.

\subsection{Levantamento Bibliográfico}

Foi realizado o levantamento bibliográfico na literatura nacional e em inglês utilizando os Descritores em Ciências da Saúde (DeCS - Biblioteca Virtual da saúde - BVS - BIREME. htpp://decs.bvs.br/). 


\section{RESULTADOS}

\subsection{Características Clínicas e Demográficas}

Foram avaliados prospectivamente e através do exame de LCINT, 70 pacientes com CA de mama, no período de março de 2009 a agosto de 2011. Todos os pacientes são do sexo feminino (100\%). As características demográficas e clínicas de todos os pacientes podem ser visualizadas na Tabela 6 e Tabela 9.

A idade dos pacientes variou de 28 a 77 anos, com média de 54 anos e desvio padrão (DP) de +/- 12,94 anos.

O tamanho do tumor de CA de mama dos pacientes variou de 0,2 a $3,5 \mathrm{~cm}$ em seu maior diâmetro, com média de 1,46 cm e DP de $+/-2,35 \mathrm{~cm}$. A maioria dos Pacientes apresentou T1 em 57 (81,5\%) pacientes, T2 em 12 (17\%) pacientes (Pacientes 14, 15, 23, 24, 30, 38, 53, 59, 61, 65, 66, 69) e T3 em apenas 1 (1,5\%) paciente (Paciente 54).

Segundo a classificação da Organização Mundial da Saúde de 2002 sobre os tipos histológicos de CA de mama, 45 (64,4\%) pacientes apresentaram Carcinoma Ductal invasivo (CDI), 16 (22,8\%) com Carcinoma Ductal in situ (CDIS), 2 (2,8\%) com Carcinoma Lobular Invasivo (CLI) e 7 (10\%) com os demais tipos histológicos (Carcinoma Tubulo-Lobular Invasivo; Carcinoma Micropapilar Invasivo, Adenocarcinoma Mucinoso, Carcinoma Mucinoso, Carcinoma Misto Ductal/Lobular invasivo Multicentrico, Carcinoma Medular Atipico e Carcinoma Invasivo Misto Ductal). (Figura 6)

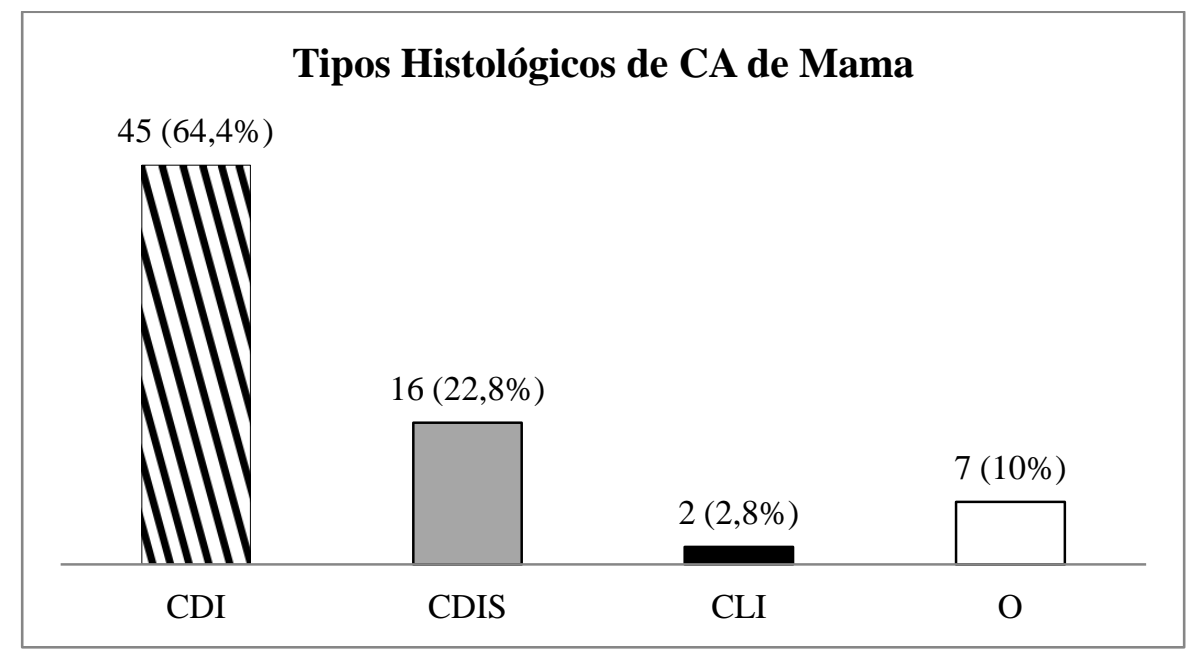

Figura 6 - Tipos Histológicos de CA de Mama encontrados nos pacientes submetidas ao estudo. 
Segundo o grau histológico proposto pela classificação de Scarff-Bloom-Richardson e modificado por Elston-Ellis, 18 (25.7\%) pacientes apresentaram grau I, 34 (48.6\%) grau II e $18(25.7 \%)$ grau III. (Figura 7$)$

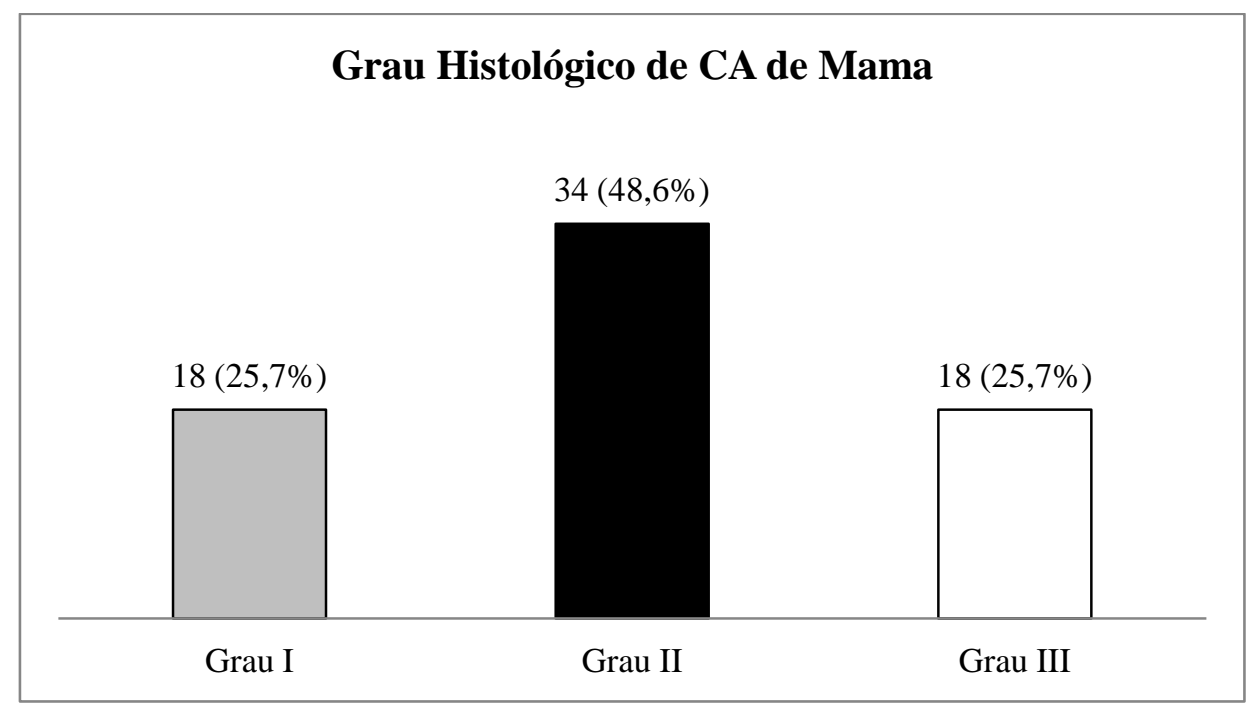

Figura 7 - Grau Histológico do CA de Mama encontrado nos pacientes submetidas ao estudo.

Quanto aos procedimentos cirúrgicos abordados nos pacientes com CA de mama, 44 (62.8\%) dos pacientes submeteram-se a cirurgias conservadoras (Quadrantectomia e Tumorectomia) e 26 (37,2\%) cirurgia radical (Mastectomia Radical Modificada). (Figura 8)

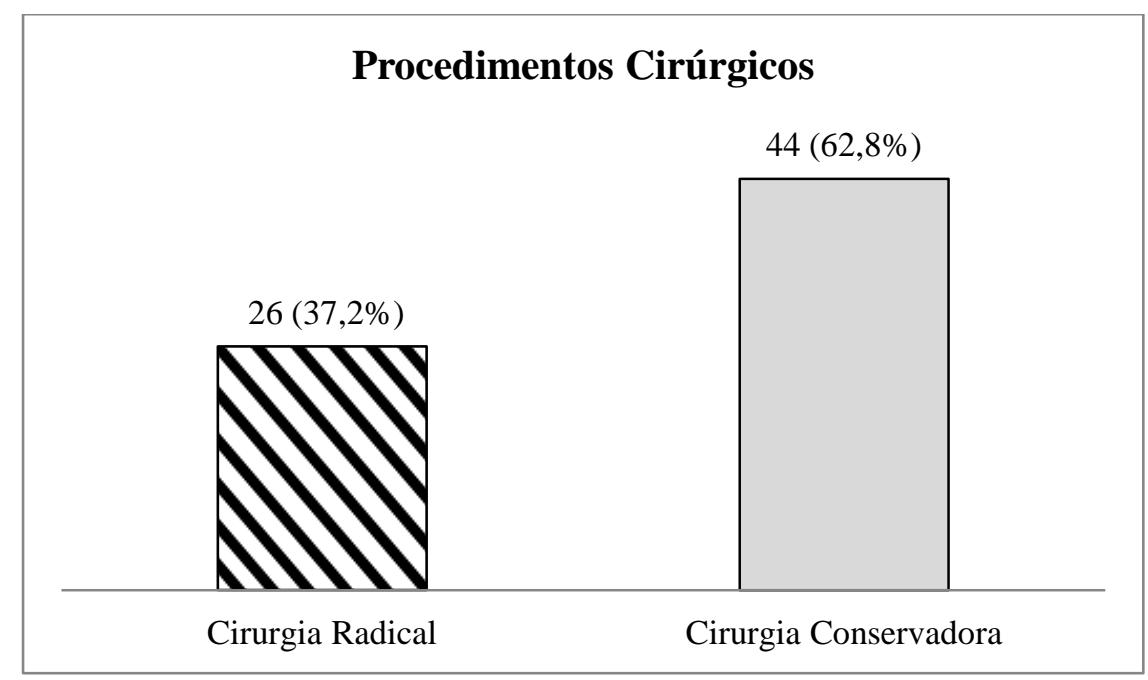

Figura 8 - Procedimentos Cirúrgicos realizados nos pacientes com CA de mama. 
Quanto à localização do tumor primário, em 37 (52.8\%) paciente a lesão se encontrava no quadrante superior externo (QSE), 7 (10\%) no quadrante inferior externo (QIE), 5 (7.2\%) no quadrante superior interno (QSI), 5 (7.2\%) no quadrante inferior interno (QII), $10(14.4 \%)$ no quadrante central (QC) e em 6 (8.4\%) pacientes o tumor se encontrava em dois quadrantes (2Q), sendo nos quadrantes externos, nos quadrantes internos ou nos quadrantes superiores. (Figura 9)

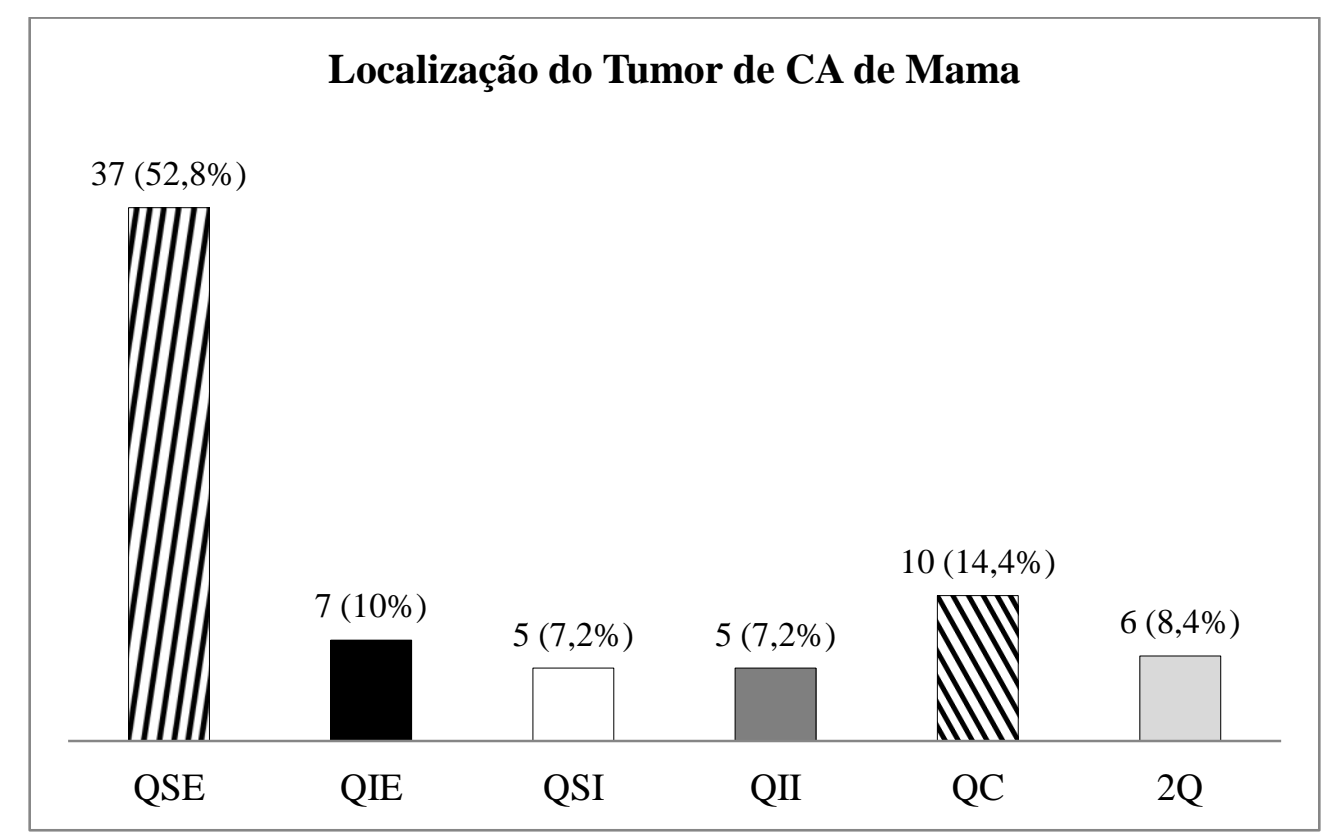

Legenda: QSE - Quadrante Superior Externo; QIE - Quadrante Inferior Externo; QSI - Quadrante Superior Interno; QII - Quadrante Inferior Interno; QC Quadrante Central; 2 Q - Dois Quadrantes.

Figura 9 - Localização do Tumor de CA de Mama nos pacientes submetidos ao estudo.

Tabela 6 - Características Demográficas e Clínicas.

\begin{tabular}{lccccccl}
\hline Paciente & Sexo & $\begin{array}{c}\text { Idade } \\
\text { (anos) }\end{array}$ & $\begin{array}{c}\text { Localização } \\
\text { do Tumor }\end{array}$ & $\begin{array}{c}\text { Tamanho } \\
\text { do Tumor } \\
\text { (cm) }\end{array}$ & $\begin{array}{c}\text { Tipo } \\
\text { Histológ } \\
\text { ico }\end{array}$ & $\begin{array}{c}\text { Grau } \\
\text { Histológico }\end{array}$ & Procedimento Cirúrgico \\
\hline 1. VMJS & F & 41 & QSE & 0,3 & CDI & III & Quadrantectomia \\
2. NFR & F & 70 & QSE & 1 & CDI & II & Tumorectomia \\
3. WZV & F & 33 & QSI & 1,5 & CDI & III & Tumorectomia \\
4. EO & F & 59 & QSE & 1,8 & CDIS & III & Tumorectomia \\
5. VLVS & F & 57 & QSE & 0,7 & CDI & II & Tumorectomia e Linfadenectomia \\
6. MLB & F & 57 & QSE & 1,5 & CDIS & II & Tumorectomia \\
7. SLW & F & 58 & QII & 1,8 & CDI & II & Tumorectomia \\
8. MHT & F & 55 & QSE & 1,9 & CDI & II & Tumorectomia \\
9. MADM & F & 33 & QSE & 2 & CDI & II & Tumorectomia \\
\hline
\end{tabular}




\begin{tabular}{|c|c|c|c|c|c|c|c|}
\hline \multicolumn{8}{|c|}{ Continuação da Tabela Características Demográficas e Clínicas } \\
\hline 10. HU & $\mathrm{F}$ & 48 & QSE & 0,6 & CDI & III & Tumorectomia \\
\hline 11. SAF & $\mathrm{F}$ & 55 & QSI & 1,9 & CDIS & III & Mastectomia \\
\hline 12. RSM & $\mathrm{F}$ & 42 & QIE & 1,3 & CDI & I & Tumorectomia \\
\hline \multicolumn{8}{|l|}{13.} \\
\hline MMDG & $\mathrm{F}$ & 46 & QSE & 0,31 & CDIS & III & Mastectomia \\
\hline 14. LNGC & $\mathrm{F}$ & 38 & QSE & 2,5 & CTLI & II & Quadrantectomia \\
\hline 15. MMS & $\mathrm{F}$ & 52 & QSE & 2,5 & CLI & I & Quadrantectomia \\
\hline 16. RMBG & $\mathrm{F}$ & 67 & $\mathrm{QC}$ & 0,9 & CDI & I & Quadrantectomia \\
\hline 17. DOM & $\mathrm{F}$ & 71 & QSI & 0,6 & $\mathrm{CDI}$ & I & Mastectomia \\
\hline 18. VMCA & $\mathrm{F}$ & 55 & QC & 1,2 & CDI & I & Quadrantectomia \\
\hline 19. IGS & $\mathrm{F}$ & 64 & QSE E QIE & 1,5 & CMI & II & Tumorectomia \\
\hline 20. VLFP & $\mathrm{F}$ & 57 & QSE & 0,5 & CDI & II & Tumorectomia \\
\hline 21. JRMO & $\mathrm{F}$ & 61 & QSI E QII & 1,5 & $\mathrm{CDI}$ & II & Mastectomia \\
\hline 22 BCSR & $\mathrm{F}$ & 76 & QSE & 1 & CDI & II & Mastectomia \\
\hline \multicolumn{8}{|l|}{23.} \\
\hline MRPCZ & $\mathrm{F}$ & 49 & QII & 3,2 & CDI & III & Tumorectomia e Linfadenectomia \\
\hline 24. MHJD & $\mathrm{F}$ & 55 & QSI e QSE & 2,8 & $\mathrm{CDI}$ & III & Mastectomia e Linfadenectomia \\
\hline 25. MHRC & $\mathrm{F}$ & 66 & QSE & 0,36 & $\mathrm{CDI}$ & II & Tumorectomia \\
\hline 26. MPA & $\mathrm{F}$ & 43 & QSE & 0,2 & CDI & II & Tumorectomia \\
\hline 27. RRO & $\mathrm{F}$ & 42 & QSE & 1,4 & CDIS & II & Mastectomia \\
\hline 28. CAA & $\mathrm{F}$ & 59 & QSE E QSI & 0,6 & $\mathrm{CDI}$ & II & Quadrantectomia \\
\hline 29. NMS & $\mathrm{F}$ & 53 & QSE & 2 & CIMD & II & Mastectomia e Linfadenectomia \\
\hline 30. MJBO & $\mathrm{F}$ & 42 & QSE & 3,7 & CDI & II & Mastectomia \\
\hline 31. ELLS & $\mathrm{F}$ & 61 & $\mathrm{QC}$ & 0,53 & CDIS & I & Mastectomia \\
\hline 32. CSF & $\mathrm{F}$ & 51 & QII & 0,1 & CDIS & III & Mastectomia e Linfadenectomia \\
\hline 33. MDN & $\mathrm{F}$ & 66 & QIE & 1,2 & CDIS & I & Mastectomia \\
\hline 34. NMT & $\mathrm{F}$ & 50 & QIE & 1,9 & $\mathrm{CDI}$ & II & Tumorectomia e Linfadenectomia \\
\hline 35. FAA & $\mathrm{F}$ & 45 & QSE & 0,25 & CDIS & III & Mastectomia \\
\hline 36. JSAS & $\mathrm{F}$ & 29 & QSE & 2,3 & CDI & I & Tumorectomia e Linfadenectomia \\
\hline 37. OOC & $\mathrm{F}$ & 49 & $\mathrm{QC}$ & 0,23 & $\mathrm{CDI}$ & II & Mastectomia \\
\hline 38. TRS & $\mathrm{F}$ & 66 & QSE & 2,1 & CDI & III & Tumorectomia e Linfadenectomia \\
\hline 39. DBG & $\mathrm{F}$ & 73 & QSE & 1,63 & $\mathrm{CDI}$ & II & Mastectomia \\
\hline 40. MJSC & $\mathrm{F}$ & 51 & QSE & 1,4 & CDIS & II & Mastectomia \\
\hline 41. TSP & $\mathrm{F}$ & 77 & QSE & 0,9 & $\mathrm{CDI}$ & II & Mastectomia \\
\hline 42. CAVV & $\mathrm{F}$ & 49 & QSE & 1,5 & CDI & II & Tumorectomia e Linfadenectomia \\
\hline 43. MEFP & $\mathrm{F}$ & 54 & QII & 0,2 & CDIS & III & Mastectomia \\
\hline 44. CFA & $\mathrm{F}$ & 71 & QIE & 2 & CDI & III & Quadrantectomia \\
\hline 45. SAL & $\mathrm{F}$ & 37 & $\mathrm{QC}$ & 0,2 & $\mathrm{CDI}$ & I & Tumorectomia \\
\hline 46. DFM & $\mathrm{F}$ & 28 & QSI & 1,8 & CDI & III & Tumorectomia \\
\hline 47. LST & $\mathrm{F}$ & 36 & $\mathrm{QC}$ & 1 & $\mathrm{CDI}$ & II & Quadrantectomia \\
\hline 48. SAS & $\mathrm{F}$ & 50 & QSE & 0,9 & $\mathrm{CDI}$ & II & Mastectomia \\
\hline 49. GBB & $\mathrm{F}$ & 58 & $\mathrm{QC}$ & 1 & CDI & I & Tumorectomia \\
\hline 50. NPBS & $\mathrm{F}$ & 73 & QII & 2,5 & $\mathrm{ACM}$ & I & Mastectomia \\
\hline 51. DFM & $\mathrm{F}$ & 28 & QIE & 2 & CDIS & III & Mastectomia \\
\hline 52. PMR & $\mathrm{F}$ & 40 & $\mathrm{QC}$ & 1,6 & CDIS & I & Mastectomia e Linfadenectomia \\
\hline 53. AVS & $\mathrm{F}$ & 67 & QSE & 2,4 & $\mathrm{CM}$ & I & Tumorectomia \\
\hline 54. RFG & $\mathrm{F}$ & 27 & QSI & 7,5 & $\mathrm{CDI}$ & II & Mastectomia \\
\hline 55. LAA & $\mathrm{F}$ & 50 & QSE e QSI & 1,4 & CDIS & III & Mastectomia \\
\hline 56. MEPL & $\mathrm{F}$ & 64 & QSE & 0,84 & CDIS & II & Tumorectomia \\
\hline 57. TLGS & $\mathrm{F}$ & 66 & $\mathrm{QC}$ & 1,1 & CLI & I & Quadrantectomia \\
\hline 58. IBAA & $\mathrm{F}$ & 57 & QSE & 0,42 & $\mathrm{CDI}$ & II & Quadrantectomia Linfadenectomia \\
\hline
\end{tabular}




\begin{tabular}{lccccccl}
\hline \multicolumn{7}{c}{ Continuação da Tabela de Características Demográficas e Clínicas } \\
\hline 59. APS & F & 67 & QSE & 2,6 & CDI & III & Mastectomia \\
60. UPPA & F & 77 & QSI E QSI & 1,3 & CDI & I & Tumorectomia e Linfadenectomia \\
61. MDV & F & 67 & QSE & 2,16 & CDI & II & Tumorectomia e Linfadenectomia \\
62. MASF & F & 56 & QSE & 1,7 & CDI & II & Tumorectomia \\
63. RHML & F & 33 & QSE & 1 & CDI & II & Tumorectomia Linfadenectomia \\
64. AM & F & 73 & QSE & 0,2 & CDI & I & Tumorectomia \\
65. MGMP & F & 53 & QSE & 2,2 & CDI & III & Tumorectomia \\
66. AA & F & 46 & QIE & 2,2 & CDI & II & Quadrantectomia Linfadenectomia \\
67. MCFO & F & 64 & QIE & 1,7 & CDI & II & Tumorectomia \\
& & & & & CMDLI & & \\
68. AIRA & F & 61 & QSE & 1,5 & M & I & Mastectomia \\
69. RCCN & F & 52 & QC & 2,5 & CMA & II & Tumorectomia e Linfadenectomia \\
70. ICFS & F & 46 & QSE & 0,4 & CDIS & I & Tumorectomia \\
\hline
\end{tabular}

Legenda: F - Feminino; QSE - Quadrante Superior Externo; QSI - Quadrante Superior Interno; QIE Quadrante Inferior Externo; QII - Quadrante Inferior Interno; QC - Quadrante Central; CDI Carcinoma Ductal Invasivo; CDIS - Carcinoma Ductal in situ; CLI - Carcinoma Lobular Invasivo; CTLI - Carcinoma Túbulo-Lobular Invasivo; CIMD - Carcinoma Invasivo Misto Ductal; CMI Carcinoma Micropapilar Invasivo; ACM - Adenocarcinoma Mucinoso; CM - Carcinoma Mucinoso; CMDLIM - Carcinoma Ductal/Lobular Invasivo Multicêntrico; CMA - Carcinoma Medular Atípico.

\subsection{Características Linfocintilográficas}

\subsubsection{Número de LNS/LNNS por Paciente}

Todos os pacientes apresentaram drenagem linfática do radiofármaco, documentados pela LCINT, a partir do local da injeção. Em 43 (61.5\%) pacientes, observamos drenagem para 1 LNS, em 21 (30\%) para 2 LNS/LNNS, em 5 (7\%) para 3 LNS/LNNS e em 1 (1.5\%) para 4LNS/LNNS. (Figura 10) Em 70 pacientes foram visualizados pela LCINT 104 linfonodos. 


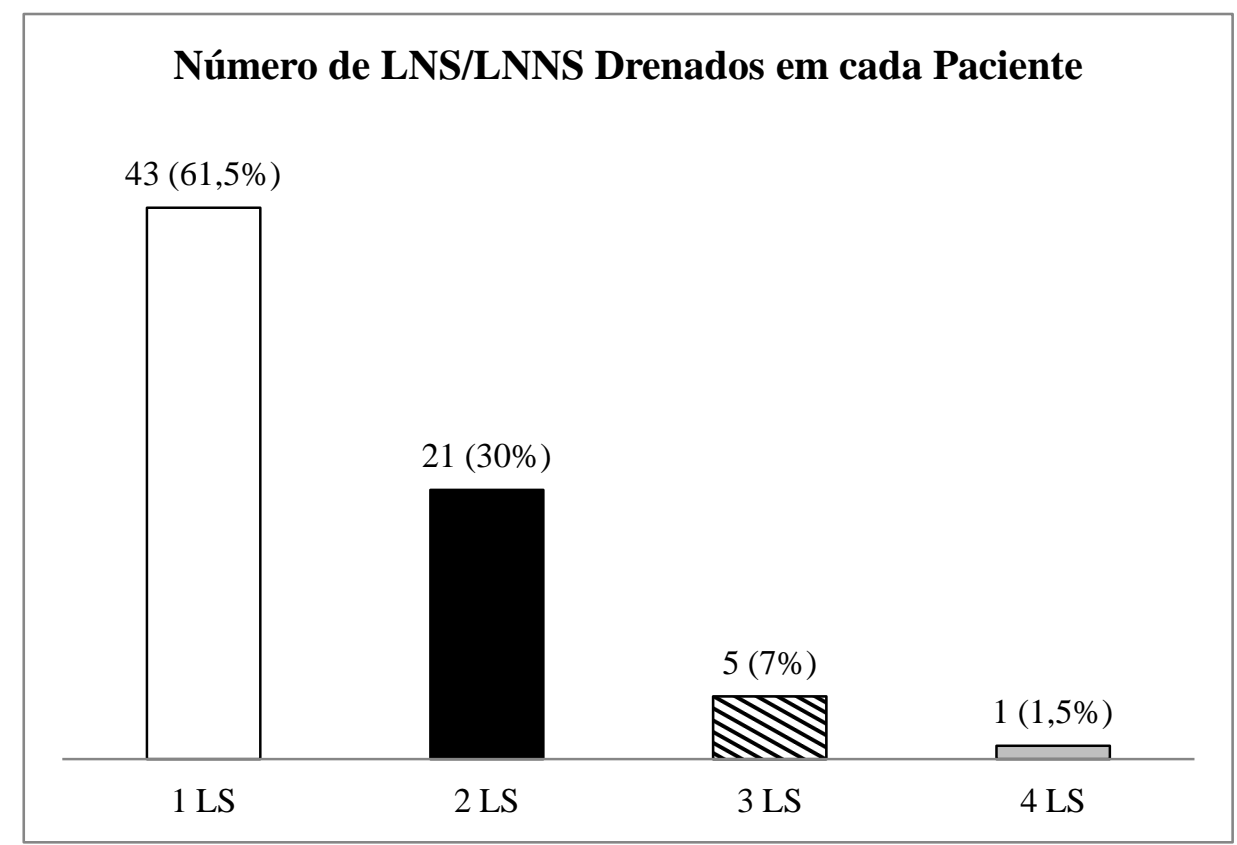

Legenda: LNS - Linfonodo Sentinela; LNNS - Linfonodo não Sentinela.

Figura 10 - Número de LNS/LNNS Drenado pelo radiofármaco Fitato${ }^{99 \mathrm{~m}} \mathrm{Tc}$ em cada paciente com CA de Mama.

A figura 11 mostra a drenagem linfática do radiofármaco para os LNS/LNNS nos pacientes com CA de Mama que foram submetidos ao estudo. 

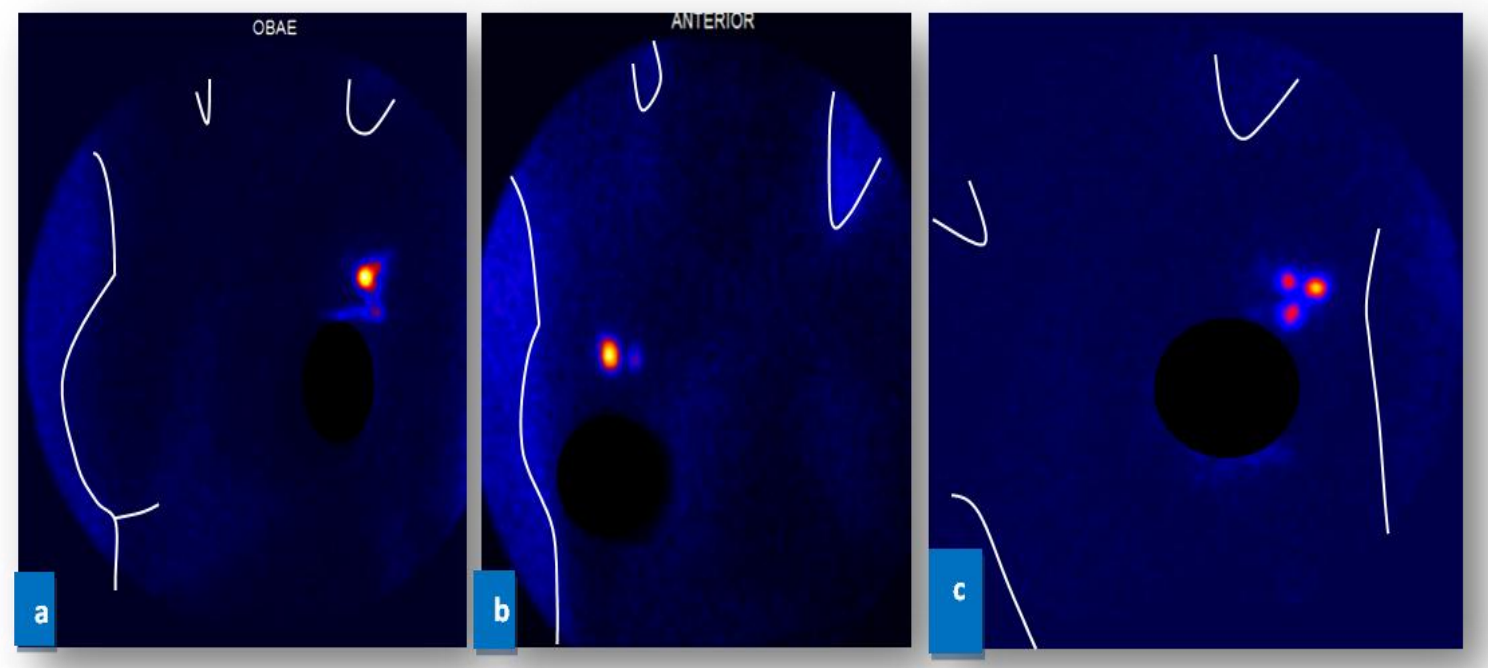

Legenda: Na figura acima podemos observar: (a) 1 LNS axilar esquerdo e a visualização do seu respectivo ducto linfático (Pacientes 18); (b) Um LNS e um LNNS axilares à direita (Paciente 30); (c) Um LNS e 2 LNNS axilares à esquerda (Paciente 48).

Figura 11 - Imagens de linfocintilografia na projeção anterior, mostrando a drenagem linfática do radiofármaco para os LNS/LNNS axilares.

\subsubsection{Padrões de Drenagem Linfática}

Sobre a distribuição dos LNS/LNNS em relação aos territórios de drenagem linfática, dos 70 pacientes, 68 (97\%) apresentaram drenagem linfática ipsilateral. Destes pacientes, o Paciente 46 apresentou drenagem para 1 LNS na região axilar esquerda e 1 LNNS na região mamária interna. E dos 70 pacientes, apenas 2 (3\%) destas apresentaram drenagem bilateral, sendo: o Paciente 4 e o Paciente 53 apresentaram drenagem linfática para as regiões axilares direita e esquerda. (figura 12) 

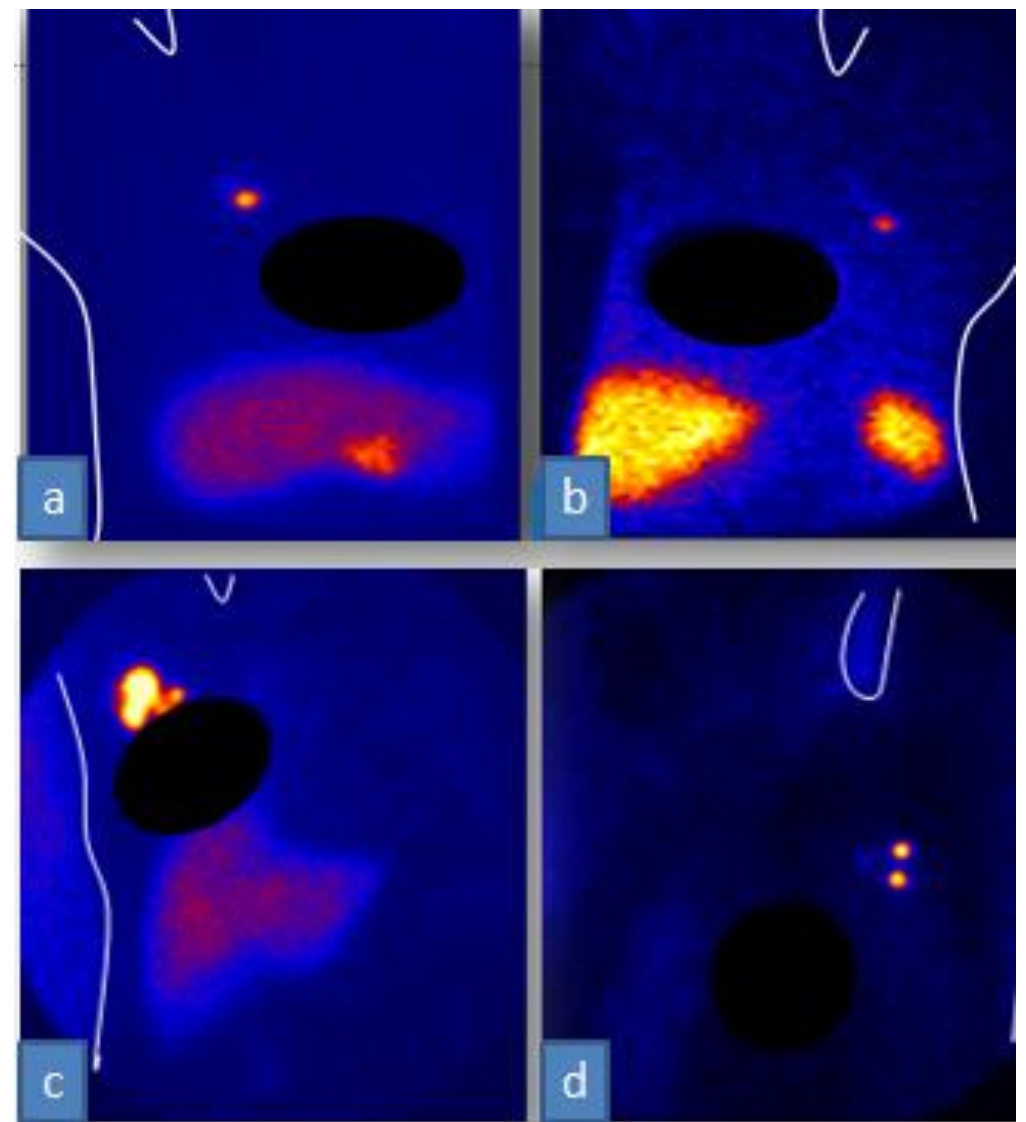

Legenda: Nas figuras acima podemos observar a drenagem linfática bilateral. As figuras (a) e (b) são do Paciente 4 e as figuras (c) e (d) são do Paciente (53). O Paciente 4 apresentou 1 LNS axilar direito (a) e 1 LNS axilar esquerdo (b). O Paciente 53 apresentou 2 LNS axilares direitos (c) e 2 LNS axilares esquerdos (d).

Figura 12 - Imagens de Linfocintilografia nas projeções anteriores mostrando a drenagem linfática do radiofármaco para LNS/LNNS axilares bilaterais.

Em relação à região de drenagem linfática dos LNS/LNNS, dos 70 pacientes, 68 (97\%) apresentaram drenagem para a região axilar, 1 (1,5\%) paciente para a região mamária interna (Paciente 38$)$ e $1(1,5 \%)$ paciente para as regiões axilar e mamária interna (Paciente 46). (Figura 13) 

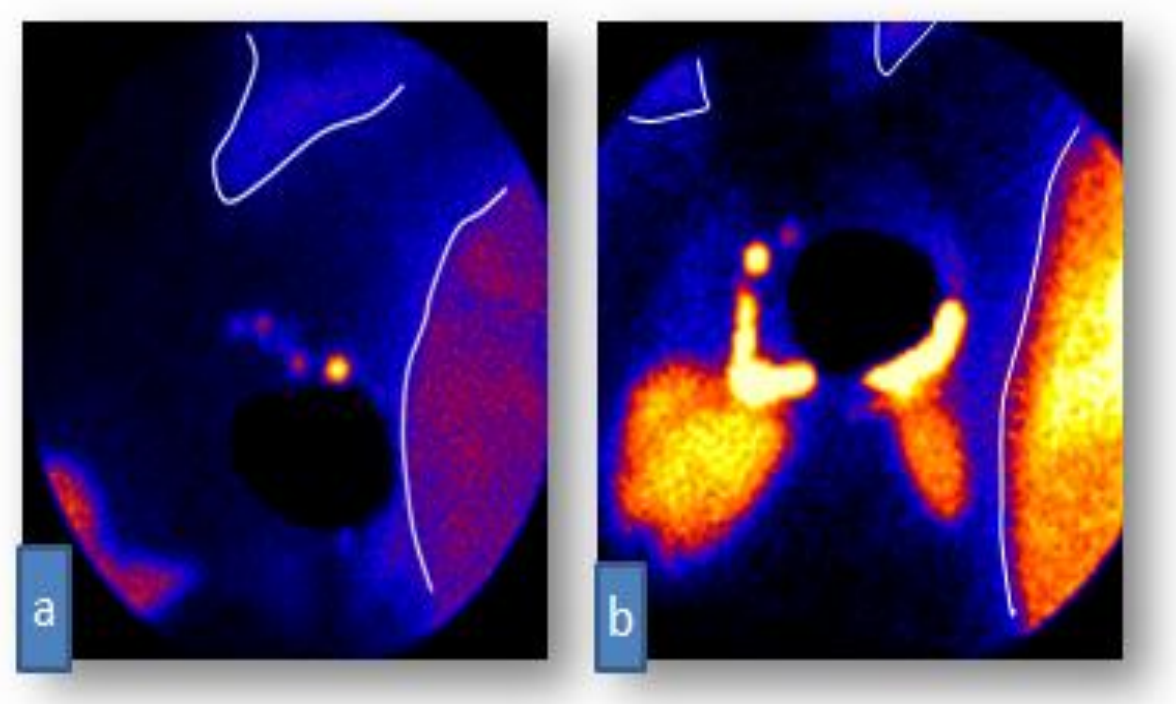

Legenda: Nas figuras acima podemos observar: (a) drenagem linfática para 1 LNS axilar esquerdo e 1 LNS na cadeia mamária interna (Paciente 46); (b) drenagem linfática para 1 LNS na cadeia mamária interna e sua via de drenagem (Paciente 38 ).

Figura 13 - Imagens de Linfocintilografia nas projeções anteriores mostrando a drenagem do radiofármaco para LNS axilares e na cadeia mamária interna.

\subsubsection{Descrição dos Padrões de Drenagem Linfática Axilares}

Dos 70 pacientes submetidos ao estudo, 68 (97\%) apresentaram drenagem linfática para a região axilar. (Tabela 5) Destes pacientes, apenas 2 (Paciente 4 e Paciente 53) apresentaram drenagem bilateral (axilar direita e axilar esquerda). O Paciente 4 já havia realizado anteriormente, uma tumorectomia na mama direita, então foi feito tumorectomia na mama esquerda e retirada dos LNS axilares direito e esquerdo. No Paciente 53 foi retirado apenas os 2 LNS/LNNS axilares direitos e realizado tumorectomia da lesão no lado direito, os LNS axilares esquerdos não foram retirados pois não havia nenhuma lesão. Os demais pacientes apresentaram drenagem para LNS/LNNS ipsilaterais ao lado da lesão e todos foram retirados.

Quanto ao número de LNS/LNNS axilares dos 68 pacientes foram encontrados no total de 102 LNS/LNNS, sendo 70 LNS e 32 LNNS com média de 1,5 LNS por paciente. Os Pacientes (1, 3, 9, 11-16, 18-20, 22-27, 29, 31, 32, 35, 38, 41-45, 50-52, 54, 56, 57, 59, 60, 62, 65-70) apresentaram drenagem para apenas 1 LNS, os Pacientes (2, 4-8, 10, 17, 21, 28, 30, 
33, 34, 36, 37, 39, 40, 47, 55, 58, 61) para 2 LNS/LNNS, os Pacientes (46, 48, 49, 63, 64) para 3 LNS/LNNS e o Paciente 53 para 4 LNS/LNNS.

Em relação ao ducto linfático responsável por drenar o radiofármaco Fitato- ${ }^{99 \mathrm{~m}} \mathrm{Tc}$ até o LNS/LNNS, nas imagens de LCINT, esta via linfática foi visualizada em 18 (25,5\%) pacientes (Pacientes 3, 4, 9, 14, 18, 21, 31, 32, 39, 44-46, 49, 57, 61, 64, 68, 70).

\subsubsection{Descrição dos Padrões de Drenagem Linfática da Região Mamária Interna}

Dos 70 pacientes estudados apenas 2 (3\%) pacientes (Paciente 38 e Pacientes 46) apresentaram drenagem linfática para a região mamária interna. O Paciente 46, além do LNS presente na região mamária interna, também apresentou 1 LNNS na região axilar. Quanto à lateralidade, os pacientes apresentaram drenagem para os LNS/LNNS ipsilaterais ao lado da lesão. Em relação ao número de LNS/LNNS encontrados, estes pacientes apresentaram apenas 1 LNS na região mamária interna, totalizando 2 LNS mamários internos. (Tabela 7), (Tabela 9)

Quanto à visualização do ducto linfático responsável pela drenagem do radiofármaco, o mesmo foi visualizado nos dois pacientes.

Tabela 7 - Características Linfocintilográficas

\begin{tabular}{lccccc}
\hline \multicolumn{1}{c}{ Paciente } & $\begin{array}{c}\text { Data da } \\
\text { LCINT }\end{array}$ & $\begin{array}{c}\text { Número Total } \\
\text { de LN } \\
\text { (LNS/LNNS) } \\
\text { LCINT }\end{array}$ & $\begin{array}{c}\text { Região de } \\
\text { Drenagem }\end{array}$ & $\begin{array}{c}\text { Padrão de } \\
\text { Drenagem }\end{array}$ & $\begin{array}{c}\text { Vias Linfáticas } \\
\text { Visíveis }\end{array}$ \\
\hline 1. VMJS & $17 / 04 / 2009$ & $1(1 / 0)$ & Axilar E & Ipsilateral & Não \\
2. NFR & $24 / 04 / 2009$ & $2(1 / 1)$ & Axilar E & Ipsilateral & Não \\
3. WZV & $11 / 05 / 2009$ & $1(1 / 0)$ & Axilar D & Ipsilateral & Sim \\
4. EO & $26 / 05 / 2009$ & $2(1 / 1)$ & Axilar D e Axilar E & Bilateral & Sim \\
5. VLVS & $01 / 06 / 2009$ & $2(1 / 1)$ & Axilar E & Ipsilateral & Não \\
6. MLB & $02 / 06 / 2009$ & $2(1 / 1)$ & Axilar E & Ipsilateral & Não \\
7. SLW & $23 / 06 / 2009$ & $2(1 / 1)$ & Axilar E & Ipsilateral & Não \\
8. MHT & $03 / 07 / 2009$ & $2(2 / 0)$ & Axilar E & Ipsilateral & Não \\
9. MADM & $23 / 07 / 2009$ & $1(1 / 0)$ & Axilar E & Ipsilateral & Sim \\
10. HU & $08 / 09 / 2009$ & $2(1 / 1)$ & Axilar E & Ipsilateral & Não \\
11. SAF & $08 / 09 / 2009$ & $1(1 / 0)$ & Axilar E & Ipsilateral & Não \\
12. RSM & $08 / 09 / 2009$ & $1(1 / 0)$ & Axilar D & Ipsilateral & Não \\
\hline
\end{tabular}




\begin{tabular}{|c|c|c|c|c|c|}
\hline \multicolumn{6}{|c|}{ Continuação da Tabela Características Linfocintilográficas } \\
\hline 13. MMDG & $15 / 09 / 2009$ & $1(1 / 0)$ & Axilar E & Ipsilateral & Não \\
\hline 14. LNGC & 29/09/2009 & $1(1 / 0)$ & Axilar E & Ipsilateral & Sim \\
\hline 15. MMS & 29/09/2009 & $1(1 / 0)$ & Axilar E & Ipsilateral & Não \\
\hline 16. RMBG & $01 / 10 / 2009$ & $1(1 / 0)$ & Axilar E & Ipsilateral & Não \\
\hline 17. DOM & 08/10/2009 & $2(1 / 1)$ & Axilar D & Ipsilateral & Não \\
\hline 18. VMCA & $18 / 11 / 2009$ & $1(1 / 0)$ & Axilar E & Ipsilateral & Sim \\
\hline 19. IGS & $03 / 12 / 2009$ & $1(1 / 0)$ & Axilar E & Ipsilateral & Não \\
\hline 20. VLFP & $08 / 12 / 2009$ & $1(1 / 0)$ & Axilar D & Ipsilateral & Não \\
\hline 21. JRMO & $10 / 02 / 2010$ & $2(1 / 1)$ & Axilar D & Ipsilateral & Sim \\
\hline 22 BCSR & $02 / 03 / 2010$ & $1(1 / 0)$ & Axilar D & Ipsilateral & Não \\
\hline 23. MRPCZ & 09/03/2010 & $1(1 / 0)$ & Axilar E & Ipsilateral & Não \\
\hline 24. MHJD & $16 / 03 / 2010$ & $1(1 / 0)$ & Axilar E & Ipsilateral & Não \\
\hline 25. MHRC & $18 / 03 / 2010$ & $1(1 / 0)$ & Axilar E & Ipsilateral & Não \\
\hline 26. MPA & $25 / 03 / 2010$ & $1(1 / 0)$ & Axilar D & Ipsilateral & Não \\
\hline 27. RRO & $06 / 04 / 2010$ & $1(1 / 0)$ & Axilar D & Ipsilateral & Não \\
\hline 28. CAA & $15 / 04 / 2010$ & $2(1 / 1)$ & Axilar E & Ipsilateral & Não \\
\hline 29. NMS & $20 / 04 / 2010$ & $1(1 / 0)$ & Axilar D & Ipsilateral & Não \\
\hline 30. MJBO & $04 / 05 / 2010$ & $2(1 / 1)$ & Axilar D & Ipsilateral & Não \\
\hline 31. ELLS & $04 / 05 / 2010$ & $1(1 / 0)$ & Axilar D & Ipsilateral & Sim \\
\hline 32. CSF & $12 / 05 / 2010$ & $1(1 / 0)$ & Axilar E & Ipsilateral & Sim \\
\hline 33. MDN & $18 / 05 / 2010$ & $2(1 / 1)$ & Axilar D & Ipsilateral & Não \\
\hline 34. NMT & $18 / 05 / 2010$ & $2(1 / 1)$ & Axilar D & Ipsilateral & Não \\
\hline 35. FAA & $28 / 05 / 2010$ & $1(1 / 0)$ & Axilar E & Ipsilateral & Não \\
\hline 36. JSAS & $28 / 05 / 2010$ & $2(1 / 1)$ & Axilar D & Ipsilateral & Não \\
\hline 37. OOC & 01/06/2010 & $2(1 / 1)$ & Axilar D & Ipsilateral & Não \\
\hline 38. TRS & 08/06/2010 & $1(1 / 0)$ & Intramamária E & Ipsilateral & Sim \\
\hline 39. DBG & 08/06/2010 & $2(1 / 1)$ & Axilar D & Ipsilateral & Sim \\
\hline 40. MJSC & $10 / 06 / 2010$ & $2(1 / 1)$ & Axilar E & Ipsilateral & Não \\
\hline 41. TSP & 23/06/2010 & $1(1 / 0)$ & Axilar E & Ipsilateral & Não \\
\hline 42. CAVV & 29/06/2010 & $1(1 / 0)$ & Axilar E & Ipsilateral & Não \\
\hline 43. MEFP & $13 / 07 / 2010$ & $1(1 / 0)$ & Axilar D & Ipsilateral & Não \\
\hline 44. CFA & $10 / 08 / 2010$ & $1(1 / 0)$ & Axilar E & Ipsilateral & Sim \\
\hline 45. SAL & $12 / 08 / 2010$ & $1(1 / 0)$ & $\begin{array}{c}\text { Axilar E } \\
\text { Axilar E e }\end{array}$ & Ipsilateral & Sim \\
\hline 46. DFM & $30 / 08 / 2010$ & $3(1 / 2)$ & Intramamária $\mathrm{E}$ & Ipsilateral & Sim \\
\hline 47. LST & $24 / 09 / 2010$ & $2(1 / 1)$ & Axilar E & Ipsilateral & Não \\
\hline 48. SAS & 28/09/2010 & $3(1 / 2)$ & Axilar D & Ipsilateral & Não \\
\hline 49. GBB & $28 / 10 / 2010$ & $3(1 / 2)$ & Axilar E & Ipsilateral & Sim \\
\hline 50. NPBS & $26 / 11 / 2010$ & $1(1 / 0)$ & Axilar D & Ipsilateral & Não \\
\hline 51. DFM & $26 / 11 / 2010$ & $1(1 / 0)$ & Axilar E & Ipsilateral & Não \\
\hline 52. PMR & 09/12/2010 & $1(1 / 0)$ & Axilar D & Ipsilateral & Não \\
\hline 53. AVS & $14 / 12 / 2010$ & $4(1 / 3)$ & Axilar D e E & Bilateral & Não \\
\hline 54. RFG & $24 / 01 / 2011$ & $1(1 / 0)$ & Axilar D & Ipsilateral & Não \\
\hline 55. LAA & $31 / 02 / 2011$ & $2(1 / 1)$ & Axilar D & Ipsilateral & Não \\
\hline 56. MEPL & $15 / 02 / 2011$ & $1(1 / 0)$ & Axilar D & Ipsilateral & Não \\
\hline 57. TLGS & $22 / 02 / 2011$ & $1(1 / 0)$ & Axilar D & Ipsilateral & Sim \\
\hline 58. IBAA & 29/03/2011 & $2(1 / 1)$ & Axilar D & Ipsilateral & Não \\
\hline 59. APS & $31 / 03 / 2011$ & $1(1 / 0)$ & Axilar D & Ipsilateral & Não \\
\hline 60. UPPA & $31 / 03 / 2011$ & $1(1 / 0)$ & Axilar D & Ipsilateral & Não \\
\hline 61. MDV & 08/05/2011 & $2(1 / 1)$ & Axilar D & Ipsilateral & Sim \\
\hline 62. MASF & $25 / 05 / 2011$ & $1(1 / 0)$ & Axilar D & Ipsilateral & Não \\
\hline
\end{tabular}




\begin{tabular}{|c|c|c|c|c|c|}
\hline \multicolumn{6}{|c|}{ Continuação da Tabela Características Linfocintilográficas } \\
\hline 63. RHML & $25 / 05 / 2011$ & $3(1 / 2)$ & Axilar E & Ipsilateral & Não \\
\hline 64. AM & $31 / 05 / 2011$ & $3(1 / 2)$ & Axilar E & Ipsilateral & Sim \\
\hline 65. MGMP & $02 / 06 / 2011$ & $1(1 / 0)$ & Axilar E & Ipsilateral & Não \\
\hline 66. AA & $07 / 06 / 2011$ & $1(1 / 0)$ & Axilar D & Ipsilateral & Não \\
\hline 67. MCFO & 09/06/2011 & $1(1 / 0)$ & Axilar E & Ipsilateral & Não \\
\hline 68. AIRA & $29 / 06 / 2011$ & $1(1 / 0)$ & Axilar D & Ipsilateral & Sim \\
\hline 69. $\mathrm{RCCN}$ & $22 / 07 / 2011$ & $1(1 / 0)$ & Axilar E & Ipsilateral & Não \\
\hline 70. ICFS & $23 / 08 / 2011$ & $1(1 / 0)$ & Axilar D & Ipsilateral & Sim \\
\hline
\end{tabular}

Legenda: LCINT - Linfocintilografia; E - Esquerda; D - Direita; LN - Linfonodos; LNS Linfonodo Sentinela; LNNS - Linfonodo Não Sentinela.

\subsection{Características Cirúrgicas}

\subsubsection{Retirada de LNS}

Os cirurgiões utilizaram o corante azul patente em 35 (50\%) dos 70 pacientes incluídas no estudo. Destes 35 pacientes, 3 (8,5\%) pacientes o corante azul patente não corou nenhum LNS/LNNS, em 5 (14,5\%) pacientes o corante corou apenas o LNS e não LNNS. Em 27 (77\%) pacientes o corante azul patente corou corretamente LNS/LNNS. Dos 35 pacientes que utilizaram o corante, foram localizados e removidos 57 LNS/LNNS. Destes o corante azul patente conseguiu identificar 45 (79\%) LNS/LNNS. (Tabela 8), (Tabela 9)

A sonda gama foi utilizada em 69 pacientes avaliadas, apenas o Paciente 38 a sonda gama não foi utilizada porque o LNS encontrava-se na região mamária interna, não sendo retirado, e por isso foi realizado linfadenectomia axilar.

Em 69 pacientes foi realizada a excisão dos LNS/LNNS. O Paciente 4 que apresentava drenagem bilateral (1 LNS axilar esquerdo e 1 LNS axilar direito), ambos os LN foram retirados. O Paciente 38, como já mencionado, não retirou o LNS mamário interno. O Paciente 46 apresentava drenagem para 1 LNS axilar esquerdo e 1 LNS mamário interno esquerdo, o LN axilar foi retirado e submetido a BLNS e o LN mamário interno não foi retirado devido a sua localização. O Paciente 53 apresentava drenagem bilateral (2 LN axilares direitos e 2 LNS axilares esquerdos), apenas os LN axilares direitos foram retirados 
pois a lesão encontrava-se neste lado e como não havia lesão no outro lado os LN axilares esquerdos não foram retirados.

A técnica de LCINT possibilitou a visualização de 104 LNS/LNNS, destes 4 LN não foram retirados (1LNS do Paciente 38, $1 \mathrm{LN}$ do Paciente 46, $2 \mathrm{LN}$ do Paciente 53), no total de 100 LNS/LNNS. Com auxílio da sonda gama foi retirado 113 LNS/LNNS, ou seja, 13 $(11,5 \%) \mathrm{LN}$ a mais que a LCINT. Estes $13 \mathrm{LN}$ que não foram visualizados na LCINT, todos eram LNNS, e os LNS referentes a estes pacientes foram visualizados com a técnica (Pacientes: 1, 7, 9, 11, 16, 21, 24, 25, 41, 43, 52, 62, 67). Então a técnica de LCINT foi capaz de visualizar $100(88,5 \%)$ LNS/LNNS.

Tabela 8 - Características Cirúrgicas

\begin{tabular}{|c|c|c|c|c|c|c|c|c|}
\hline Paciente & $\begin{array}{l}\text { Data da } \\
\text { Cirurgia }\end{array}$ & $\begin{array}{c}\text { Uso do } \\
\text { Corante } \\
\text { Azul } \\
\text { Patente }\end{array}$ & $\begin{array}{c}\mathbf{N}^{\circ} \text { de } \\
\text { LN } \\
\text { Corados } \\
\text { com AP }\end{array}$ & $\begin{array}{l}\text { Uso da } \\
\text { Sonda } \\
\text { Gama }\end{array}$ & $\begin{array}{l}\mathbf{N}^{\circ} \text { de } \mathbf{L N} \\
\text { Retirados }\end{array}$ & $\begin{array}{l}\text { Biópsi } \\
\text { a LNS/ } \\
\text { LNNS }\end{array}$ & $\begin{array}{c}\text { Estado Axilar (n } \\
\text { LN Dissecados }\end{array}$ & Observação \\
\hline 1. VMJS & $17 / 04 / 2009$ & Não & & Sim & 2 & $\mathrm{~N} / \mathrm{N}$ & & LCINT (-) 1 LNNS \\
\hline 2. NFR & 24/04/2009 & Não & & Sim & 2 & $\mathrm{~N} / \mathrm{N}$ & & \\
\hline 3. WZV & $11 / 05 / 2009$ & Não & & Sim & 1 & $\mathrm{~N}$ & & \\
\hline 4. EO & $26 / 05 / 2009$ & Não & & Sim & 2 & $\mathrm{~N} / \mathrm{N}$ & & \\
\hline 5. VLVS & 01/06/2009 & Não & & Sim & 2 & $\mathrm{~N} / \mathrm{S}$ & 21/21 LNS neg. & \\
\hline 6. MLB & 02/06/2009 & Não & & Sim & 2 & $\mathrm{~N} / \mathrm{N}$ & & \\
\hline 7. SLW & 23/06/2009 & Não & & Sim & 2 & $\mathrm{~N} / \mathrm{N}$ & & LCINT (-) 1 LNNS \\
\hline 8. MHT & 03/07/2009 & Não & & Sim & 2 & $\mathbf{S} / \mathbf{S}$ & LN N I, II e III neg & \\
\hline 9. MADM & $24 / 07 / 2009$ & Não & $\mathrm{S} / \mathrm{S}$ & Sim & 2 & $\mathrm{~N} / \mathrm{N}$ & & LCINT (-) 1 LNNS \\
\hline 10. HU & 08/09/2009 & Sim & $\mathrm{S} / \mathrm{N}-\mathrm{N}$ & Sim & 3 & $\mathrm{~N} / \mathrm{N}$ & & \\
\hline 11. SAF & 08/09/2009 & Sim & $\mathrm{S} / \mathrm{N}$ & Sim & 2 & $\mathrm{~N} / \mathrm{N}$ & & LCINT (-) 1 LNNS \\
\hline 12. RSM & 08/09/2009 & Não & & Sim & 1 & $\mathrm{~N}$ & & \\
\hline 13. MMDG & $15 / 09 / 2009$ & Sim & S & Sim & 1 & $\mathrm{~N}$ & & \\
\hline 14. LNGC & 29/09/2009 & Não & S & Sim & 1 & $\mathrm{~N}$ & & \\
\hline 15. MMS & 29/09/2009 & Sim & & Sim & 1 & $\mathrm{~N}$ & & \\
\hline 16. RMBG & 02/10/2009 & Sim & $\mathrm{S} / \mathrm{S}$ & Sim & 2 & $\mathrm{~N} / \mathrm{N}$ & & LCINT (-) 1 LNNS \\
\hline 17. DOM & 08/10/2009 & Não & & Sim & 2 & $\mathrm{~N} / \mathrm{N}$ & & \\
\hline 18. VMCA & $18 / 11 / 2009$ & Não & & Sim & 1 & $\mathrm{~N}$ & & \\
\hline 19. IGS & 03/12/2009 & Sim & $S$ & Sim & 1 & $\mathrm{~N}$ & & \\
\hline 20. VLFP & 08/12/2009 & Não & & Sim & 1 & $\mathrm{~N}$ & & \\
\hline 21. JRMO & $10 / 02 / 2010$ & Não & & Sim & 3 & $\mathrm{~N} / \mathrm{N}-\mathrm{N}$ & & LCINT (-) 1 LNNS \\
\hline 22 BCSR & 02/03/2010 & Não & & Sim & 1 & $\mathrm{~N}$ & & \\
\hline 23. MRPCZ & 09/03/2010 & Não & & Sim & 1 & $\mathbf{S}$ & 34/34 LNS neg. & \\
\hline 24. MHJD & $16 / 03 / 2010$ & Não & & Sim & 2 & $\mathbf{S} / \mathbf{S}$ & 11/11 LNS neg. & LCINT (-) 1 LNNS \\
\hline 25. MHRC & $18 / 03 / 2010$ & Sim & $\mathrm{S} / \mathrm{S}$ & Sim & 2 & $\mathrm{~N} / \mathrm{N}$ & & LCINT (-) 1 LNNS \\
\hline
\end{tabular}




\begin{tabular}{|c|c|c|c|c|c|c|c|c|}
\hline \multicolumn{9}{|c|}{ Continuação da Tabela de Características Cirúrgicas } \\
\hline 26. MPA & $25 / 03 / 2010$ & Sim & $\mathrm{S}$ & Sim & 1 & $\mathrm{~N}$ & & \\
\hline 27. RRO & $06 / 04 / 2010$ & Sim & $S$ & Sim & 1 & $\mathrm{~N}$ & & \\
\hline 28. CAA & $15 / 04 / 2010$ & Sim & $\mathrm{S} / \mathrm{S}$ & Sim & 2 & $\mathrm{~N} / \mathrm{N}$ & & \\
\hline 29. NMS & $20 / 04 / 2010$ & Não & & Sim & 1 & $\mathrm{~N}$ & & \\
\hline 30. MJBO & $04 / 05 / 2010$ & Sim & $\mathrm{S} / \mathrm{S}$ & Sim & 2 & $\mathrm{~N} / \mathrm{N}$ & & \\
\hline 31. ELLS & $04 / 05 / 2010$ & Sim & $S$ & Sim & 1 & $\mathrm{~N}$ & & \\
\hline 32. CSF & $12 / 05 / 2010$ & Sim & $S$ & Sim & 1 & $\mathrm{~N}$ & & \\
\hline 33. MDN & $18 / 05 / 2010$ & Sim & $\mathrm{S} / \mathrm{S}$ & Sim & 2 & N/N & & \\
\hline 34. NMT & $18 / 05 / 2010$ & Sim & $\mathrm{S} / \mathrm{N}$ & Sim & 2 & $\mathrm{~S} / \mathrm{N}$ & 28/28 LNS neg. & \\
\hline 35. FAA & $28 / 05 / 2010$ & Sim & $S$ & Sim & 1 & $\mathrm{~N}$ & & \\
\hline 36. JSAS & $28 / 05 / 2010$ & Sim & $\mathrm{S} / \mathrm{N}$ & Sim & 2 & $\mathbf{N} / \mathbf{S}$ & 8/8 LNS neg. & \\
\hline 37. OOC & $01 / 06 / 2010$ & Não & & Sim & 2 & $\mathrm{~N} / \mathrm{N}$ & & \\
\hline 38. TRS & 08/06/2010 & Não & & & & & 4/4LNS posit. & Não retirou o LNS \\
\hline 39. DBG & 08/06/2010 & Sim & $\mathrm{S} / \mathrm{S}$ & Sim & 2 & $\mathrm{~N} / \mathrm{N}$ & & \\
\hline 40. MJSC & $10 / 06 / 2010$ & Sim & $\mathrm{S} / \mathrm{S}$ & Sim & 2 & N/N & & \\
\hline 41. TSP & $23 / 06 / 2010$ & Sim & $\mathrm{N} / \mathrm{N}$ & Sim & 2 & $\mathrm{~N} / \mathrm{N}$ & & LCINT (-) 1 LNNS \\
\hline 42. CAVV & $29 / 06 / 2010$ & Sim & $S$ & Sim & 1 & $\mathbf{S}$ & 16/16 LNS neg. & \\
\hline 43. MEFP & $13 / 07 / 2010$ & Não & & Sim & 2 & $\mathrm{~N} / \mathrm{N}$ & & LCINT (-) 1 LNNS \\
\hline 44. CFA & $10 / 08 / 2010$ & Não & & Sim & 1 & $\mathrm{~N}$ & & \\
\hline 45. SAL & $12 / 08 / 2010$ & Não & & Sim & 2 & N/N & & \\
\hline 46. DFM & $30 / 08 / 2010$ & Sim & $\mathrm{S} / \mathrm{S}$ & Sim & 2 & $\mathrm{~N} / \mathrm{N}$ & & \\
\hline 47. LST & $24 / 09 / 2010$ & Sim & $S$ & Sim & 2 & N/N & & \\
\hline 48. SAS & $28 / 09 / 2010$ & Sim & $\mathrm{S} / \mathrm{S}$ & Sim & 2 & $\mathrm{~N} / \mathrm{N}$ & & \\
\hline 49. GBB & $29 / 10 / 2010$ & Sim & $S$ & Sim & 2 & N/N & & \\
\hline 50. NPBS & $26 / 11 / 2010$ & Não & & Sim & 1 & $\mathrm{~N}$ & & \\
\hline 51. DFM & $26 / 11 / 2010$ & Não & & Sim & 1 & $\mathrm{~N}$ & & \\
\hline 52. PMR & $10 / 12 / 2010$ & Não & & Sim & 2 & $\mathbf{S} / \mathbf{S}$ & 17/04 LNS posit. & LCINT (-) 1 LNNS, \\
\hline & & & & & & & & LN axilares D \\
\hline 53. AVS & $14 / 12 / 2010$ & Não & & Sim & 2 & $\mathrm{~N} / \mathrm{N}$ & & retirados \\
\hline 54. RFG & $25 / 01 / 2011$ & Não & & Sim & 1 & $\mathrm{~N}$ & & \\
\hline 55. LAA & $01 / 02 / 2011$ & Sim & $\mathrm{S} / \mathrm{S}$ & Sim & 2 & $\mathrm{~N} / \mathrm{N}$ & & \\
\hline 56. MEPL & $15 / 02 / 2011$ & Não & & Sim & 1 & $\mathrm{~N}$ & & \\
\hline 57. TLGS & $22 / 02 / 2011$ & Sim & $S$ & Sim & 1 & $\mathrm{~N}$ & & \\
\hline 58. IBAA & $29 / 03 / 2011$ & Não & & Sim & 2 & $\mathrm{~N} / \mathrm{S}$ & 7/7 LNS posit. & \\
\hline 59. APS & $01 / 03 / 2011$ & Sim & $S$ & Sim & 1 & $\mathrm{~N}$ & & \\
\hline 60. UPPA & $01 / 03 / 2011$ & Não & & Sim & 1 & $\mathbf{S}$ & 27/25 LNS posit. & \\
\hline 61. MDV & 09/05/2011 & Sim & $\mathrm{S} / \mathrm{S}$ & Sim & 2 & $\mathbf{S} / \mathbf{S}$ & 18/18LNS neg. & \\
\hline 62. MASF & $26 / 05 / 2011$ & Sim & $\mathrm{N} / \mathrm{N}$ & Sim & 2 & $\mathrm{~N} / \mathrm{N}$ & & LCINT (-) 1 LNNS \\
\hline 63. RHML & $26 / 05 / 2011$ & Não & & Sim & 3 & $\mathrm{~S} / \mathrm{N}-\mathrm{N}$ & 6/3 LNS posit. & \\
\hline 64. AM & $31 / 05 / 2011$ & Sim & $\mathrm{S} / \mathrm{N}-\mathrm{N}$ & Sim & 3 & $\mathrm{~N} / \mathrm{N}-\mathrm{N}$ & & \\
\hline 65. MGMP & 03/06/2011 & Sim & $S$ & Sim & 1 & $\mathrm{~N}$ & & \\
\hline 66. AA & $07 / 06 / 2011$ & Sim & $\mathrm{N}$ & Sim & 1 & $\mathbf{S}$ & 15/2 LNS posit. & \\
\hline 67. MCFO & $10 / 06 / 2011$ & Não & & Sim & 2 & $\mathrm{~N} / \mathrm{N}$ & & LCINT (-) 1 LNNS \\
\hline 68. AIRA & $29 / 06 / 2011$ & Sim & $S$ & Sim & 1 & $\mathrm{~N}$ & & \\
\hline
\end{tabular}




\begin{tabular}{lllllll}
\hline & \multicolumn{5}{c}{ Continuação da Tabela de Características Cirúrgicas } \\
\hline 69. RCCN & $22 / 07 / 2011$ & Não & & Sim & 2 & N \\
70. ICFS & $23 / 08 / 2011$ & Sim & S & Sim & 1 & N \\
\hline
\end{tabular}

Legenda: AP - Azul Patente; $\mathrm{N}^{\circ}$ - Número; LN - Linfonodo; LNS - Linfonodo Sentinela; LNNS Linfonodo Não Sentinela; LCINT - Linfocintilografia; N - Negativo; P - Positivo, Neg. - Negativo; Posit. - Positivo.

\subsubsection{Avaliação dos Exames Anatomopatológicos}

Dos 113 LNS/LNNS retirados e submetidos a exame anatomopatológico, 18 (16\%) LNS/LNNS apresentaram comprometimento metastático. Estes 18 LNS/LNNS estavam presentes em $13(18,8 \%$ ) dos 70 pacientes, todos os 13 pacientes (Pacientes: 5, 8, 23, 24, 34, $36,42,52,58,60,61,63,66)$ e o Paciente 38 realizaram linfadenectomia axilar. (Figura 14)

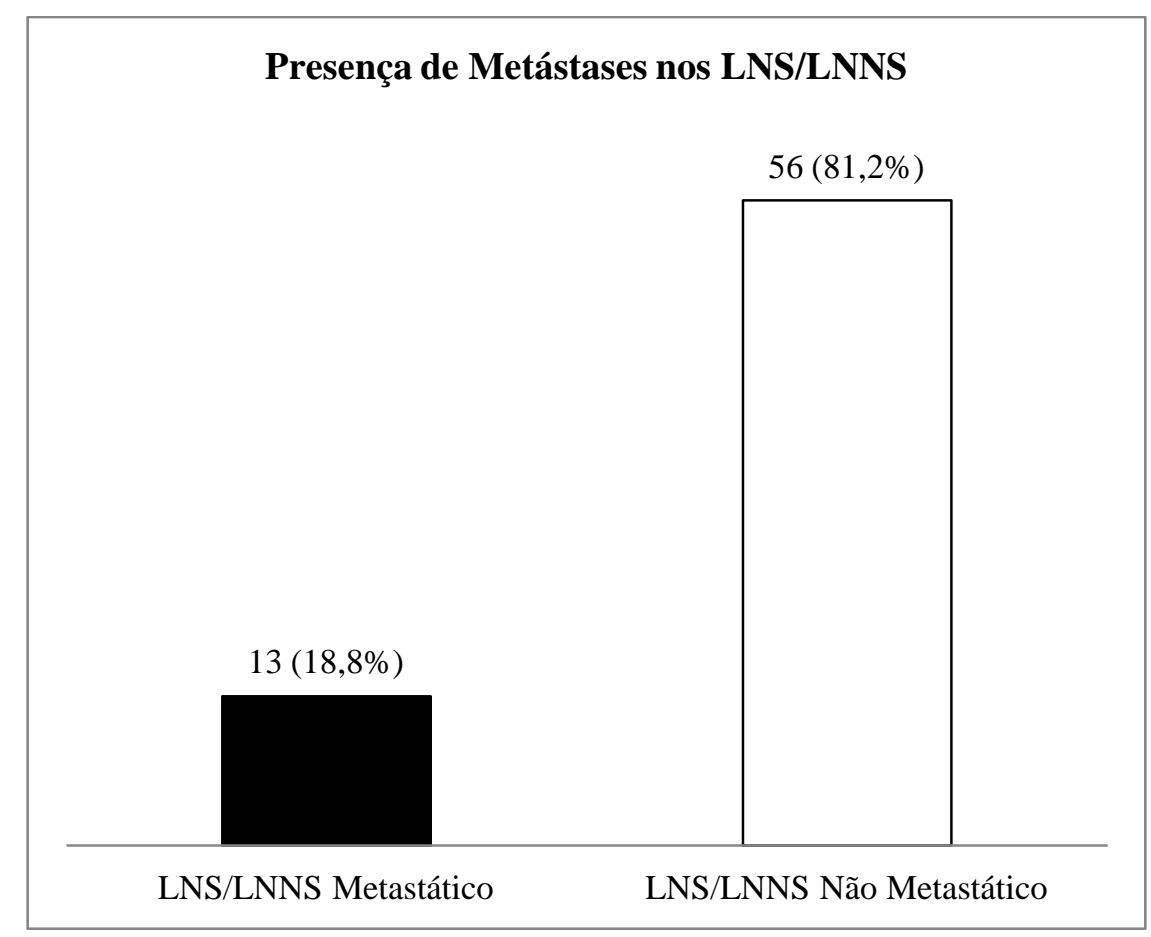

Figura 14 - Presença de metástases nos LNS/LNNS. 
Foi retirado do Paciente 5 dois LNS/LNNS, apenas o LNNS apresentou comprometimento metastático, na linfadenectomia dos $21 \mathrm{LN}$ dissecados, todos foram negativos para comprometimento metastático. No Paciente 8 retirou 2 LNS/LNNS, os dois LN apresentaram comprometimento metastático e na linfadenectomia todos os LN dissecados nos níveis de Burg. I, II e III foram negativo para metástases. O Paciente 23 foi retirado 1 LNS metastático, na linfadenectomia dos $34 \mathrm{LN}$ dissecados todos foram negativos para metástases. No Paciente 24 retirou-se 2 LNS/LNNS metastáticos, na linfadenectomia dos 11 LN dissecados todos foram negativos para metástases. O Paciente 34 foi retirado 2 LNS/LNNS, apenas 1 LNS era metastático no esvaziamento axilar dos 28 LN dissecados todos eram negativos. No Paciente 36 retirou-se 2 LNS/LNNS, apenas o LNNS era metastático, na linfadenectomia dos $8 \mathrm{LN}$ dissecados todos eram negativos. O Paciente 38 que apresentou 1 LNS na região mamária interna o qual não foi retirado, na linfadenectomia dos 4 LN dissecados, todos possuíam comprometimento metastático. O Paciente 42 foi retirado 1 LNS metastático, no esvaziamento axilar dos $16 \mathrm{LN}$ dissecados todos eram negativos. $\mathrm{O}$ Paciente 52 retirou-se 2 LNS/LNNS metastáticos na linfadenectomia de 17 LN dissecados, 4 LN apresentaram comprometimento metastático. O Paciente 58 foi retirado 2 LNS/LNNS, apenas o LNNS era metastático, na linfadenectomia de 7 LN dissecados, todos apresentaram comprometimento metastático. No Paciente 60 retirou-se 1 LNS metastático, no esvaziamento axilar de $27 \mathrm{LN}$ dissecados, $25 \mathrm{LN}$ apresentaram comprometimento metastático. O Paciente 61 foi retirado 2 LNS/LNS metastáticos, na linfadenectomia dos $18 \mathrm{LN}$ dissecados, todos eram negativos para metástases. O Paciente 63 retirou-se 3 LNS/LNNS, apenas 1 LNS era metastático, no esvaziamento axilar de $6 \mathrm{LN}$ dissecados, 3 apresentaram comprometimento metastático. No paciente 66 retirou-se 1 LNS metastático, na linfadenectomia dos 15 LNS/LNNS dissecados, 2 apresentaram acometimento metastático. Portanto dos 14 pacientes submetidas à linfadenectomia axilar, $8(57 \%)$ pacientes apresentaram axila negativa para comprometimento metastático (Pacientes: 5, 8, 23, 24, 34, 36, 42, 61), 2 (14,5\%) pacientes apresentaram entre 1 e 3 LN metastáticos (Pacientes 63 e 66) e 4 (28,5\%) pacientes mais de 4 LN dissecados metastáticos $(38,52,58,60)$. (Figura 15) 


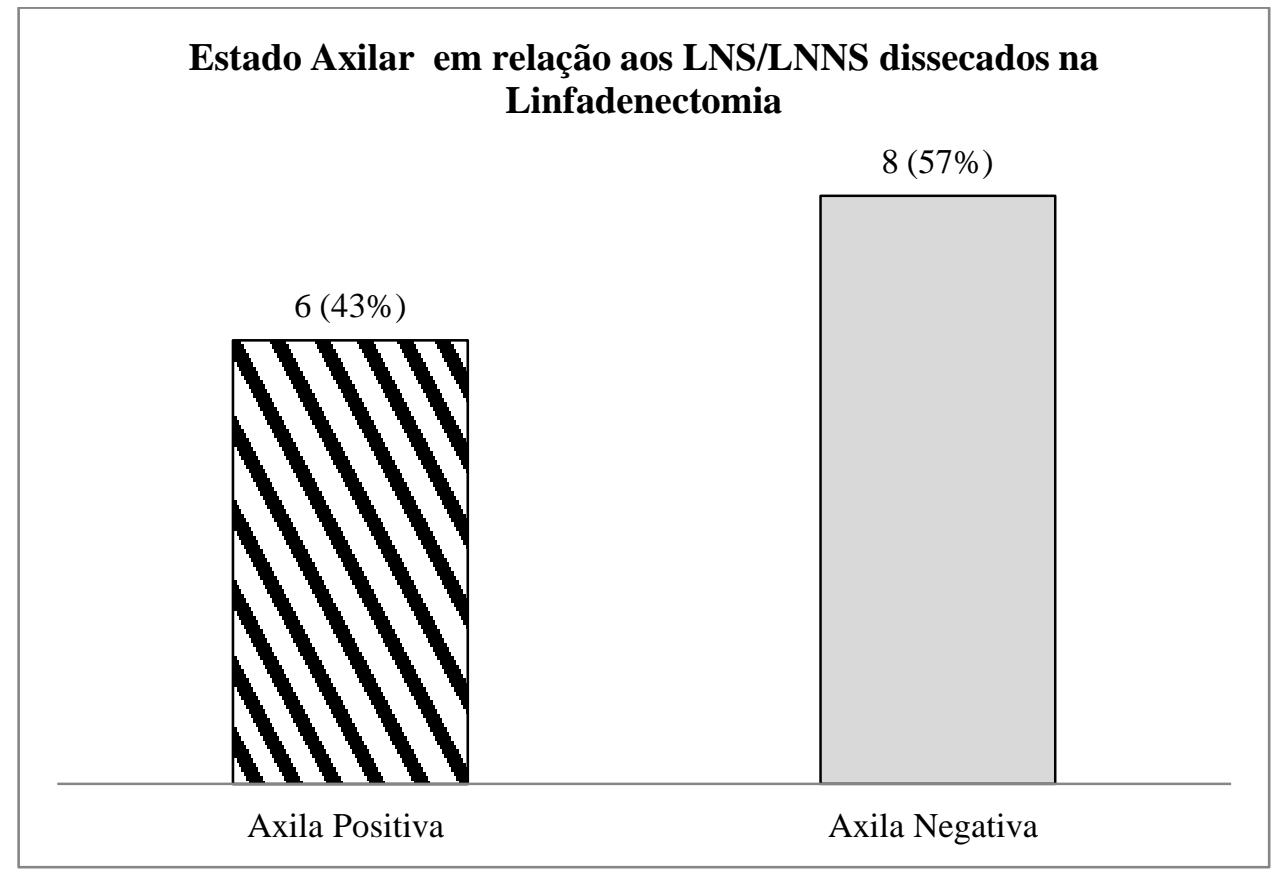

Figura 15 - Estado Axilar em relação aos LN dissecados na linfadenectomia axilar. 
Tabela 9 - Resumo das Características Demográficas, Clínicas e Cirúrgicas dos Pacientes com $\mathrm{CA}$ de Mama submetidos ao estudo.

\begin{tabular}{|c|c|c|}
\hline \multicolumn{3}{|c|}{ Características Clínicas, Demográficas e Cirúrgicas } \\
\hline \multicolumn{3}{|l|}{ Variáveis } \\
\hline \multirow[t]{2}{*}{ Número de Pacientes } & 70 & \\
\hline & Média & Intervalo \\
\hline Idade Média & 54 & 27-77 \\
\hline \multirow[t]{2}{*}{ Tamanho do tumor $(\mathrm{cm})$} & 1,4 & $0,1-7,5$ \\
\hline & Número de Casos & Porcentagem \\
\hline \multicolumn{3}{|l|}{ Localização do Tumor: } \\
\hline QSE & 37 & $52,80 \%$ \\
\hline QIE & 7 & $10,00 \%$ \\
\hline QSI & 5 & $7,20 \%$ \\
\hline QII & 5 & $7,20 \%$ \\
\hline QC & 10 & $14,40 \%$ \\
\hline $2 \mathrm{Q}$ & 6 & $8,40 \%$ \\
\hline \multicolumn{3}{|l|}{ Tipos Histológicos: } \\
\hline CDI & 45 & $64,20 \%$ \\
\hline CDIS & 16 & $22,80 \%$ \\
\hline CLI & 2 & $2,80 \%$ \\
\hline $\mathrm{O}$ & 7 & $10,00 \%$ \\
\hline \multicolumn{3}{|l|}{ Grau Histológico: } \\
\hline Grau I & 18 & $25,70 \%$ \\
\hline Grau II & 34 & $48,60 \%$ \\
\hline Grau III & 18 & $25,70 \%$ \\
\hline \multicolumn{3}{|l|}{ Estado do LNS/LNNS: } \\
\hline Metastático & 13 & $18,80 \%$ \\
\hline Não Metastático & 56 & $81,20 \%$ \\
\hline \multicolumn{3}{|l|}{ Procedimento Cirúrgico } \\
\hline Mastectomia Radical & 24 & $34,30 \%$ \\
\hline Cirurgia Conservadora & 30 & $42,85 \%$ \\
\hline $\mathrm{O}$ & 16 & $22,85 \%$ \\
\hline
\end{tabular}

Legenda: QSE - Quadrante Superior Externo; QIE - Quadrante Inferior Externo; QSI - Quadrante Superior Interno; QII - Quadrante Inferior Interno; QC -

Quadrante Central; 2Q - Dois Quadrantes; O - Outros; CDI - Carcinoma Ductal Invasivo; CDIS - Carcinoma Ductal in situ; CLI - Carcinoma Lobular Invasivo; LNS - Linfonodo Sentinela; LNNS - Linfonodo Não Sentinela. 


\subsection{Otimização da Técnica de Linfocintilografia (LCINT)}

Finalmente, como um dos objetivos específicos deste projeto de pesquisa de mestrado foi o de revisar e implementar a técnica diagnóstica da LCINT. Como resultados práticos destes projeto, melhorias foram feitas, as quais descrevemos a seguir:

(a) Foi implementada a utilização de um formulário para o registro dos dados referentes a este projeto de pesquisa e que será utilizado, doravante, no registro das informações relativas à LCINT; (ANEXO B)

(b) Padronização da administração de 4 injeções intradérmicas do radiofármaco Fitato - ${ }^{99 \mathrm{~m}} \mathrm{Tc}$ ao redor do sítio da aréola mamária, considerando que antes deste projeto, o número de injeções ficava a critério de cada médico nuclear, tendo variado pregressamente de 2 a 4 injeções;

(c) Padronização da aquisição das imagens após 60 minutos das injeções. Tal janela temporal tem fundamento no fato de que imagens adquiridas muito antes de 60 minutos podem ser muito precoces ao tempo necessário para a drenagem linfática do radiofármaco até no LNS. Por outro lado, a injeção mais tardia que 60 minutos poderá documentar a drenagem linfática do radiofármaco para LNNS, além dos LNS que se deseja adquirir imagens;

(d) Padronização do uso de um simulador de radiação de fundo (também denominado Flood), preenchido com ${ }^{99 \mathrm{~m}} \mathrm{Tc}$, o qual posicionado e movimentado em posição oposta ao do detector, tendo como centro o corpo do paciente, permite então a criação de uma radiação de fundo que criará uma imagem do perfil do corpo do paciente. 


\section{DISCUSSÃO}

\subsection{Características Clínicas e Demográficas}

Embora a casuística do presente estudo $(n=70)$ seja relativamente pequena, quando comparada à de estudos com amostras significativamente maiores, nossa amostra de 70 pacientes possibilitou uma análise comparativa com a literatura. Encontramos no estudo apenas mulheres com CA de mama. O CA de mama em homens é considerado raro. Estima-se que para cada 100 novos casos de CA de mama feminino, apenas um caso, ou menos, de CA masculino será encontrado, correspondendo entre $0,8 \%$ e $1,0 \%$ do total de casos de CA de mama. (GIORDANO, BUZDAR e HORTOBAGY, 2002) (PHILOPTTS e SMITH, 2003) Além deste predomínio em mulheres, o CA de mama é também o segundo tipo de CA mais frequente no mundo e o mais comum entre as mulheres. A cada ano cerca de $22 \%$ dos casos novos de CA em mulheres são de mama. (INCA, 2009), (SAMPHAO et al., 2008)

A média de idade dos nossos pacientes foi de aproximadamente 54 anos, o que é similar ao descrito na literatura, a qual evidencia a ocorrência de CA de mama em populações mais maduras, com média de idade variando entre 47 e 56 anos. (SEOK et al., 2010), (NALASHIMAN et al., 2010), (NOGUCHI et al., 2010), (SEOK et al., 2009) Segundo o INCA (2009) a idade continua sendo um dos principais fatores de risco do CA de mama. As taxas de incidência aumentam rapidamente até os 50 anos e posteriormente, este aumento ocorre lentamente. Essa mudança no comportamento da taxa é denominada de Clemmesen's hook, sendo atribuída ao início da menopausa. Além disso, a exposição à radiação ionizante, mesmo em baixas doses, aumenta o risco de desenvolver o CA de mama, particularmente durante a puberdade. Adicionalmente, o CA de mama pode estar relacionado também ao processo de urbanização da sociedade, com maiores riscos de adoecimento entre mulheres com elevado status socioeconômico. (INCA, 2009), (TIEZZI, 2009)

O tamanho médio do tumor primário de mama dos nossos pacientes foi de $1,4 \mathrm{~cm}$ em seu maior diâmetro. Em nossa casuística, 57 (81,5\%) pacientes apresentaram T1, 12 (17\%) T2 e $1(1,5 \%)$ paciente apresentou T3. A literatura descreve tamanhos médios entre 1,4 e 1,8 cm para os tumores de mama encontrados em mulheres, ou seja, classificação T1 do TNM. (NALASHIMAN et al., 2010), (NOGUCHI et al., 2010) (ABDOLLAHI et al., 2009)

Em relação aos tipos histológicos, a maioria dos nossos pacientes $(64,2 \%)$ apresentaram CDI, seguido de CDIS com 22,8\%, CLI com 2,8\% e, finalmente, $10 \%$ para 
todos os outros tipos histológicos de CA de mama. Estes valores estão de acordo com a literatura, que evidencia em ordem decrescente de frequiência o CDI, seguido pelo CDIS, CLI e, então, os demais tipos histológicos. (SEOK et al., 2010), (NALASHIMAN et al., 2010), (NOGUCHI et al., 2010), (SEOK et al., 2009), (ABDOLLAHI et al., 2009)

Quanto ao grau histológico do tumor presente nos pacientes submetidos ao estudo, de acordo com a classificação de Scarff-Bloom-Richardson modificado por Elston-Ellis, a maioria apresentou grau II (48,6\%), seguido do grau I e grau III com 25,7\% cada. Na literatura o grau histológico é variável e depende do tipo de estudo abordado. Alguns artigos mostraram ser mais incidentes os grais I e II, já outros apresentam os grais II e III como sendo mais incidentes. (MERETOJA et al., 2010), (ESSER et al., 2011), (ABREU et al., 2008)

Em relação aos procedimentos cirúrgicos realizados nos pacientes do estudo, a maioria realizou cirurgia conservadora. Os dados são compatíveis com a literatura, em que a maioria das cirurgias realizadas em pacientes com CA de mama são conservadoras. (SEOK et al., 2010), (ABREU et al., 2008) Os estudos clínicos randomizados que compararam cirurgia conservadora com a mastectomia radical não demonstraram prejuízo de sobrevida global em seguimento, em longo prazo, com as cirurgias conservadoras. (FISHER et al., 2002), (VERONESI et al., 2002)

Quanto à localização do tumor de CA de mama, nosso estudo mostrou que a maioria dos pacientes o tumor encontrava-se no QSE, seguido do QC, QIE, 2Q, QSI e QII. Há vários estudos na literatura que a maioria dos tumores de CA de mama também está localizado no QSE. (SEOK et al., 2010), (NALASHIMAN et al., 2010), (NOGUCHI et al., 2010), (SEOK et al., 2009), (ABDOLLAHI et al., 2009), (ESSER et al., 2011), (SADEGHI et al., 2009)

\subsection{Características Linfocintilográficas e Cirúrgicas}

A LCINT tem contribuído muito para a visualização dos padrões de drenagem linfática e para a visualização dos LNS. O estado patológico do LNS é considerado um importante fator no prognóstico do CA de mama. E é nesse contexto que a biópsia do LNS nos permite avaliar este estado patológico e seleciona os pacientes que deverão ser submetidos ao completo esvaziamento da cadeia linfática nos casos de acometimento metastático, além de diminuir a morbidade pós-operatória daquelas com resultado negativo para invasão metastática no linfonodo. (KRAG et al., 1993) Magaldi et al. (2005) 
compararam um grupo de mulheres com CA de mama que se submeteu a linfadenectomia axilar com um grupo que se submeteu a BLNS. Os autores observaram que o segundo grupo tinha menos linfedema, dor e rigidez no ombro.

No entanto, há algumas controvérsias sobre o LNS no CA de mama, e dentre elas citase: a presença de micrometástases axilares e LNS na cadeia mamária interna. Os pacientes que apresentam micrometástases no LNS são submetidos à linfadenectomia axilar (esvaziamento) e quimioterapia adjuvante. Giuliano et al. (1994) ressaltaram que a linfadenectomia axilar não é necessária quando há presença de micrometástases de tumores T1 e T2, pois a probabilidade de comprometer os demais LN da cadeia linfática de drenagem é aproximadamente de 6\%. Em relação à presença de LNS na cadeia mamária interna, estes LNS não são retirados na rotina cirúrgica e permanece sob investigação. Veronesi et al. (2002) mostraram que pacientes com metástases para um LNS na cadeia mamária interna têm pior prognóstico do que pacientes que apresentaram metástases em LNS axilares.

Quanto à distribuição dos LNS/LNNS nos territórios de drenagem linfática, no nosso estudo, a maioria dos pacientes apresentou drenagem linfática ipsilateral ao lado da lesão, estando de acordo com vários estudos. (TANIS et al., 2001), (NOGUCHI et al., 2010), (SOMASUNDARAM et al., 2009), (UREN et al., 2001) Embora a drenagem linfática axilar ipsilateral seja predominante, quando a drenagem linfática é prejudicada, seja por irradiação do tumor ou cirurgia axilar realizada anteriormente, os canais de drenagem linfática viáveis são bloqueados e alternativas de rotas de drenagem podem ser utilizadas. (PERRE et al., 1996) Em nosso estudo, dois pacientes apresentaram drenagem linfática bilateral (Paciente 4 e Paciente 53). O Paciente 4 apresentava uma recidiva, pois já havia realizado anteriormente, uma tumorectomia na mama esquerda, então, foi retirado os dois LNS/LNNS axilares esquerdo e direito e a lesão mamária direita pela tumorectomia. O Paciente 53 apresentava em estádio inicial da doença com lesão na mama direita, apresentou drenagem linfática bilateral, o qual só foi retirado apenas os LNS/LNNS axilares direitos, sendo estes do mesmo lado da lesão. A drenagem do LNS/LNNS contralateral ao lado da lesão ocorre através de dois prováveis caminhos de drenagem contralateral, sendo o plexo linfático profundo facial da parede torácica e o plexo linfático superficial cutâneo que atravessa a linha média, proporcionando uma via linfática direta na parede torácica. (DAOULD et al., 1998) No estudo de Huston et al. (2007) sobre a presença de metástases nos LNS contralaterais em carcinomas de mama, revelou que pode ocorrer metástases axilar contralateral devido a interrupção da via de drenagem ipsilateral normal realizada por intervenções cirúrgicas 
prévias. E também que a presença de metástases nestes LNS em pacientes com CA de mama é considerada incomum e está relacionada em estágios avançados da doença.

Quanto à região de drenagem linfática dos LNS/LNNS, em nosso estudo, 97\% dos pacientes apresentaram drenagem para a região axilar, este dado está de acordo com a literatura (SEOK et al., 2010), (SALDEGHI et al., 2009), (PAVLISTA et al., 2006), pois a maioria dos tumores de CA de mama é drenado pelos LNS axilares. No nosso estudo, a maioria dos tumores está localizada no QSE e QC e a drenagem linfática axilar ipsilateral é predominante, estes dados estão de acordo com a literatura. (CHUA et al., 2001), (PAVLISTA et al., 2006) Estes estudos reconhecem que a disseminação do tumor ocorre a partir dos quadrantes laterais e mediais da mama através de vasos linfáticos para os gânglios axilares ipsilaterais. Em 3\% dos pacientes apresentaram drenagem para a região mamária interna A avaliação do LNS na cadeia mamária interna permanece sob investigação e não é realizada como prática de rotina clínica. (PAREDES et al., 2005), (CHEN et al., 2008)

$\mathrm{Na}$ pesquisa, os cirurgiões utilizaram o corante azul patente em $50 \%$ dos pacientes, pois com a disponibilidade das imagens de LCINT, auxílio da sonda gama e o tempo entre a aplicação e a drenagem do corante para o LNS fez com que o corante azul patente não fosse utilizado em todos os procedimentos cirúrgicos. Dos 35 pacientes que utilizaram o corante, em 3 pacientes o corante não corou nenhum LNS/LNNS, mas as imagens de LCINT mostraram pelo menos o LNS. Nos Pacientes 41 e 62 a LCINT mostrou apenas o LNS e não o LNNS. Isso ocorreu devido à janela temporal, pois o tempo entre a aplicação do radiofármaco e a realização das imagens é de aproximadamente 60 minutos, após a aquisição de imagens até a incisão cirúrgica há um intervalo de tempo entre 2 e 16 horas, o que possibilitou a drenagem do radiofármaco para um segundo LN (LNNS). Estes LNNS foram localizados e retirados com o auxílio da sonda gama. O resultado da BLNS destes LNNS foram negativos para acometimento metastático. Dos 35 pacientes que usaram o corante, em 5 o corante corou apenas o LNS e não o LNNS o qual foi localizado e retirado com a sonda gama. As imagens de LCINT mostraram o LNNS nos Pacientes 10, 34, 36, 64. Apenas o Paciente 11 a LCINT também não mostrou o LNNS, em função da janela temporal. A BLNS destes LN apresentou acometimento metastático para o LNS do Paciente 66 e para o LNNS do Paciente 36 que não foram corados com o corante azul patente. Diante destes resultados, a LCINT foi eficaz na identificação de $88,5 \%$ dos LNS/LNNS e o corante azul patente em $79 \%$ dos LNS/LNNS. Então, a LCINT mostrou ser mais eficaz que o corante azul patente, mas deve-se utilizar de pelo menos duas técnicas para a identificação de maior número de LNS/LNNS. (SEOK et al., 2010), (ABREU et al., 2008) Estes resultados estão de acordo com o estudo realizado por 
Sadeghi et al. (2009) sobre a comparação das técnicas de LCINT, sonda gama e corante azul em pacientes com CA de mama, mostrou que a LCINT identificou corretamente $77,5 \%$ dos LNS e o corante azul pode identificar $75 \%$ dos LNS encontrados com a sonda gama. Por tanto, no nosso estudo e no estudo do Sadeghi et al. (2009), não houve uma contribuição significativa do corante azul patente para a identificação do LNS/LNNS em relação a técnica de LCINT.

Quanto ao auxílio da sonda gama, esta foi utilizada em todos os pacientes que realizaram procedimento cirúrgico para retirada do LNS/LNNS. Com a sonda gama foi possível localizar 13 LNNS a mais que a técnica de LCINT. Estes LNNS foram submetidos à BLNS que mostrou que apenas os Pacientes 24 e 52 tanto o LNS (visualizado na LCINT) quanto o LNNS apresentaram acometimento metastático, os demais LN foram negativo para metástases. Com a técnica de LCINT foi possível identificar 88,5\% dos LNS/LNNS nos pacientes submetidos ao estudo. Nosso estudo está de acordo com a literatura, esta mostra que a técnica de LCINT é eficaz em identificar os LNS/LNNS em aproximadamente $75 \%$ a $98 \%$ dos casos e se associada a outras técnicas como corante azul patente e sonda gama, essa porcentagem pode aumentar. (KRAG et al., 1993), (GIULIANO et al., 1991), (SEOK et al., 2010), (ABREU et al., 2008), (SALDEGHI et al., 2009)

Nos exames anatomopatológicos avaliados, apenas 13 (18,8\%) pacientes apresentaram acometimento metastático nos LNS/LNNS. Este resultado mostra a grande importância da realização da BLNS, pois dos 69 pacientes submetidos à BLNS, apenas 13 apresentaram metástases nos LNS/LNNS. Estes pacientes apresentaram idade média de 51 anos, tamanho médio do tumor de $1,7 \mathrm{~cm}$, a maioria CDI e grau histológico II. Todos estes pacientes e o Paciente 38 foram submetidos à linfadenectomia axilar. O estudo de Fitzgibbons et al., (2000) preconiza que se o tamanho médio do tumor de CA mama for menor que $1 \mathrm{~cm}$, aproximadamente de 10-20\% dos pacientes possuem metástases linfonodais. Em nosso estudo, os pacientes apresentam 18,8\% de comprometimento metastático nos LNS/LNNS e possuem tamanho médio do tumor maior que $1 \mathrm{~cm}$. Dos 14 pacientes submetidos à linfadenectomia em que os LN axilares presentes nos níveis I, II e III foram dessecados. A maioria destes pacientes apresentou LN dissecados negativos para metástases, ou seja, apenas a BLNS do LNS/LNNS apresentava metástases. E 2 pacientes houve a presença de 2 e 3 LN dissecados metastáticos, e 3 pacientes apresentaram 4, 7, e 25 LN dissecados com metástases. De acordo com a literatura, (GIGLIO e IYEYASU, 2008), (FISHER et al., 1983) a presença de um a três linfonodos metastáticos de CA da mama tem sido considerada mais favorável a uma sobrevida livre de doença do que o encontro de quatro ou mais linfonodos positivos. 
Quanto maior o número de linfonodos acometidos, pior será o prognóstico dos pacientes. No estudo realizado por Veronesi et al. (1993) em seus resultados mostrou que a maioria dos LN dissecados metastáticos encontravam-se no nível I e também mostrou que a quantidade destes LN influencia na sobrevida global, quanto menos LN positivos para metástases maior a sobrevida global. Em nosso estudo não foi possível identificar quais LN dissecados foram do nível axilar I.

Em relação à otmização da técnica de LCINT, houve uma padronização da técnica entre os médicos nucleares, melhorando a qualidades das imagens e consequentemente a visualização dos LNS/LNNS funcionalmente ativos e das vias linfáticas. Esta otmização encontra-se de acordo com a literatura. (BYRD et al., 2001), (NIEWEG et al., 2004b) 


\section{LIMITAÇÕES}

Para o presente momento, não foi realizado nenhuma correção das imagens e também não foram aplicados métodos estatísticos para o teste de hipóteses científicas.

Como idéia para estudos futuros, propomos a realização de estudo semiquantitativo prognóstico de infiltração de linfonodos e valor prognóstico da LCINT. 


\section{CONCLUSÕES}

\subsection{Características Clínicas e Demográficas}

7.1.1. Em nosso estudo de 70 pacientes com CA de mama, observamos que todos os pacientes são do sexo feminino, maioria mais idosa, com grau de diferenciação intermediário, predominância de CDI e de cirurgias conservadoras.

\subsection{Características Linfocintilográficas}

7.2.1 No estudo, a técnica de LCINT foi eficaz para evidenciar 88,5\% dos LNS/LNNS nos pacientes submetidos a essa técnica. Os LN não visualizados na LCINT foram todos LNNS, possivelmente, em função da janela temporal;

7.2.2. Houve predominância de drenagem linfática para apenas 1 LNS;

7.2.3. Houve predominância de territórios de drenagem linfática ipsilateral para a região axilar;

7.2.4. Houve territórios de drenagem linfática inesperados, drenagem linfática bilateral;

7.2.5. Presença de drenagem linfática para a região mamária interna;

\subsection{Características Cirúrgicas}

7.3.1. No presente estudo encontramos envolvimento metastático linfonodal em 18,8\% dos pacientes com CA de mama. Este achado enfatiza a grande importância da realização da BLNS. Por meio dessa técnica, os pacientes com invasão linfonodal puderam submeter-se ao esvaziamento completo da cadeia linfática, favorecendo sua sobrevida.

7.3.2. Dos 14 pacientes que realizaram a linfadenectomia axilar, a maioria dos pacientes apresentou axilar negativa para comprometimento metastático, apenas 2 pacientes apresentaram entre 1 e $3 \mathrm{LN}$ metastáticos e 3 pacientes mais de $4 \mathrm{LN}$ dissecados metastáticos. 
7.3.3. Em relação à utilização do corante azul patente em $50 \%$ dos pacientes, a técnica de LCINT foi mais eficaz na visualização do maior número de LNS/LNNS do que o corante azul patente.

\subsection{Otimização da Técnica de Linfocintilografia}

7.4.1. A otimização da técnica de LCINT, favorecida pelo estudo, permitiu uma melhor visualização das vias linfáticas e LNS/LNNS, bem como a visualização da silhueta do corpo dos pacientes para a localização dos mesmos. Assim o protocolo proposto favoreceu melhorias significativas que contribuíram na abordagem cirúrgica dos pacientes. 


\section{REFERÊNICAS BIBLIOGRÁFICAS *}

ABDOLLAHI, A. et al. Factors affecting sentinel lymph node detection failure in breast cancer patients using intradermal injection of the tracer. Revista Española de Medicina Nuclear, v. 3, p. 102-104, 2009.

ABREU, B. A. L. et al. Sentinel Lymph Node Detection Through Radioguided Surgery in Patients wtih Breast Cancer. Brazilian Archives of Biology and Technology, v. 51, p. 57-61, 2008.

ALBERTINI, J. J. et al. Lymphatic mapping and sentinel node biopsy in the patient with breast cancer. JAMA, v. 276, p. 276-1818, 1996.

BERG, J. The Significance of azillary node levels in the study of breast carcinoma. Cancer, v. 8, p. 776-778, 1955.

BILMORIA, M. M. The woman at increased risk for breast cancer: evaluation and management strategies. Cancer, v. 45, p. 263-278, 1995.

BLOOM, H. J.; RICHARDSON, W. W. Histological grading and prognosis in breast cancer: A study of 1409 cases of which 359 have been followed for 15 years. British Journal of Cancer, v. 11, p. 359-377, 1957.

BOCKER, W. WHO classification of breast tumors and tumors of the female genital organs: pathology and genetic. Verth Deutsch Pathology, v. 86, p. 116-119, 2002.

BONADONNA, G. et al. Primary chemoterapy in operable breast cancer: eight-year experience an the Milan Cancer Institute. Journal Clinical Oncology, v. 16, p. 93-100, 1998.

BUZDAR, A. U. Advances in endocrine treatments for postmenopausal women with metastic and eraly breast cancer. Oncology, v. 8, p. 335-341, 2003.

BYRD, D. R. et al. Internal mamary lymph node drainage patterns in patients with breast cancer documented by breast lymphoscintigraphy. Annal Surgery Oncology, v. 8, p. 234240, 2001.

CABANAS, R. M. An approach to the treatment of penile carcinoma. Cancer, v. 39, p. 455$566,1997$.

CHALA, L. F.; BARROS, N. Avaliação das mamas com métodos de imagens. Revista Brasileira de Radiologia, v. 40, p. 4-6, 2007.

CHEN, R. C. et al. Internal Mammary Nodes in Breast Cancer: Diagnosis and Implications for Patients Management - A Systematic Review. Journal of Clinical Oncology, v. 26, p. 9399, 2008.

* De acordo com a Associação Brasileira de Normas Técnicas. NBR 6023. 
CHUA, B.; TAYLOR, R.; AL., E. Treatment implications of a positive sentinel node biopsy for patients with early stage breast carcinoma. Cancer, v. 92, p. 1769-1774, 2001.

COCHRAN, A. J. et al. Principles of Sentinel Lymph Node Identification: Background and Clinical Implications. Langenbeck's Archive of Surgery, v. 385, p. 252-260, 2000.

CZERNIECKI, B. J. et al. Revolutionary impact of lymphoscintigraphy and intraoperative sentinel node mapping in the clinical practice of oncology. Semnars of Nuclear Medicine, v. 2, p. 158-164, 2001.

DAOULD, J. et al. Contralateral axillary lymph node metastasis of cancer of the breast. Bull Cancer, v. 85, p. 713-715, 1998.

ELSTON, C. W.; ELLIS, I. O. Pathological prognostic factors in breast cancer I: The value of histological grade in breast cancer: Experience form a large study with lonf-term follow-up. Histopathology, v. 19, p. 403-410, 1991.

ESSER, S. V. et al. Axillary Staging in Breast Cancer Patients with Exclusive Lymphoscintigraphc Drainage to the Internal Mammary. World Journal of Surgery, v. 35, p. 159-164, 2011.

FILHO, O. U.; FILHO, O. C. Gamma Probe assistence brain tumor microsurgical resection. Arq. Neuropsiquial, v. 60, p. 1042-1047, 2002.

FISHER, B. et al. Relation of number of positive axillary nodes to the prognosis of patients with primary breast cancer: Am NSABP update. Cancer, v. 52, p. 1551-1557, 1983.

FISHER, B. et al. Lumpectomy and axillary dissection for breast cancer: surgical, patological, and radition considerations. World Journal of Surgery, v. 5, p. 692-698, 1985.

FISHER, B. et al. Lumpectomy compared with lumpectomy and radiation therapy for the treatment os intraductal breast cancer. The New England Journal of Medicine, v. 22, p. 1581-1586, 1993.

FISHER, B. et al. Effect of preoperative chemotherapy on locoregional disease in women with operable breast cancer: finfings from National Surgical Adjuvant Breast and Bowel Project B-18. Journal Clinical Oncology, v. 15, p. 2483-1493, 1997.

FISHER, B. et al. Increased intensification and total dose pf cyclophosphamide in a doxorubibincyclophosphamide regimen for the treatment of primary breast cancer: findings from National Surgical Adjuvant Breast and Bowel Project. Jounal Clinical Oncolology, v. 15, p. 1858-1869, 1997.

FISHER, B. et al. Twenty-year follow-up os a randomized trial comparing total mastectomy, lumpectomy, and lumpectomy plus irradiation for the treatment os invasive breast cancer.

The New England Journal of Medicine, v. 16, p. 1233-1241, 2002.

FITZGIBBONS, P. L. et al. Prognostic factors in breast cancer. The Archives of Pathology

\& Laboratory Medicine, v. 4, p. 966-978, 2000. 
FLETCHER, S. W.; ELMORE, J. G. Mammographic screening for breast cancer. The New England Journal of Medicine , v. 348, p. 1672-1680, 2003.

FREGNANI, J. H. T. G.; MÁCEA, J. R. Lymphatic drainage of the breast: from theory to surgical practice. International Journal of Morphology, v. 27, p. 873-878, 2009.

GARRIDO, M. Sistema linfático: Embriologia e Anatomia. In: GUARRIDO, M.; RIBEIRO, A. Linfangites e erisipelas. Rio de Janeiro: Revinter, p. 107-127, 2000.

GARTNER, L. P.; HIATT, J. L. Tecido Linfóide. In: GARTNER, L. P.; HIATT, J. L. Atlas Colorido de Histologia. Rio de Janeiro: Guanabara Koogan, p. 167-176, 2007.

GERBER, B. et al. Skin-sparing mastectomy with conservation of the nipple-areola complex and autologous reconstruction is an oncologically safe procedure. Annals of Surgery, v. 1, p. 120-127, 2003.

GIGLIO, A. D.; IYEYASU, H. Câncer de Mama. In: LOPES, A.; LYEYASU, H.; CASTRO, R. M. R. P. S. Oncologia para a Graduação. $2^{\text {a }}$ Edição. ed. São Paulo: Tecmedd, cap. 31, p. 407-418, 2003.

GINSBURG, E. et al. Characterization of ductal and lobular breast carcinomas using prolactin receptor isoform specific antibodies. Cancer, v. 10, p. 678-689, 2010.

GIORDANO, S. H.; BUZDAR, A. U.; HORTOBAGY, G. N. Breast cancer in men. Annals International of Medicine, v. 8, p. 678-687, 2002.

GIULIANO, A. E. et al. Lymphatyc mapping and sentinel lympha denectomy for breast cancer. Annalns of Surgery, v. 220, p. 391-398, 1991.

GIULIANO, A. E. et al. Lymphatic mapping and sentinel lymphadenectomy for breast cancer. Annals of Surgery, v. 220, p. 391-401, 1994.

GIULIANO, A. E. et al. Sentinel Lymphadenectomy in breast cancer. Journal Clinical of Oncology, v. 15, p. 2345, 1997.

GRAAFF, V. D.; MARSHALL, K. Sistema Genital Feminino: Estrutura da mama e das glândulas mamárias. In: Anatomia Humana. Barueri-SP: Manole, p. 738-740, 2003.

GUENTHER, J. M.; KRISHNAMOORTHY, M.; TAN, L. R. Sentinel lymphadenectomy for breast cancer in a community managed setting. The cancer journal from Scientific American, v. 3, p. 336, 1997.

GUYTON, A. C.; HALL, J. E. A Microcirculação e o Sistema Linfático: Trocas Capilares, Líquido Intersticial e Fluxo de Linfa. In: GUYTON, A. C.; HALL, J. E. Tratado de Fisiologia Médica. São Paulo-SP: Elsevier, p. 181-194, 2003.

HAINSWORTH, P. J. et al. Detection and significance of occult metastases in node-negative breast cancer. British Journal of surgery, v. 50, p. 459-463, 1993. 
HALSTED, W. S. The results os operation for cure of cancer of the breast performed at the Johns Hopkins Hospital froma June, 1889 to January, 1894. Johns Hopkins Hospital Republic, v. 4, p. 297-350, 1894.

HUMPHREY, L. L. et al. Breast cancer screening: a summary of the evidence for the U. S. Preventive Services Task Force. Annals of Internal Medicine , v. 137, p. 347-360, 2002.

HUNG, W. K. et al. Radomized clinical trial comparing blue dye wtih combined dye and isotope for sentinel lymph node biopsy in breast cancer. Bristih Journal of Surgery, v. 92, p. 1494-1497, 2005.

HUSTON, T. L. et al. The Presentation of Contralateral Axillary Lymph Node Metastases form Brest Carcinoma: A Clinical Management Dilema. The Breast Journal, v. 13, p. 158$164,2007$.

INCA, I. N. D. C. Controle do Câncer de Mama - Docuemnto de Consenso. Instituto Nacional do Câncer ( INCA). Rio de Janeiro, p. 1-39, 2004.

INCA, I. N. D. C. TNM: classificação de tumores malignos, Rio de Janeiro, v. 6, 2004.

INCA, I. N. D. C. Estimativas 2010: incidência de câncer no Brasil., Rio de Janerio, 2009.

ISAACS, C.; STEAMS, V.; HAYES, D. F. New Prognostic Factors for Breast Cancer Recurrence. Seminars in Oncology , v. 28, p. 53-67, 2001.

JOHNSON-THOMPSON, M. C.; GUTHRIE, J. Ongoing research identify environmental risk factors in breast carcinoma. Cancer, v. 88, p. 1224-1229, 2000.

KESHTGAR, M. R. S. et al. The sentinel node in surgical oncology. [S.l.]: MRS Keshtgar,v.2, p. 112-115, 2000.

KRAG, D. N. et al. Surgical resection and radiolocalization od the sentinel lymph node in brest cancer using a gamma probe. Surgery of Oncology, v. 2, p. 335-340, 1993.

KRYNYCKYI, B. R. et al. Clinical Breast Lymphoscintigraphy: Optimal Techniques for Performing Studies, Image Atlas, and Analysis of Images. RadioGraphics, v. 24, p. 121-145, 2004.

MACÉA, J. R.; FREGNANI, J. H. T. G. Anatomy of the thoracic wall, axilla and breast. Internetional Journal of Mophology, p. 691-704, 2006.

MAGALDI, C. M. et al. Avaliação da morbidade e funcionalidade do membro superior em mulheres submetidas à linfadenectomia axilar total e biópsia do linfonodo sentinela por câncer de mama. Revista Brasileria de Mastologia, v. 15, p. 9-14, 2005.

MARIANI, L. et al. Ten year results of a randomised trial comparing two conservative treatment strategies for small size breast cancer. Europe Journal Cancer, n. 34, p. 11561162, 1998. 
MERETOJA, T. J. et al. Safety of Sentinel Node Biopsy in Breast Cancer Patients Who Receive a Second Radioisotope Injection After Visualization Failure in Lymphoscintigraphy. Journal of Surgical Oncology, v. 102, p. 649-665, 2010.

MORTON, D. L. et al. Technical details of intraoperative lymphatic mapping for early stage melanoma. Archive of Surgery, v. 127, p. 392-399, 1992.

NALASHIMAN, K. et al. Preoperative dynamic lymphoscintigraphy predicts sentinel lymph node metastasis in patients with early brest cancer. Breast Cancer, v. 17, p. 17-21, 2010.

NIEWEG, O. E.; ESTOURE, S. H. What is a Sentinel Node and What is a False Negative Sentinel Node? Annals of Surgical Oncology, v. 11, p. 169-173, 2004a.

NIEWEG, O. E. et al. Lymphatic mapping and sentinela node biopsy. In: ELL, P. J.; GAMBHIR, S. S. Nuclear Medicine in Clinical Diagnosis and Treatment. 3. ed. [S.1.]: Churchill Livingstone, v. 1, Cap. 18, p. 229-259, 2004 b.

NIEWEG, O. E.; TANIS, P. J.; KROON, B. R. Definition os Sentinel Node. Annals of Surgical Oncology, v. 8, p. 538-541, 2001.

NOGUCHI, A. et al. Predicting sentinel lymph node metastasis in breast cancer with lymphoscintigraphy. Annals of Nuclear Medicine, v. 2, p. 43-48, 2010.

NOGUCHI, M. et al. Sentinel Lymphadenectomy in brest cancer: identification os sentinel lymph node and detection of metastases. Breast Cancer Research and Treatment, v. 53, p. 97-104, 1999.

OVERGAARD, M. et al. Postoperative radiotherapy in high-risk postmenopausal breastcancer patients given adjuvant tamoxifen: Danish Breast Cancer Cooperative Group DBCG 82c randomised trial. Lancet, v. 353, p. 1641-1648, 1999.

PAREDES, P. et al. Clinical relevance of sentinel lymph nodes in the internal mammary chain in breast cancer patients. Europe Journal of Nuclear Medicine and Molecular Imaging, v. 32, p. 1283-1287, 2005.

PATEY, D. H.; DYSON, W. H. The prognosis of carcinoma of the breast in relatioship to the type of operation performed. Breast Journal Cancer, v. 2, p. 7-13, 1948.

PAVLISTA, D. et al. Localization of the Sentinel Node of the Upper Outer Breast Quadrant in the Axillary Quadrants. Annals of Surgical Oncology, v. 14, p. 633-637, 2006.

PEGRAM, M. D. et al. Targeted therapy: Wave of the future. Journal of Clinical Oncology, v. 23, p. 1776-1781, 2005.

PERRE, C. I. et al. Altered lymphatic dranainage after lymphadenectomy or radiotherapy of the axilla in patients with breast cancer. British Journal of Surgery, v. 83, p. 1258, 1996.

PHILOPTTS, L. E.; SMITH, R. A. Screening for breast cancer. Sem. Roentgenology, v. 1, p. 19-33, 2003. 
RAGAZ, J. et al. Locoregional radiation therapy in patients with high-risk breast cancer receiving adjuvant chemotherapy: 20-year results os the British Columbia randomized trial. Journal of the National Cancer Institute, v. 2, p. 116-126, 2005.

ROMRELL, L. J.; BLAND, K. I. Anatomy of the breast, axilla, chest wall, and related metastatic sites. In: BLAND, K. I.; COPELAND, E. M. The brest comprehensive management of benign and malignant disease. Philadelphia: WB Saunders Company, $\mathrm{p}$. 112-122, 1998.

ROSS, M. Sentinel Node Mapping for early stage melanoma. In: PERRY, M. C. Education Book. [S.1.]: Asco, p. 326-330, 2007.

SACCHINI, V. et al. Nipple-sparing mastectomy for breast cancer and risk reduction: oncologic or technical problem? The Journal of the American College of Surgeons , v. 5, p. 704-714, 2003.

SADEGHI, R. et al. How long the lymphoscintigraphy imaging should be continued for sentinel lymph node mapping? Annals of Nuclear Medicine, v. 23, p. 507-510, 2009.

SALDEGHI, R. et al. Comparison of pre-operative lymphoscintigraphy with inter-operative gamma probe and dye techique regarding the number of detected sentinel lymph nodes.

Journal of Nuclear Medicine, v. 1, p. 30-32, 2009.

SAMPHAO, S. et al. Management of the axilla in women with breast cancer: current clinical practice and a new selective targeted approach. Annals of the Surgery Oncology, v. 5, p. 1283-1296, 2008.

SCARFF, R. W.; TORLONI, H. Histological typing of breast tumors. International histological classification of tumours. World Health Organization, v. 2, p. 13-20, 1968.

SCHAUER, A. J. et al. Chapter 7: Lymphatic Draimage to the SLN. In: SCHAUER, A. J., et al. The Sentinel Lymph Node Concept. New York: Springer, p. 51-57, 2005.

SCHWARTZ, G. F. et al. The consensus conference on the treatment os in situ ductal carcinoma of the breast. Breast Journal, v. 6, p. 4-13, 2000.

SEOK, J. W. et al. Comparison of subareolar injection lymphoscintigraphy with the 1-day and the 2-day protocols for the detection od sentinel lymph nodes in patients with breast cancer.

Annals of Nuclear Medicine, v. 23, p. 465-469, 2009.

SEOK, J. W. et al. Sentinel lymph node identification with radiopharmaceuticals in patients with breast cancer: a comparison of 99mTc-tin colloid and 99mTc-phytate efficiency. Breast Cancer Research and Treatment, v. 122, p. 453-457, 2010.

SHERMAN, A. I.; TER-PROGOSSIAN, M.; TOCUS, E. C. Lymph Node Concentration of Radioactive Colloidal Gold Following Interstitial Injection. Cancer, v. 6, p. 1238-1240, 1953.

SHWARTZ, G. F. et al. Proceedings of the Consensus Conference on the Role os Sentinel Lymph Node Biopsy in Carcinoma of the Breast. The Breast Journal, v. 8, p. 126-138, 2002. 
SLAMON, D. J. et al. Studies of the HER-2/neu porto-oncogene in human brest and ovarian cancer. Science, v. 244, p. 707-712, 1989.

SOBIN, L. H.; GOSPODAROWICZ, M. K.; WITTEKIND, C. Classification of Malignant Tumours (TNM). União Internacional Contra o Câncer (UICC) , v. 7, 2009.

SOLIN, L. J. et al. Fifteen-year results of breast conserving surgery and definitive breast irradiation for the treatment of ductal carcinoma in situ os the breast. Journal Clinical Oncology, v. 14, p. 754-763, 1996.

SOMASUNDARAM, S. K. et al. Sentinel node imaging in breast cancer using superficial injections: Technical details and observations. The Journal of cancer surgery, v. 35, p. 1250-1256, 2009.

SUN, X. et al. Roles od preoperative lymphoscintigraphy for sentinel lymph node biopsy in breast cancer patients. Japanese Journal Clinical Oncology, v. 8, p. 722-725, 2010.

TANIS, P. J. et al. Anatomy and physiology of lymphatic drainage of the breast from the perspective of sentinel node biopsy. Journal American Collogy of Surgery, v. 192, p. 399409, 2001.

TELLES, O.; CARMO, P.; GONÇALVES, A. Estadiamento Clínico do Câncer de mama. In: FRANCO, J. Mastologia: Formação do Especialista. $1^{\text {a }}$ Edição. ed. Rio de Janeiro: Atheneu, p. 130-145, 1997.

THOMPSON, J. F.; UREN, R. F. Lymphatic Mapping in Management on Patients wtih Primary Cutaneous Melanoma. Lancet Oncology, v. 6, p. 877-785, 2005.

TIEZZI, D. G. Cirurgia Conservadora no Câncer de Mama. Rivista Brasileira de Ginecologia e Obstetrícia, v. 29, p. 428-434, 2007.

TIEZZI, D. G. Epidemiologia do câncer de mama. Revista Brasileira de Ginicologia e Obstetrícia, v. 31, p. 213-215, 2009.

TORTORA, G. J.; GRABOWSKI, S. R. Os Sistemas Genitais: Glâmdulas Mamárias. In: TORTORA, G. J.; GRABOWSKI, S. R. Corpo Humano: Fundamentos de Anatomia e Fisiologia. Porto Alegre: Artmed, p. 576-577, 2006.

TURNER-WARWICK, R. T. The lymphatic of the breast. Britsh Journal of Surgery, v. 46, p. 574-582, 1959.

URBAN, C. A. et al. Ethics in Sentinel Node Biopsy in Breast Cancer: An Open Question. The Breast Journal, v. 8, p. 253-257, 2002.

UREN, R. F. et al. Lymphatic Mapping of the Breast: Locating the Sentinel Lymph Nodes. World Journal of Surgery, v. 25, p. 789-793, 2001.

VALDOS OLMOS, R. A. et al. Lymphoscintigraphy in ocology: a rediscovered challenge. Europe Journal of Nuclear Medicine, v. 26, p. 204-207, 1999. 
VERONESI, U. et al. Comparing radical mastectomy with quadrantectomy, axllary dissectino, and radiotherapy in patients with small cancers of the breast. The New England Journal of Medicine, v. 1, p. 6-11, 1981.

VERONESI, U. et al. Conservative treatment of early breast cancer. Long-term results of 1232 cases treated with quadrantectomy axillary dissection and radiotherapy. Annals of Surgery, v. 211, p. 250-259, 1990.

VERONESI, U. et al. Prognostic significance of number and level of axillary node metastases in breast cancer. The Breast, v. 2, p. 224-228, 1993.

VERONESI, U. et al. Radiotherapy after breast-preserving surgery in women with localized cancer of the breast. The New England Journal of Medicine , v. 22, p. 1587-1591, 1993.

VERONESI, U. et al. Sentinel-node biopsy to avoid axillary dissection in breast cancer with clinically negative lymph nodes. Lancet, v. 349, p. 1864, 1997.

VERONESI, U. et al. Mastologia Onológica. Rio de Janeiro: Medsi, 2002.

VERONESI, U. et al. Twenty-year follow-up os a randomized study comparing breastconserving surgery with radical mastectomy for early breast cancer. The New England Journal of Medicine, v. 16, p. 1227-1232, 2002.

VERONESI, U. et al. Sentinel-lumph-node liopsy as a staging procedure in breast cancer: update od a randomised controlled study. Lancet Oncology, v. 12, p. 983-990, 2006.

VIDAL-SCART, S. et al. Added Value of Intraoperative Real-Time Imaging in Searchers for Difficult-to-Locate Sentinel Nodes. Journal of Nuclear Medicine, v. 51, p. 1219-1225, 2010.

WILHELM, A. J.; MIJNHOUT, G. S.; FRANSSEN, E. J. F. Radiopharmaceuticals in sentinel lymph-node detection - An Overview. Europe Journal of Nuclear Medicine, v. 26, p. 36-42, 1999.

WILLIAMS, P. L. et al. Gray's anatomy. London: Churchill Livingstone, 1989.

XAVIER, N. L. et al. Detecção do Linfonodo Sentinela em Câncer de Mama: Comparação entre Métodos. Revista Brasileira de Ginecolohia e Obstetrícia, v. 24, 2002.

ZIESSMAN, H. A.; O`MALLEY, J. P.; THRALL, J. H. Nuclear Medicine: The Reguisites in Radiology. In: Oncology. $3^{\text {a }}$. ed. [S.1.]: Massachusetts, p. 299-3000, 2006.

ZUCCARI, D. A. P. C. et al. Prognostic and predictive factors in mammary neoplasias immunohistochemical markers importance in human and canine species - comparative study. Revista Arquivos de Ciência e Saúde, v. 4, p. 189-198, 2008. 


\section{ANEXOS}

\subsection{Anexo A - Termo de Consentimento Livre e Esclarecido (TCLE)}

\section{TERMO DE CONSENTIMENTO LIVRE E ESCLARECIDO}

Você está sendo convidado a participar, como voluntário, de uma pesquisa. Após o conhecimento das informações a seguir, você poderá decidir sobre sua participação ou não neste projeto, sem perda do direito de receber os cuidados médicos de rotina ou quaisquer outros benefícios aos quais tenha direito na assistência médica regular na clínica habitual, qualquer que seja sua decisão.

Título do Projeto de Pesquisa: "Caracterização dos padrões de drenagem linfática nas Linfocintilografias de pacientes com Câncer de Mama."

Local da Pesquisa: Seção de Medicina Nuclear do Hospital das Clínicas da Faculdade de Medicina de Ribeirão Preto - Av. Bandeirantes, 3900 - Bairro Monte Alegre - CEP: 14048900 - Fone/FAX: (16) 3602-2596 - E-mail: nucmed@ hcrp.usp.br.

\section{Pesquisadores responsáveis:}

-Prof. Dr. Lauro Wichert Ana. Seção de Medicina Nuclear - Hospital das Clínicas de Ribeirão Preto FMRP - USP. Telefone: (16) 3602-2596

-Franciele Cristina Bernardes. Aluna de Mestrado do Programa de Pós-Gradução Interunidades em Bioengenharia - EESC/IQSC/FMRP - USP. Telefone (16) 3602-2596

-Emerson Nobuyuki Itikawa. Aluno de iniciação científica. Departamento de Física e Matemática - USP. Telefone: (16) 3602-2596

\section{Justificativa e Objetivos da pesquisa}

A linfocintilografia é uma técnica que permite o estudo da drenagem linfática, visualizando canais linfáticos e linfonodos funcionalmente ativos (ínguas). O objetivo desta pesquisa é o de melhorar a qualidade das Linfocintilografias pré-operatórias e caracterizar os padrões de drenagem linfática, buscando localizar as ínguas que fazem a drenagem linfática da pele onde se localiza o câncer de mama. Uma vez localizadas as ínguas, o cirurgião deverá 
retirá-las cirurgicamente para analisar se as mesmas encontram-se saudáveis ou não. Este exame será realizado na Seção de Medicina Nuclear do Hospital das Clínicas de Ribeirão Preto - FMRP - USP.

\section{Informações sobre os procedimentos que serão realizados:}

Aplicação do radiofármaco: A linfocintilografia será iniciada com a limpeza da pele no local ao redor da lesão com algodão e álcool hospitalar. Serão aplicadas quatro injeções na pele, com agulhas pequenas (seringas de insulina) e localizadas 1 centímetro acima, abaixo e dos lados da lesão mamária (pontos cardeais). Estas seringas contêm pequena quantidade de material radioativo, chamado FITATO-Tecnécio99m. Para melhorar a absorção na pele deste material injetado, você deverá massagear o local das injeções por 2 minutos.

Desconfortos e Riscos Esperados: Estas injeções não apresentarão riscos ou prejuízos a você, mas poderão causar ligeira dor ou ardência nos locais de aplicação, queixas estas típicas e próprias de uma injeção na pele. Nenhum desconforto ou risco adicional acontecerá por motivo desta pesquisa, pois todos estes procedimentos aos quais você se submeterá fazem parte do exame solicitado pelo médico para a sua investigação clínica;

Aquisição de imagens: As imagens de Linfocintilografia serão obtidas em torno de 60 minutos após as injeções, podendo ser necessárias imagens adicionais e mais tardias, de acordo com a indicação médica. Você ficará deitada em uma maca e será submetido à realização de 3 imagens de linfocintilografia: anterior, lateral e oblíqua em relação ao local das injeções. Serão realizadas pequenas marcas com caneta na sua pele, guiadas pelas imagens de linfocintilografia, as quais ajudarão o cirurgião a encontrar as ínguas a serem operadas;

Informações a serem coletadas para a pesquisa: Serão consultadas suas informações clínicas, de exames laboratoriais, imagens radiográficas e de linfocintilografia, contidas no seu prontuário médico e nos arquivos de imagens. Solicitamos a você, também, a autorização para tirar fotografia regionalizada do local onde se encontra a lesão mamária. Estas fotografias serão utilizadas apenas para auxiliar na análise dos dados da pesquisa e para a divulgação científica, não sendo disponibilizada para nenhum outro propósito sem a sua prévia autorização;

Custos: Você não terá nenhum custo quanto à sua participação nesta pesquisa.

Benefícios que se pode obter: A sua participação nesta pesquisa contribuirá para o estudo científico de como a pele drena a linfa ao redor das lesões mamárias. As imagens de linfocintilografia que você realizará fazem parte da rotina de avaliação clínica e cirúrgica para o seu tratamento. Entretanto, se você concordar, estas imagens também serão utilizadas na presente pesquisa e poderá contribuir para o conhecimento científico, para o diagnóstico e para e o tratamento de outras pessoas que apresentem a mesma lesão que você;

Privacidade: Todas as informações coletadas nesta pesquisa serão anexadas ao seu prontuário médico do Hospital das Clínicas da FMRP-USP, com exceção das fotografias. Somente médicos e outros profissionais autorizados terão acesso às informações deste prontuário. A sua privacidade será respeitada, ou seja, o seu nome ou qualquer outro dado que possa de alguma forma identificá-lo serão mantidos em sigilo. Os dados deste estudo serão mantidos em um banco de dados da Seção de Medicina Nuclear do Hospital das Clínicas FMRP - USP. 


\section{Do Consentimento do Voluntário da Pesquisa}

$\mathrm{Eu}$, abaixo assinado, concordo em participar do estudo "Caracterização dos padrões de drenagem linfática nas Linfocintilografias de pacientes com Câncer de Mama”, como sujeito da pesquisa. Fui devidamente informado em detalhes pelo(s) pesquisador(es) responsável(is) no que diz respeito aos objetivos da pesquisa, aos procedimentos que serei submetido, aos riscos e benefícios e quanto à garantia de sigilo sobre os meus dados clínicos e de identificação. Fui informado de que será assegurada a minha assistência médica durante toda a pesquisa, bem como terei livre acesso a todas as informações e esclarecimentos adicionais sobre esta pesquisa e suas consequiências. Declaro que tenho pleno conhecimento dos direitos e das condições que me foram asseguradas e que posso retirar meu consentimento a qualquer momento, sem que isto leve a qualquer penalidade ou interrupção de meu acompanhamento, assistência médica, diagnóstica e tratamento. Declaro, ainda, que concordo inteiramente com as condições que me foram apresentadas e que, livremente, manifesto a minha vontade de participar desse estudo.

Ribeirão Preto, de de

Nome do Voluntário da Pesquisa:

RG:

Nome: RG:

Nome, Registro Geral e Assinatura do responsável legal por menores de 18 anos ou com incapacidade.

\section{Pesquisadores:}

CPF: 351.951.078-23

Aluna Franciele Cristina Bernardes

$\mathrm{Ou}$

CPF: 375.558.121-34

Prof. Dr. Lauro Wichert Ana 


\subsection{Anexo B - Formulário de Aquisição das Imagens de Linfocintilografia}

Formulário para Aquisição de Imagens em Linfocintilografia: Atividade padrão: 4 seringas de $1 \mathrm{mC}$. Fitato marcado $\mathrm{com}^{99 m} \mathrm{Tc}$;

\section{1) Dados pessoais}

Nome:

Número do registro:

Data do diagnóstico do tumor primário:

Data de nascimento:

Tipo de CA:

Data da ressecção:

Localização:

Classificação:

\section{2) Exame de linfocintilografia}

Data do exame:

Horário das aplicações:

$\mathrm{N}^{\mathrm{o}}$ de aplicações e local:

Horário do exame:

$\mathrm{N}^{\mathrm{o}}$ de Linfonodos Sentinela captados na imagem:

$\mathrm{N}^{\mathrm{o}}$ de Linfonodos Satélite captados na imagem:

Região de drenagem:

\section{3) Intra-operatório}

Data da cirurgia: Horário do início:

Horário do Término:

Uso de corante azul: ( ) sim ( ) não

Sensibilidade da Sonda: ( )100 ( )250 ( )500 ( )750 ( )1000 ( )2000 ( )2500

$\mathrm{N}^{\mathrm{o}}$ de Linfonodos Sentinela encontrados:

$\mathrm{N}^{\mathrm{o}}$ de Linfonodos Satélite encontrados:

Excisão:

$\mathrm{N}^{\mathrm{o}}$ de Linfonodos não encontrados:

\section{Excisão:}

\begin{tabular}{|l|c|c|c|c|c|c|}
\cline { 3 - 7 } \multicolumn{2}{c|}{} & \multicolumn{2}{c|}{ Características } & \multicolumn{3}{c|}{ Método } \\
\hline L1 & Localização & LNS & Satélite & Linfo & Azul & Sonda \\
\hline L2 & & & & & & \\
\hline L3 & & & & & & \\
\hline
\end{tabular}

\section{4) Biópsia do LNS}

Data da biópsia:

Laudo da biópsia:

$\mathrm{N}^{\mathrm{o}}$ de linfonodos positivos:

$\mathrm{N}^{\mathrm{o}}$ de linfonodos negativos:

Indicação de esvaziamento: ( )sim ( )não

Data do esvaziamento:

\section{5) Documentário}

Fotos do leito cirúrgico: ( )sim ( )não

Fotos dos linfonodos: ( )sim ( )não

6) Equipe

Cirurgião:

Médico Nuclear:

Físico Médico:

Tecnólogo:

Enfermeiro: 